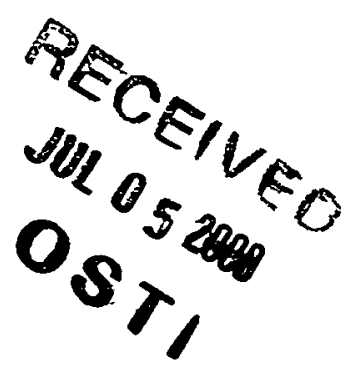

\title{
Annual Report 1999 Environmental Dynamics and Simulation
}

April 2000

\section{Pacific Northwest National Laboratory} Operated by Battelle for the U.S. Department of Energy

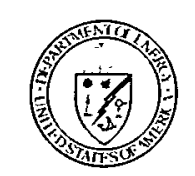




\title{
DISCLAIMER
}

This report was prepared as an account of work sponsored by an agency of the United States Government. Reference herein to any specific commercial product, process, or service by trade name, trademark, manufacturer, or otherwise does not necessarily constitute or imply its endorsement, recommendation, or favoring by the United States Government or any agency thereof, or Battelle Memorial Institute.

\author{
PACIFIC NORTHWEST NATIONAL LABORATORY \\ operated by \\ BATTELLE \\ for the
}

UNITED STATES DEPARTMENT OF ENERGY

under Contract DE-AC06-76RLO 1830

Printed in the United States of America

Available to DOE and DOE contractors from the

Office of Scientific and Technical Information, P.O. Box 62, Oak Ridge, TN 37831;

prices available from (615) 576-8401.

Available to the public from the National Technical Information Service, U.S. Department of Commerce, 5285 Port Royal Rd., Springfield, VA 22161

PNNL-13054

This document was printed on recycled paper. 


\section{DISCLAIMER}

This report was prepared as an account of work sponsored by an agency of the United States Government. Neither the United States Government nor any agency thereof, nor any of their employees, make any warranty, express or implied, or assumes any legal liability or responsibility for the accuracy, completeness, or usefulness of any information, apparatus, product, or process disclosed, or represents that its use would not infringe privately owned rights. Reference herein to any specific commercial product, process, or service by trade name, trademark, manufacturer, or otherwise does not necessarily constitute or imply its endorsement, recommendation, or favoring by the United States Government or any agency thereof. The views and opinions of authors expressed herein do not necessarily state or reflect those of the United States Government or any agency thereof. 


\section{DISCLAIMER}

Portions of this document may be illegible in electronic image products. Images are produced from the best available original document. 


\section{Annual Report 1999}

\section{Environmental Dynamics and Simulation}

J. M. Zachara, Associate Director and the Staff of the Environmental Dynamics and Simulation Directorate

June 2000

Prepared for the U.S. Department of Energy under Contract DE-AC06-76RLO 1830 
Environmental Dynamics and Simulation 1999 Annual Report

\section{Contents}




\section{Introduction}

EMSL Research.

$1-1$

Research Capabilities

Accessing the EMSL

Mission of the Environmental Dynamics

and Simulation Directorate

\section{Modeling/Simulation}

The Free Energies of Reactions of Chlorinated Methanes with Aqueous Monovalent Anions: Application of $\mathrm{Ab}$ Initio Electronic Structure Theory $^{(\text {a) }}$

E. J. Bylaska, D. A. Dixon, and

A. R. Felmy.

Mixed Hamiltonian Methods for Geochemical Electronic Structure Studies ${ }^{(a)}$

E. J. Bylaska, J. R. Rustad, and

M. Dupuis.

Application of Pitzer's Equations for Modeling the Aqueous Thermodynamics of Actinide Species in Natural Waters: A Review ${ }^{(\mathrm{e})}$ A. R. Felmy and D. Rai

Non-Equilibrium Thermodynamic Simulation of Metal Uptake in the Bacterial Electrical Double Layer ${ }^{(a)}$

E. Wasserman, A. R. Felmy, and

A. Chilakapati

$\mathrm{Ab}$ Initio Calculation of Homogeneous Outer Sphere Electron Transfer Rates: Application to $\mathrm{M}\left(\mathrm{OH}_{2}\right)_{6}{ }^{3+/ 2+}$ Redox Couples ${ }^{(\mathrm{d})}$

K. M. Rosso and J. R. Rustad

Thermodynamics and Kinetics of Cation

Exchange in Micas: Development of

Molecular Modeling Approaches ${ }^{(a)}$

K. M. Rosso and E. J. Bylaska

Molecular Simulation of Oxide Surface

Chemistry $^{(\mathrm{d})}$

J. R. Rustad, E. J. Bylaska, D. A. Dixon,

A. R. Felmy, and K. M. Rosso.

Molecular Dynamics Simulations of Hydrated

Silicate Liquids and Glasses ${ }^{(\mathrm{b}, \mathrm{d})}$

F. J. Serpa and J. R. Rustad. 2-15

\section{Spectroscopy/Microscopy}

A Spectroscopic Study of Phenanthrene Adsorption on Porous Silica ${ }^{(\mathbf{b}, t)}$

Z. Wang, D. M. Friedrich, M. R. Beversluis,

A. G. Joly, M. H. Huesemann, M. J. Truex,

R. G. Riley and C. J. Thompson and

B. M. Peyton

Competitive Trace-Level Sorption of Chromate and Phosphate to Hematite Surfaces: A Spectroscopic Approach ${ }^{(\mathrm{e})}$

N. S. Foster-Mills, J. E. Amonette,

B. K. William, and A. E. Taylor $3-4$

Mössbauer Spectroscopic Study of Iron Redox in Silicate Glasses ${ }^{(\text {b.e.t) }}$

R. K. Kukkadapu, G. L. Smith, H. Li,

J. V. Crum, M. C. Weinberg, and

H. Poisl

Mineralization Processes Associated with the Bacterial Reduction of Fe(III) Oxides ${ }^{(m)}$

J. M. Zachara, J. K. Fredrickson,

Y. A. Gorby, S. C. Smith, and

R. K. Kukkadapu $3-10$

Redox Chemistry at Mineral Surfaces ${ }^{(\text {a.b.m })}$

J. E. Amonette, K. M. Rosso,

Y. A. Gorby, H. R. Divanfard,

J. F. Marquez, E. A. Rodriguez,

and $C . K$. Russell

Electron Paramagnetic Resonance Studies of Mineral Surface Chemistry ${ }^{(b)}$

J. E. Amonette, R. K. Kukkadapu,

A. S. Lea, C. J. Matocha, D. L. Sparks,

W. F. Bleam, and S. J. Yoon

Geochemical Mechanisms in Terrestrial

Carbon Sequestration ${ }^{(b . c)}$

J. E. Amonette, J. A. Capp, A. Lüttge,

D. R. Baer, and R. S. Arvidson

Corrosion Products of Mild Steel in High Ionic Strength Brines and the Effect on $\mathrm{Pu}(\mathrm{VI})$ Reduction $^{(\mathrm{b} . \mathrm{u})}$

Z. Wang, R. C. Moore, A. R. Felmy. M. Mason and R. K. Kukkadapu. $3-28$ 
Mineral Structure Controls on Cs Adsorption in Hanford Sediments ${ }^{\text {(e) }}$

J. M. Zachara, J. P. McKinley,

R. J. Serne, S. C. Smith, and

P. L. Gassman

\section{Capability Reviews}

Laser Photoacoustic Spectroscopy: Basic

and Applied Research ${ }^{\text {(a.b.f.h) }}$

N. S. Foster-Mills, J. E. Amonette,

T. Autrey, J. R. Small, Yu Chen, and

E. Small

Mössbauer Spectroscopy

R. K. Kukkadapu and J. E. Amonette.

Commissioning and Initial Results from the PNC-CAT Insertion Device Beamline at the Advanced Photon Source ${ }^{(\mathrm{d} . f)}$

S. M. Heald, D. L. Brewe, J. O. Cross,

E. D. Crozier, D. Jiang, and

E. A. Stern

\section{Appendix}

Environmental Dynamics and

Simulation Staff.

Publications and Presentations 1999

Publications

In Press

Patents

Presentations

Honors and Recognition $5-11$

Collaborations $5-12$

External Collaborations $5-12$

Collaborations within PNNL $5-14$

Acronyms and Abbreviations $5-16$

Where ED\&S Fits in PNNL $5-17$

\section{Funding Support}

(a) Pacific Northwest National Laboratory (PNNL) Laboratory Directed Research and Development (LDRD)

(b) EMSL Operations, supported by DOE Office of Biological and Environmental Research (OBER)

(c) National Science Foundation

(d) DOE Office of Basic Energy Sciences (BES)

(e) DOE Environmental Management Science Program (EMSP)

(f) National Science Foundation

(g) DOE-Experimental Program to Stimulate Competitive Research (EPSCOR)

(h) National Institutes of Health

(i) U.S. Department of Agriculture

(j) Laboratory Technology Research (LTR) Program

(k) Motorola, Inc.

(l) Defense Advanced Research Projects Agency (DARPA)

(m) Natural and Accelerated Bioremediation Research Program (NABIR)

(n) DOE Office of Industrial Technologies, Industry of the Future Program, Forest Products

(o) University of Western Sydney (UWS) Nepean Staff Development Fund

(p) Environmental and Health Sciences Division (EHSD)

(q) DOE Energy Efficiency Office of Advanced Automotive Technology

(r) Cooperative Research and Development Agreement (CRADA)

(s) National Aeronautics and Space Administration (NASA)

(t) DOE Office of Science

(u) DOE WIPP Program 
This annual report describes selected 1999 research accomplishments for the Environmental Dynamics and Simulation (ED\&S) directorate, one of six research organizations in the William R. Wiley Environmental Molecular Sciences Laboratory (EMSL). These accomplishments are representative of the different lines of research underway in the ED\&S directorate. EMSL is one of U.S. Department of Energy's (DOE) national scientific user facilities and is the centerpiece of DOE's commitment to providing world-class experimental, theoretical, and computational capabilities for solving the nation's environmental problems.

Capabilities in the EMSL include over 100 major instrument systems for use by our resident research staff, their collaborators, and users of the EMSL. These capabilities are used to address the fundamental science that will be the basis for finding solutions to national environmental issues such as cleaning up contaminated areas at DOE sites across the country and developing "green" technologies that will reduce or eliminate future pollution production. The capabilities also are used to further our understanding of global climate change and environmental issues relevant to energy production and use and health effects resulting from exposure to contaminated environments.

As a national scientific user facility and a research organization, the mission of EMSL is to

- provide advanced resources to scientists engaged in research on critical environmental problems and other national issues, including health issues related to exposure to contaminated or hazardous environments

- conduct fundamental research on the physical, chemical, and biological processes that underlie critical environmental issues

- educate young scientists in the molecular sciences to meet the demanding environmental challenges of the future

- advance molecular science in support of DOE missions.
EMSL is part of the Environmental and Health Sciences Division (EHSD) at Pacific Northwest National Laboratory (PNNL), which operates the facility for the DOE Office of Biological and Environmental Research (BER). Of the four research divisions at PNNL, EHSD has the strongest emphasis on basic science with research focused on analytical chemistry, atmospheric sciences and global change, biogeochemistry, materials, statistics, and the environmental molecular sciences. Although EMSL's primary focus area is the environmental molecular sciences, our scientists and capabilities of the facility impact research throughout EHSD and the other three PNNL research divisions-Energy Science and Technology, Environmental Technology, and National Security.

\section{EMSL Research}

EMSL research focuses on attaining a molecular-level understanding of the physical, chemical, and biological processes that underlie pressing environmental issues facing the DOE. The issues include

- waste processing - provide a technical basis for retrieving, separating, converting, disposing, and minimizing waste streams ranging from DOE radioactive and hazardous wastes to industrial pollutants

- contaminant fate and transport - understand the transformation and migration of contaminants in soils and groundwater, and to assist in developing innovative solutions for passive and active remediation of contaminated lands

- cellular response to environmental contaminants - contribute to the scientific knowledge needed to extrapolate studies at high dose levels in animals to the low exposure/dose levels needed to set regulatory guidelines for humans

- atmospheric chemistry - provide insight into molecular processes in the gas phase and at gas/liquid and gas/solid interfaces, and to develop unique computational and experimental instruments for identifying and characterizing important tropospheric molecules and their reactions. 
EMSL staff members are key players in national research programs focused on environmental issues, such as the Environmental Management Science Program and the Natural and Accelerated Bioremediation Research Program. Both of these programs are funded and managed by DOE.

The expertise of our staff and the facility's capabilities also are contributing to research undertaken in Environmental Molecular Science Institutes (EMSI) funded by the National Science Foundation and DOE at Columbia University and Northwestern University. Each EMSI provides a unique program for academic scientists, engineers, and students to work with colleagues from industry and national laboratories to improve understanding of how nature and technology affect environmental systems at the molecular level.

\section{Research Capabilities}

EMSL offers at one location a comprehensive array of state-of-the-art equipment for research in the environmental molecular sciences. These capabilities can be integrated as needed by multidisciplinary teams of scientists to address complex problems. EMSL equipment and capabilities are grouped into seven facilities:

- High Field Magnetic Resonance Facility

- High Field Mass Spectrometry Facility

- Molecular Science Computing Facility

- Nanomaterials and Technology Facility

- Interfacial Structures and Compositions Facility

- Reactions at Interfaces Facility

- Gas- and Liquid-Phase Monitoring and Detection Facility.
In addition, the Environmental Molecular Sciences Collaboratory is being developed to make the EMSL facilities and capabilities more available to scientists and engineers located anywhere in the nation or in the world.

\section{Accessing the EMSL}

As a user facility, the EMSL supports users who are involved in both nonproprietary and proprietary research. Capabilities are available to the general scientific and engineering communities to conduct research in the environmental sciences and other areas relevant to national science and technology issues. Users gain access to the EMSL capabilities by submitting proposals, which are reviewed for

- $\quad$ scientific merit

- appropriateness for the facilities or capabilities being requested

- relevance to DOE missions

- technical competence of the principal investigators.

More detailed information can be obtained via the User Info and Proposal Form links on the EMSL web site at http://www.emsl.pnl.gov/.

We hope you find the research highlights and other information included in this report to be interesting and informative. If you would like to receive reports describing the 1999 accomplishments of the other EMSL research directorates, please contact the associate director identified in Figure 1.1. More information about our Environmental Dynamics and Simulation directorate and the organization of this report follows. 
Chemical Structure \& Dynamics

S.D. Colson, Associate Director

Telephone: (509) 376-4598

Facsimile: (509) 376-0846

Email: steven.colson@pnl.gov

\section{EMSL Director's Office}

J.H. Futrell, Director

Telephone: (509) 376-0223

Facsimile: (509) 376-6742

Email: jean.futrell@pnl.gov

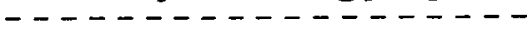

D. Ray, Deputy Director

Telephone: (509) 376-8069

Facsimile: (509) 376-6742

Email: dray@pnl.gov

Computing \& Information Sciences

R.A. Bair, Deputy Director

Telephone: (509) 376-7939

Facsimile: (509) 376-0420

Email: raybair@pnl.gov

\begin{tabular}{|l|}
\hline Environmental Dynamics \& Simulation \\
J.M. Zachara, Associate Director \\
Telephone: (509) 376-3254 \\
Facsimile: (509) 376-3650 \\
Email: john.zachara@pnl.gov
\end{tabular}

Interfacial \& Processing Sciences

J.W. Rogers, Jr., Associate Director

Telephone: (509) 376-1833

Facsimile: (509) 376-5106

Email: jw.rogers@pnl.gov

\begin{tabular}{l} 
Macromolecular Structure \& Dynamics \\
D.W. Koppenaal, Associate Director \\
Telephone: (509) 376-0368 \\
Facsimile: (509) 376-2303 \\
Email: david.koppenaal@pnl.gov \\
\hline
\end{tabular}

Theory, Modeling \& Simulation

D.A. Dixon, Associate Director

Telephone: (509) 372-4999

Facsimile: (509) 375-6631

Email: david.dixon@pnl.gov

Figure 1.1. Contact information for EMSL research organizations. 


\section{Mission of the Environmental Dynamics and Simulation Directorate}

The EMSL ED\&S directorate is focused on environmental molecular science and the application of fundamental physical chemistry concepts to the study and understanding of chemical reaction in heterogeneous natural material, with emphasis on soil and subsurface systems. The ED\&S directorate is a multidisciplinary organization, with staff trained in chemistry. mineral physics, geochemistry, soil chemistry, microbiology, hydrology, and environmental engineering (see staff summaries). They function as principal investigators on environmental research, and as co-principal investigators with others in EMSL to assist in the bridging of more fundamental molecular science studies to applied studies that are focused on finding solutions to important environmental problems at DOE sites.

The main emphasis of ED\&S research is chemical reactivity at the mineral/water and microbe/water interface. These broad topical areas are studied using various types of molecular spectroscopies and microscopies: molecular, thermodynamic, and kinetic modeling; and macroscopic physical chemistry and mineralogic measurements. The following scientific theme areas have been the focal points for ED\&S research over the past five years:

- surface chemistry of Fe and $\mathrm{Al}$ oxides, carbonates, and layer silicates

- redox reactions of organic and metal contaminants with $\mathrm{Fe}$ - and Mn-containing mineral solids

- biogeochemistry of Fe(III) and Mn (IV) oxide reduction by bacteria and associated biomineralization processes

- mineral surface structure and dynamics by modeling and microscopy

- sorbate surface structure and dynamics on mineral surfaces by spectroscopy

- contaminant reactivity and thermodynamics at high ionic strength.
An overall goal of much of this research has been to develop improved microscopic models of key environmental processes that can be applied to the real environment with appropriate scale considerations. Collaborative research with users is solicited and encouraged in these scientific theme areas.

ED\&S research capabilities and interests range from fundamental to applied, and accordingly the staff derives its support from diverse funding sources. Important long-term funding sources for our fundamental studies include the DOE's Office of Basic Energy Sciences (Geosciences Program) and Office of Biological and Environmental Research (Natural and Accelerated Bioremediation Research Program). Other important funding sources have been the DOE Office of Environmental Management (DOE-EM) through its Environmental Management Science Program (EMSP), other federal agencies (e.g., U.S. Nuclear Regulatory Commission), and private research organizations (e.g., the Electric Power Research Institute). Growth has occurred in our research that supports cleanup activities at DOE's Hanford Site. Support for this work is provided by the Hanford high-level waste tank management and vitrification contractors, and through DOE-EM's new Hanford Science and Technology Program.

The ED\&S directorate is steward for a number of capabilities that it provides to users from the scientific community. Significant among these are a Mössbauer spectroscopy facility with variable temperature and conversion electron capabilities; a multi-technique environmental spectroscopy facility with emphasis on optical, vibrational, and photoacoustic spectroscopy; a scanning probe microscopy facility with emphasis on water-wet mineral and mineral-microbe systems; and environmental molecular modeling expertise and software for various mineral and chemical systems including layer lattice silicates. The ED\&S directorate also is involved with the Pacific Northwest Consortium-Collaborative Access Team (PNC-CAT) at the Advanced Photon Source (APS) at Argonne National Laboratory. ED\&S staff participated in beamline development and the beamlines are now open for research by PNNL researchers and their collaborators. Following is a list of current capabilities and the staff members who have expertise in these capabilities. 
Analytical Chemistry Instrumentation

- Inductively Coupled Plasma-Mass Spectrometer

(ICP-MS)

- Ion Chromatography (IC)

- Gas Chromatography-Mass Spectrometer (GC-MS)

- Liquid Chromatography-Mass Spectrometer (LC-MS)

- Total Organic Carbon Analyzer (TOC)

Scanning Probe Microscopy

- Atomic Force Microscopy (AFM)

- Scanning Tunneling Microscopy (STM)

Spectrophotometers

- Ultraviolet-Visible Absorbance Spectrometer (UV-Vis)

- Fourier-Transform Infrared Spectrometer (FTIR)

- Fluorescence Spectrometer

Laser Fluorescence Microscopy

Laser Spectroscopy and Kinetic Systems

- Raman

- High-resolution streak camera system

- Time-correlation single photon counting system

- Lasers

Scanning and Transmission Electronic Microscopies

Laser Photoacoustic Spectrometer (LPAS)

Mössbauer Spectroscopy System

Electron Paramagnetic Resonance Spectrometer

Pressure Jump Kinetics System

Controlled Atmosphere Chambers

Autoclave

Calorimetry

Molecular Modeling Software and Hardware

Hydro and Biogeochemical Modeling and Software

Synchrotcon Science
Tom Wietsma/Nancy Foster-Mills

Kevin Rosso/Zheming Wang

Nancy Foster-Mills/Tom Wietsma

Paul Gassman/Jim Amonette/Nancy Foster-Mills

Paul Gassman/Zheming Wang

Zheming Wang/Alan Joly

Zheming Wang/Alan Joly

Yuri Gorby/Alice Dohnalkova

Nancy Foster-Mills/Jim Amonette

Ravi Kukkadapu/Jim Amonette

Ravi Kukkadapu/Jim Amonette

Jim Amonette/Paul Gassman

Tom Wietsma/Paul Gassman

Colleen Russell

Andy Felmy

Jim Rustad/Kevin Rosso/Eric Bylaska/ Andy Felmy

Chongxuan Liu/Steve Yabusaki

Steve Heald (at APS/ANL) 
The technical content of the report that follows contains brief, selected summaries of programmatic research, collaborative studies with users, and user facility capabilities. These summaries have been selected to be representative of the scope of ED\&S activities, but are by no means inclusive. 


\section{Modeling/Simulation}

The research summaries that follow have been selected as representative examples of ED\&S research. Some may be viewed as project summaries, while others integrate related work in a given topical area supported by multiple projects. The summaries are organized into two primary topical areas that generally define our research/user portfolio: 1) modeling and simulation and 2) spectroscopy and microscopy. A third section, Capability Reviews, is provided on selected key capabilities within ED\&S that are available to users. 


\section{The Free Energies of Reactions of Chlorinated Methanes with Aqueous Monovalent Anions: Application of Ab Initio Electronic Structure Theory}

\author{
E. J. Bylaska, D. A. Dixon, and \\ A. R. Felmy
}

Supported by PNNL Laboratory Directed Research and Development, Molecular Sciences

Computing Facility Grand Challenge Proposal, DOE, NERSC.

The presence of different anionic species in natural waters can significantly alter the degradation rates of chlorinated methanes and other organic compounds. Favorable reaction energetics is a necessary feature of these nucleophilic substitution reactions that can result in the degradation of the chlorinated methanes. In this study, $a b$ initio electronic structure theory was used to evaluate the free energies of reaction of a series of monovalent anionic species $\left(\mathrm{OH}^{-}, \mathrm{SH}^{-}, \mathrm{NO}_{3}{ }^{-}, \mathrm{HCO}_{3}{ }^{-}\right.$, $\mathrm{HSO}_{3}^{-}, \mathrm{HSO}_{4}^{-}, \mathrm{H}_{2} \mathrm{PO}_{4}^{-}$, and $\mathrm{F}^{-}$) that can occur in natural waters with the chlorinated methanes, $\mathrm{CCl}_{4}$, $\mathrm{CCl}_{3} \mathrm{H}, \mathrm{CCl}_{2} \mathrm{H}_{2}$, and $\mathrm{CClH}_{3}$.

Our theoretical study of reactions between the chlorinated methanes and the monovalent anions, $\mathrm{N}^{-}=\mathrm{OH}^{-}, \mathrm{SH}^{-}, \mathrm{NO}_{3}^{-}, \mathrm{HCO}_{3}^{-}, \mathrm{HSO}_{3}^{-}, \mathrm{HSO}_{4}^{-}, \mathrm{H}_{2} \mathrm{PO}_{4}^{-}$, and $\mathrm{F}^{-}$, showed that the energetics of the nucleophilic displacement reaction is strongly dependent on the nucleophile and less so on the degree of chlorination. Of the nucleophiles studied, the smaller ions $\mathrm{OH}^{-}$, $\mathrm{SH}^{-}$, and $\mathrm{F}^{-}$as well as the larger $\mathrm{HCO}_{3}{ }^{-}$ion are the most thermodynamically favored candidates for nucleophilic substitution with the chlorinated methanes. In addition, reactions with the $\mathrm{NO}_{3}{ }^{-}$ion are expected to be slightly exothermic to thermoneutral, and those with the $\mathrm{HSO}_{3}{ }^{-}$ion are slightly endothermic to thermoneutral. The reactions of the $\mathrm{HSO}_{4}{ }^{-}$, and $\mathrm{H}_{2} \mathrm{PO}_{4}^{-}$are clearly not likely to occur. The degree of chlorination can change the thermodynamics of the nucleophilic reactions by as much as $18 \mathrm{kcal} / \mathrm{mol}$, but only the $\mathrm{OH}^{-}$nucleophile exhibits such a dramatic effect. For most of the nucleophiles, the calculations indicate that the heat of reaction decreases for the chlorinated methanes with a larger degree of chlorination. The exception was the $\mathrm{HSO}_{4}{ }^{-}$nucleophile, which showed a slight increase in the Gibbs free energy of reaction in going from $\mathrm{CH}_{3} \mathrm{Cl}$ to $\mathrm{CCl}_{4}$.

In looking at the gas phase reaction enthalphies, it was found that the $\mathrm{OH}^{-}, \mathrm{SH}^{-}$, and $\mathrm{F}^{-}$reactions have a strong enthalphic driving force. The $\mathrm{HCO}_{3}^{-}$reactions also had an enthalpic driving force, but it was not quite as strong as the other reactions. On the other hand, the $\mathrm{NO}_{3}^{-}, \mathrm{HSO}_{3}^{-}, \mathrm{HSO}_{4}^{-}$, and $\mathrm{H}_{2} \mathrm{PO}_{4}^{-}$reactions did not have an enthalpic driving force. In looking at the differences between the gas phase reaction enthalpies and solution phase reaction heats (see Figure 2.1), it was found that the effect of solvent was somewhat correlated to the size of anion with respect to the size of the $\mathrm{Cl}^{-}$anion. The reactions with the less bulky anions, i.e., $\mathrm{OH}^{-}$and $\mathrm{F}^{-}$, were substantially less exothermic as compared to the gas phase value when the effects of solvent were included. The reactions with the bulkier anions, i.e., $\mathrm{SH}^{-}, \mathrm{NO}_{3}^{-}, \mathrm{HCO}_{3}^{-}, \mathrm{HSO}_{3}^{-}$, $\mathrm{HSO}_{4}^{-}$, and $\mathrm{H}_{2} \mathrm{PO}_{4}^{-}$, were substantially more exothermic than the gas phase values when the effects of solvent were included. However, other parameters besides the charge-to-size ratio must play a role in solvation. While reactions with the least bulky anion, $\mathrm{F}^{-}$, did have the most endothermic solvent effect, the reactions with the most bulky anion, $\mathrm{H}_{2} \mathrm{PO}_{4}^{-}$, did not have the most exothermic solvent effect. This suggests that other chemical parameters must play a role in the solvent effect for these reactions.

Finally, it is important to emphasize that the thermodynamic quantities presented here are initial studies to determine if a reaction is even allowed or not. Equally important in understanding these reactions are the height and shape of kinetic barriers existing between the reactants and products including the role of solvent on the reaction pathways. We are currently extending our studies to investigate the role of kinetics for these reactions. 


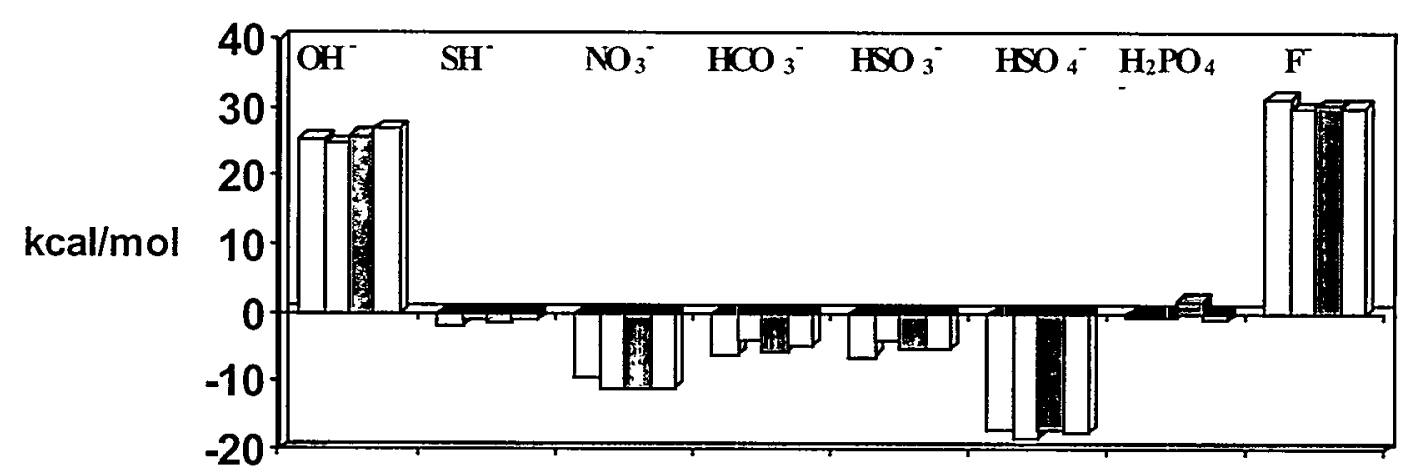

\section{$\square \mathrm{CCl} 3 \mathrm{X} \square \mathrm{CHCl} 2 \mathrm{X}$ 国 $\mathrm{CH} 2 \mathrm{ClX} \square \mathrm{CH} 3 \mathrm{X}$}

Figure 2.1. The effect of solvent in driving the $S_{N} 2$ reactions of chlorinated methanes and inorganic nucleophiles. In this figure the difference between theoretically determined gas-phase enthalpies of reaction and theoretically determined solution phase heats of reaction is shown. 


\section{Mixed Hamiltonian Methods for Geochemical Electronic Structure Studies}

\author{
E. J. Bylaska, J. R. Rustad, and \\ M. Dupuis
}

Supported by PNNL Laboratory Directed Research and Development.

Of all the geochemical processes occurring at the mineral/water interface, oxidation/reduction (redox) processes are some of the most important and least understood processes affecting the fate and transport of contaminants in the subsurface. Redox processes are difficult to understand because the fundamental process of electron exchange between oxidants and reductants can involve multiple pathways and numerous intermediate species and structures, all of which can vary with the specific geochemical conditions. This situation makes theoretical models of electron exchange valuable in providing insight into the fundamental nature of the oxidation/reduction process, and indicating how these processes are altered by changes in geochemical conditions. However, modeling redox-active mineral/water interfaces is difficult for several reasons. First and foremost, redox-active mineral surfaces are difficult to calculate at a first principles level, and the addition of solvent and bulk mineral make it even more arduous. Clearly, to accurately simulate the reduction of a pollutant such as carbon tetrachloride at the mineral/water interface will require an accurate quantum mechanical description of the waterpollutant-surface-complex. At the same time, the simulation region must be exceedingly large so that the reaction involves the chemical participation of solid and water.

In recent years, there have been a number of significant advances that have the potential to facilitate quantum mechanical modeling of reduction processes at these interfaces. One recently emerged technique, Blochl's projector-augmented wave (PAW) method, can simulate redox-active mineral surfaces accurately and efficiently. The PAW method is an allelectron approach that has many of the advantages of typical pseudopotential plane-wave (Car-Parrinello) approaches with the added ability to handle first-row elements with d electrons (Blochl 1994). Another recently emerged technique, the quantum mechanical/molecular mechanical (QM/MM) approach, which combines first principles simulations with classical modeling, has opened up the door to include long-range effects of solvent and bulk into first principle simulations (Gao and Furlani 1995). The computational cost of such simulations is thus greatly reduced as a result of representing the solvent molecules classically. In the QM/MM approach, the system is broken up into two parts: a localized quantum mechanical region surrounded by a molecular mechanical region (Figure 2.2). This will allow for a water-pollutant-surface-complex to be modeled quantum mechanically, while at the same time the long-range effects of solvent and bulk mineral can be included with classical modeling.

We have begun to develop a QM/MM model based upon Blochl's PAW approach. We are combining the very powerful methodology of a plane-wave density functional method, namely Blochl's PAW formalism with the popular mixed Hamiltonian techniques of quantum chemistry to create a unique capability for a quantum treatment of increasingly complex and realistic models of interfacial processes. The model includes a quantum plane-wave description of the active site with a classical pseudopotential representation of underlying mineral lattices and solvent water molecules. The PAW formalism was selected, since it is one of the most efficient ab initio approaches for studying large systems, including transition metal atoms, with computational scaling of $\mathrm{N}^{2}-\mathrm{N}^{3}$ $(\mathrm{N}=$ number of atoms). In addition it can calculate

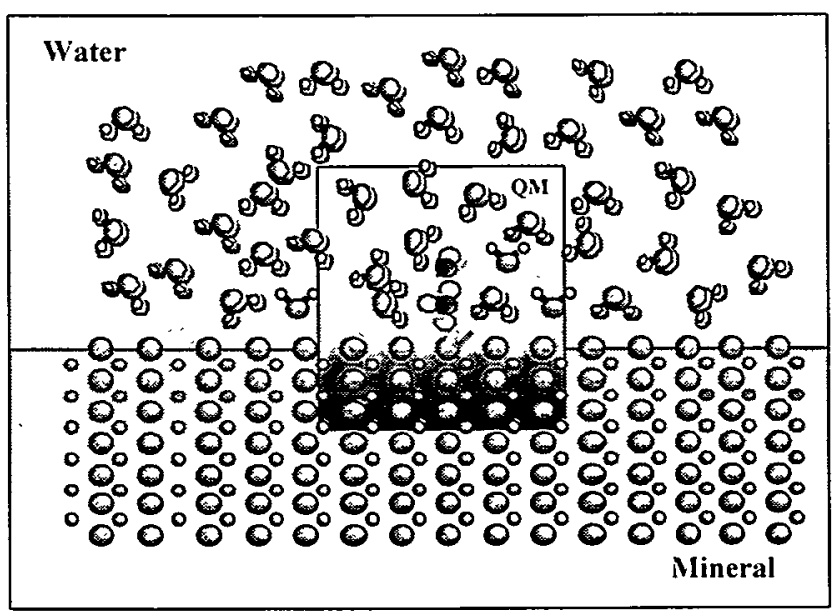

Figure 2.2. Schematic representation of the partition of a mineral/water/pollutant interface region. 
ionic forces quickly, compared to Gaussian atomcentered basis set methods, giving it the ability to perform ab initio molecular dynamics calculations on the fly.

This approach will allow us for the first time to simulate geochemically important interfacial processes, including changes in oxidation and coordination states (i.e., bond breaking and bond formation), and redox reactions of pollutants such as. halogenated organics, on iron-oxides and other environmentally important surfaces.

\section{References}

Blochl, P. E., Phys. Rev. B 50, 17,953 (1994).

Gao, J. and T. R. Furlani, Sci. Technol. Fall 1995, 24 (1995). 


\section{Application of Pitzer's}

\section{Equations for Modeling the}

Aqueous Thermodynamics of

Actinide Species in Natural

\section{Waters: A Review}

\section{A. R. Felmy and D. Rai}

Supported by the Japan Nuclear Cycle

Development Institute, DOE EMSP, and Sandia

National Laboratories.

A review of the applicability of Pitzer's equations to the aqueous thermodynamics of actinide species in natural waters was prepared. This review includes a brief historical perspective on the application of Pitzer's equations to actinides, information on the difficulties and complexities of studying and modeling the different actinide oxidation states, and a discussion of the use of chemical analogs for different actinide oxidation states. Tables were included of Pitzer ioninteraction parameters and associated standard state equilibrium constants for each actinide oxidation state, which allow the modeling of the aqueous thermodynamics of different actinide oxidation states to high ionic strength.

An example of the ability of this model to accurately predict the solubility of tetravalent actinides (e.g., $\mathrm{ThO}_{2}(\mathrm{am})$ ) is illustrated in Figure 2.3 (solid lines).

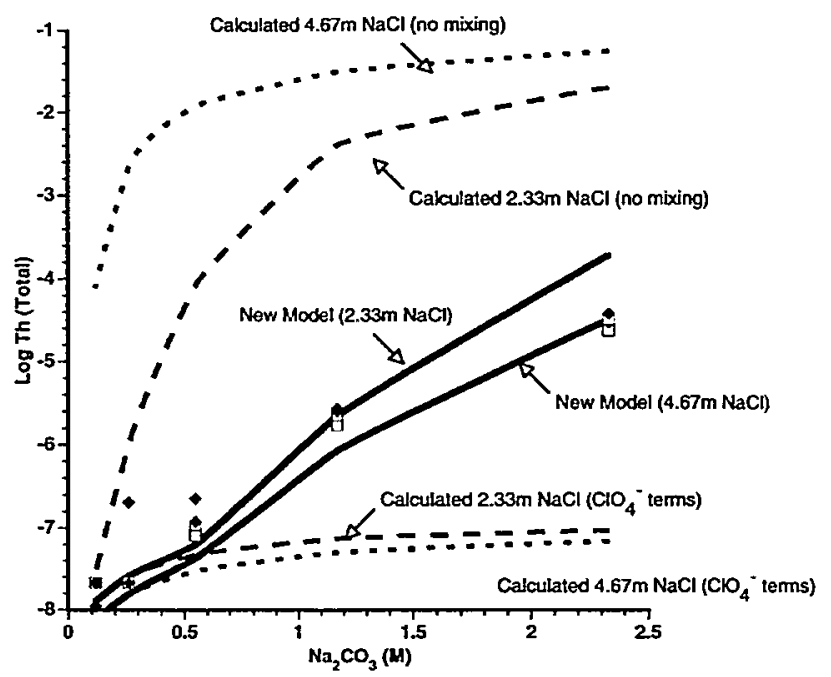

Figure 2.3. Model prediction of the solubility of tetravalent actinides.

Also illustrated are different chemical models with varying assumptions as to the magnitude of the Pitzer ion-interaction parameters for the highly charged thorium pentacarbonate $\left(\mathrm{Th}\left(\mathrm{CO}_{3}\right)_{5}{ }^{6-}\right)$ species. As can be clearly noted, accurate model parameterizations are required or the predicted actinide solubilities will be in error by orders of magnitude in concentrated electrolytes.

Reference

Pitzer, K., J. Solution Chemistry, 28, 533 (1999). 


\section{Non-Equilibrium}

Thermodynamic Simulation of Metal Uptake in the Bacterial Electrical Double Layer

\section{E. Wasserman, ${ }^{(a)}$ A. R. Felmy, and \\ A. Chilakapati}

Supported by PNNL Laboratory Directed Research and Development.

(a) Postdoctoral Research Fellow.

A non-equilibrium thermodynamic (Onsager) formalism is presented for modeling transport processes in the bacterial electrical double layer. This formalism is then applied to model the time-dependent metal uptake within the bacteria electrical double layer that occurs in response to gradients in concentration and electrostatic potential. The formal development of the equations is presented along with an efficient numerical procedure to solve the system of equations for the spherical geometry. Numerical results are given for two values of the ionic strength, $\mathrm{I}=0.1 \mathrm{M}$ and $\mathrm{I}=0.001 \mathrm{M}$ and the bulk trivalent tracer concentration of $1 \times 10^{-6} \mathrm{M}$. Equilibrium distribution of the trivalent tracer cations was shown to be reached very rapidly, in about $2 \mathrm{~ms}$ at $\mathrm{I}=0.1 \mathrm{M}$ and $0.2 \mathrm{~ms}$ at $\mathrm{I}=0.001 \mathrm{M}$ (see Figure 2.4). Therefore diffusionconduction was demonstrated to be a highly efficient mechanism of the ionic transport at the nanoscale for the conditions at which electrostatic metal uptake is significant.

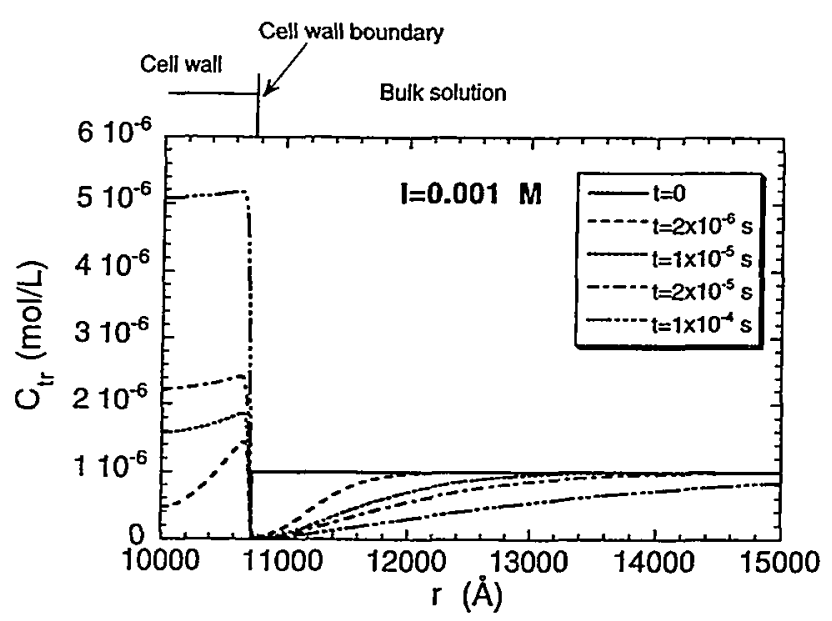

Figure 2.4. Equilibrium distribution of trivalent trace cations. 


\section{Ab Initio Calculation of Homogeneous Outer Sphere Electron Transfer Rates: Application to $\mathrm{M}\left(\mathrm{OH}_{2}\right)_{6}{ }^{3+/ 2+}$ Redox Couples}

\section{K. M. Rosso and J. R. Rustad}

Supported by BES Geosciences.

\section{Abstract}

$\mathrm{Ab}$ initio density functional theory calculations are applied to the prediction of homogeneous outer sphere electron transfer rates for a series of transition metal hexaquo ions in a background electrolyte. Reorganization energies, frequency factors, and the effective electron transfer distances are calculated for use in Marcus' theory. Important energy contributions arising from Jahn-Teller distortions are accurately included in the inner sphere term. Calculated adiabatic self-exchange rates agree well with observed self-exchange rates. The methods presented provide a convenient means to produce usefully accurate parameters for Marcus' theory to predict outer sphere electron transfer rates.

\section{Introduction}

Knowing the rates of individual electron transfer reactions can be fundamentally important in understanding the behavior of overall redox processes in natural waters. This is because any particular electron transfer step can be slow, thereby controlling the overall rate. Rate limiting electron transfer can play a dominant role in trace metal cycling and the speciation and transport of contaminants in the environment. Predictive models based on thermodynamic redox equilibria are inadequate in such cases and must incorporate disequilibrium kinetics. Knowing the rates of the component elementary electron transfer steps is a necessary prerequisite to developing accurate overall models.

In this study, we have targeted the outer sphere selfexchange reactions of a series of important $\mathrm{M}\left(\mathrm{OH}_{2}\right)_{6}$ complexes where $\mathrm{M}=\mathrm{Fe}, \mathrm{Co}, \mathrm{V}, \mathrm{Mn}, \mathrm{Cr}$. Marcus developed a useful quantitative theory for predicting outer sphere homogeneous electron transfer rates in solution, and later extended the theory to heterogeneous electron transfer at interfaces. The basic principle relates the activation free energy $\left(\Delta \mathrm{G}^{*}\right)$ for the electron transfer step to the driving force $\left(\Delta \mathrm{G}^{\circ}\right)$ and the reorganization energy $(\lambda)$. The latter is the sum of the energies required to reorganize the molecular structure of the reactants $\left(\lambda_{\mathrm{Is}}=\right.$ inner sphere contribution) and the surrounding solvent molecules ( $\lambda_{\text {os }}=$ outer sphere contribution) to the configuration compatible with electron transfer. Both components were calculated entirely from theory in this study. Klimkans and Larsson (1994) suggested that $\lambda_{\text {is }}$ could be calculated in a convenient way from the ab initio total energies of the isolated reactant molecules in their ground and excited electronic states as diagrammed in Figure 2.5. We adopt this approach in this study for its simplicity. We calculated $\lambda_{\text {os }}$ using continuum equations for aqueous solution, with corrections for ionic strength, and using the ab initio $\mathrm{M}-\mathrm{O}$ bond lengths for cavity radii. The results of the calculations are compared directly with measured selfexchange rates.

\section{Self-Exchange Reactions}

The series of five $\mathrm{M}\left(\mathrm{OH}_{2}\right)_{6}$ clusters are not expected to have significant differences in solvent reorganization energies because the small differences in the average bond lengths for the reactant molecules

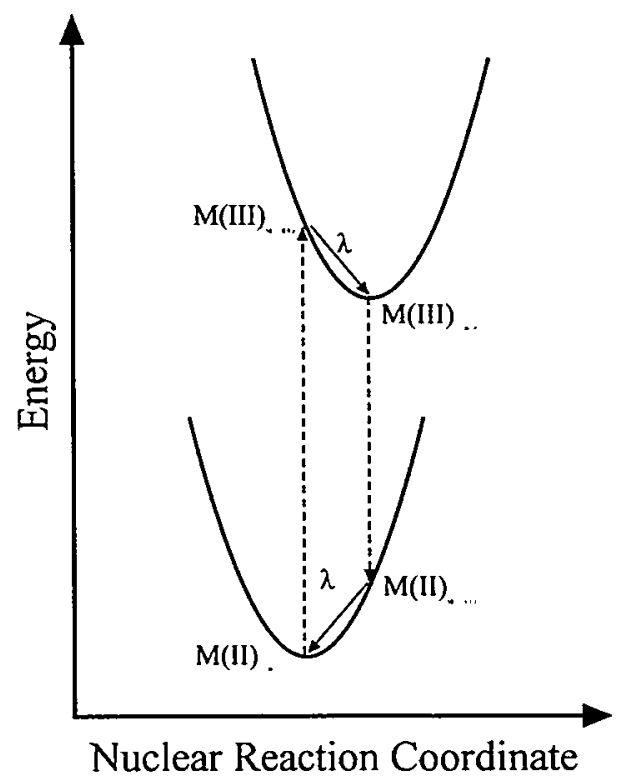

Figure 2.5. A diagram of the relationships between the potential energy surfaces of the reactants and products, and the steps by which the contributions to the inner sphere reorganization energy are calculated. 
equate to minor difference in $\lambda_{\text {os }}(\sim 0.04 \mathrm{eV})$. Likewise, values for $v$ derived from calculated symmetric stretching frequencies are expected to be similar in magnitude $\left(\sim 10^{13}\right)$, and, in similar ionic strength solutions, the work terms should be similar because all reactant charges are +2 and +3 . Hence, we expect that most of the differences in observed rates are a reflection of differences in $\lambda_{\text {is. }}$.

In the final values of $\lambda_{1 s}, \mathrm{Cr}$ and $\mathrm{Mn}$ show higher inner sphere reorganization energies than $\mathrm{Fe}, \mathrm{V}$, and $\mathrm{Co}$. This result is consistent with expectations from molecular orbital theory. $\lambda_{\text {is }}$ can generally be correlated with the type of electron accepting d-orbital on the metal atom. The reduction of both $\mathrm{Cr}(\mathrm{III})$ and $\mathrm{Mn}(\mathrm{III})$ involves the transfer of an electron into the $\mathrm{e}_{\mathrm{g}} *$ orbitals, which are the anti-bonding counterparts to the $d_{22}$ and $d_{12-y_{2}}$ bonding orbitals pointing toward the ligands. Occupation of the $\mathrm{e}_{\mathrm{z}}{ }^{*} \mathrm{~d}$-orbitals causes substantial bond lengthening and distortion in the complex, leading to large inner sphere reorganization energies. In contrast, Fe(III) and V(III) accept the electron into non-bonding $t_{2 \mathrm{~g}}$ orbitals pointing between the ligands, equating to smaller changes in $\mathrm{M}-\mathrm{O}$ bond length and lower $\lambda_{\text {is }}$ energies. Likewise, because we have chosen to model the $\mathrm{Co}(\mathrm{II}) /(\mathrm{III})$ selfexchange as a simple, high spin exchange, our calculations result in $\lambda_{\text {is }}$ for Co that is similar in magnitude to that for $\mathrm{Fe}$ and $\mathrm{V}$ because high spin $\mathrm{Co}(\mathrm{III})$ accepts an electron into a $\mathrm{t}_{2 \mathrm{~g}}$ non-bonding orbital.

The success of this method must ultimately be judged based on a comparison with experiment. Our calculated total reorganization energies are plotted against those extracted from experimental selfexchange rates in Figure 2.6. The relation shows a remarkably good 1 -to-1 trend. The largest deviation in $\lambda_{\mathrm{ss}}$ in this trend is due to $\mathrm{V}\left(\mathrm{OH}_{2}\right)_{6}^{3+22}$, which apparently is underestimated using the $a b$ initio method B3LYP/6-311+G.

We used our calculation results to predict observable rates of self-exchange at differing ionic strengths. The rates are reported in Table 2.1. The agreement can easily be seen to be satisfactory when one considers that an entirely outer sphere pathway is assumed, nonadiabatic effects are neglected, and orbital mixing leading to a decreased activation energy barrier for electron transfer has been assumed to be insignificant.

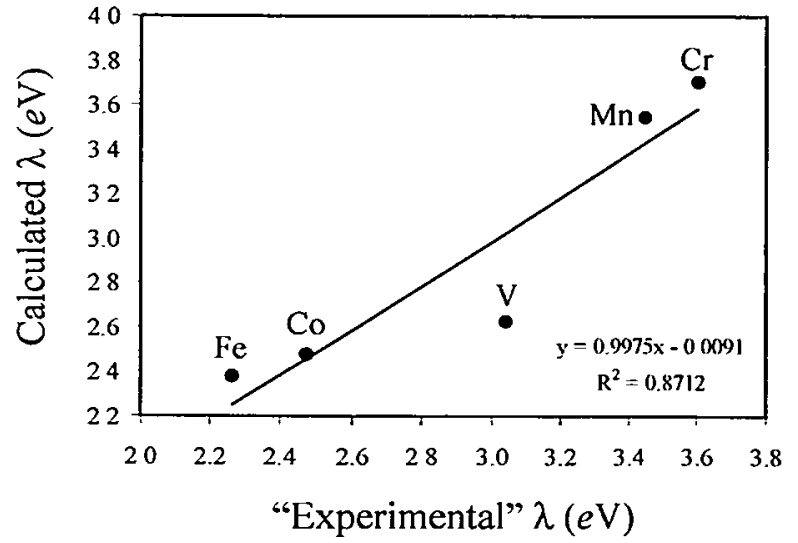

Figure 2.6. A plot of the calculated total reorganization energies for self-exchange vs. that extracted from experimental rate data using the Marcus relations.

Table 2.1. Experimentally observed self-exchange rates
and their associated ionic strength conditions, and
calculated rates using the ab initio methods in this study.
\begin{tabular}{lcccccc}
\multicolumn{6}{c}{} \\
& kobs & $\mu$ & kcalculated & $\begin{array}{c}\text { Log } \\
\text { kobs }\end{array}$ & $\begin{array}{c}\text { Log } \\
\text { kcalculated }\end{array}$ \\
\hline $\mathrm{Fe}(\mathrm{II}) / \mathrm{Fe}(\mathrm{III})$ & 4.2 & 0.6 & 1.5 & 0.623 & 0.170 \\
$\mathrm{Cr}(\mathrm{II}) / \mathrm{Cr}(\mathrm{III})$ & $2.0 \times 10^{-5}$ & 1.0 & $7.4 \times 10^{-6}$ & -4.699 & -5.128 \\
$\mathrm{Mn}(\mathrm{II}) / \mathrm{Mn}(\mathrm{III})$ & $3.0 \times 10^{-4}$ & 3.0 & $1.1 \times 10^{-4}$ & -3.523 & -3.952 \\
$\mathrm{~V}(\mathrm{II}) / \mathrm{V}(\mathrm{III})$ & $1.0 \times 10^{-2}$ & 2.0 & $5.5 \times 10^{-1}$ & -2.000 & -0.263 \\
$\mathrm{Co}(\mathrm{II}) / \mathrm{Co}(\mathrm{III})$ & 3.3 & 3.0 & 3.1 & 0.519 & 0.487 \\
\hline
\end{tabular}

\section{Conclusions}

Inner sphere reorganization energies calculated using the ab initio approach of Klimkans and Larsson lead to useful and accurate values, assuming care is taken with choice of basis set and ab initio method.

Observed self-exchange rates for $\mathrm{M}\left(\mathrm{OH}_{2}\right)_{6}$ complexes are shown to be predominantly due to the energy to reorganize the first hydration sphere. Jahn-Teller contributions are conveniently and accurately included in the calculated $\lambda_{\text {is }}$ value. This theoretical approach is the first to lead to $\lambda_{\text {is }}$ values that properly correlate with observed self-exchange rates for the hexaquo ions in this study.

The methods developed here provide a convenient means to produce reasonably accurate estimates of the Marcus parameters to estimate outer sphere electron transfer rates. In a broader perspective, the methods employed here could easily be extended to a wide variety of reactants where necessary experimental data are unavailable and/or difficult to acquire. Such systems include outer sphere electron transfer as a 
function of speciation, and also heterogeneous electron transfer at interfaces, the subject of future work. Marcus' theory provides the unique ability to predict observable rates at the macroscopic scale using only molecular scale information on the elementary electron transfer step. It is envisioned that this remarkable transferability from microscopic to macroscopic scales will undoubtedly lead to a better understanding of many redox processes in geochemistry.

\section{Reference}

Klimkans and Larsson, Chem. Phys 189, 25 (1994). 


\section{Thermodynamics and Kinetics of Cation Exchange in Micas: Development of Molecular Modeling Approaches}

\author{
K. M. Rosso and E. J. Bylaska \\ Supported by PNNL Laboratory Directed Resarch \\ and Development.
}

\section{Project Description}

The project involves the development of a molecular modeling capability in the area of radionuclide/ layered silicate mineral interactions. The focus is on the calculation of thermochemical cycles and relative kinetics of cation exchange in interlayer sites in the mineral muscovite. Density functional theory (DFT) methods are utilized to calculate optimized structural parameters and total energies for muscovite with different important cations in the interlayer site. Energy changes as a function of cation position in the interlayer site are used to calculate the relative ease with which the cations may migrate into the interlayer sites. This project goal is to produce accurate theoretical descriptions of cation exchange processes that may be used to elucidate observed field behavior.

\section{Technical Accomplishments}

Accomplishments include the successful implementation and benchmarking of planewave DFT codes on model mineral systems, calculation of optimized structural parameters for muscovite and Cs-exchanged muscovite. and calculation of $\mathrm{Cs} / \mathrm{K}$ cation exchange thermodynamics. These achievements are addressed in more detail below.

\section{Benchmarking DFT Methods}

A variety of planewave DFT methods and calculation parameters are potentially applicable to the problem of cation exchange. The relative accuracies of the particular methods can be difficult to gauge against experiment on complicated systems. Therefore, the various methods were applied to simpler but related model mineral systems to benchmark their performance. Using the mineral diaspore, we evaluated the ability of local-density (LDA) and generalized gradient (GGA) DFT methods to mimic the compressibility of an anisotropic structure as a function of pressure up to $25 \mathrm{GPa}$ (Figure 2.7).

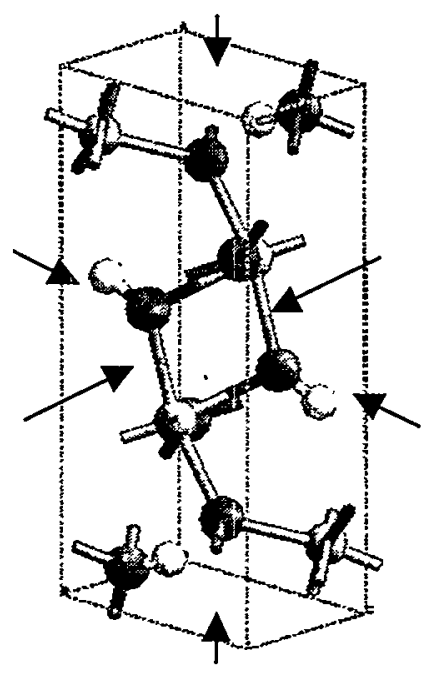

Figure 2.7. The structure of the mineral diaspore. The structure is known to compress unequally along the three unit cell axes. GGA DFT methods accurately reproduce the anisotrophy in the compressibility.

Calculated structures, bulk moduli, and anisotropic compressibilities for diaspore using the GGA DFT method demonstrated better agreement with experiment. The test implies that GGA DFT is sufficiently accurate to describe changes in the total energy of a mineral phase as a function of subtle structural changes.

DFT methods were also benchmarked to evaluate their ability to calculate total relative energies for significantly different structures of equivalent chemical composition, or polymorphism. Phase relationships for geometry optimized $\mathrm{AlOOH}$ and FeOOH polymorphs were calculated. LDA DFT methods outperformed GGA in properly depicting the relative stabilities of these phases, as compared with experiment.

\section{The Structure of Muscovite}

The structure of muscovite is complicated because it contains both strongly covalent and strongly ionic interactions. This presents a challenge to any theoretical attempts to properly predict the structure (Figure 2.8). So-called 2:1 layers are composed of $\mathrm{Si}_{2} \mathrm{O}_{5}$ and $(\mathrm{Al}, \mathrm{Si}) \mathrm{O}_{6}$ groups connected by rigid covalent bonds. Interlayer $\mathrm{K}$ cations bind the layers together with ionic bonds. The strength of the ionic bonding depends on isomorphic substitutions in the 


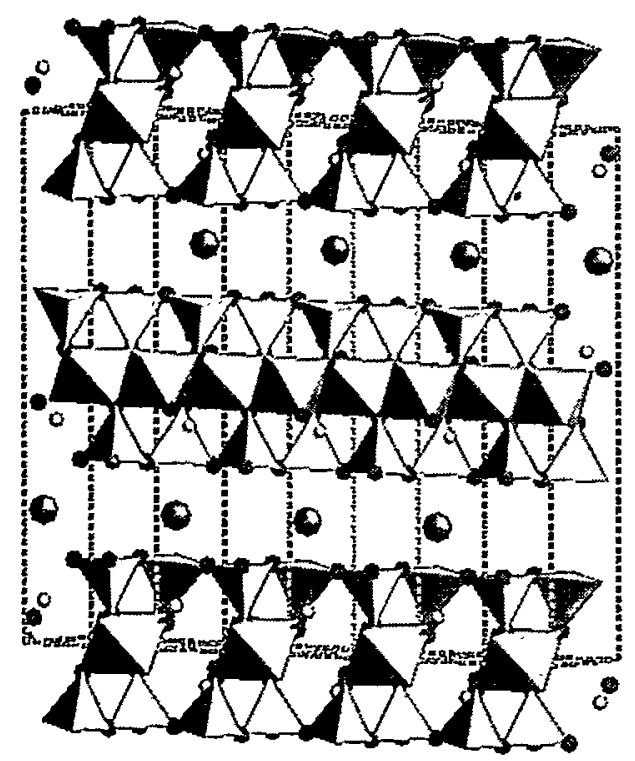

Figure 2.8. The structure of muscovite. Interlayer cations (large grey spheres) bind the layers together. Cation exchange occurs primarily at this site. Cs slowly exchanges with interlayer $\mathrm{K}$ over time. DFT modeling approaches are being used to understand the thermodynamic and kinetic aspects of this process.

2:1 layers. Using a variety of DFT methods to predict the minimum energy structure, we found that the GGA approach resulted in excellent agreement with the experimental structure. The unit cell parameters were remarkably predicted to an accuracy of $1 \%$. We were able to go beyond available experimental data by investigating the effect of small compositional changes on the strength of ionic bonding reaching the interlayer site. Isomorphic substitutions leading to charge depletion near the interlayer site resulted in a larger predicted interlayer separation. Potential implications include easier interlayer access for larger exchangeable cations.

\section{Thermodynamics of Cation Exchange}

GGA DFT methods, successfully applied to muscovite, were extended to Cs-substituted muscovite. Total energy differences were used in conjunction with experimental ionization potentials and heats of solution for $\mathrm{Cs}$ and $\mathrm{K}$ to calculate the thermodynamic driving force for $\mathrm{Cs} / \mathrm{K}$ exchange in aqueous solution (Figure 2.9). Calculated exchange energies were very low $(+33 \mathrm{meV})$, close to the mean thermal energy available at room temperature, indicating that muscovite has no strong "preference" for either interlayer constituent. This is consistent with the observed exchange behavior. Some important subtle substitutional changes in the 2:1 layers are found to cause charge depletion near the interlayer site, making the site less energetically favorable for the large Cs cation. This leads to substantial increases in the exchange energy, indicating that the exchange process is more energetically uphill.

Future work in this area will incorporate more exchangeable cations and a larger variety of isomorphic substitutions. Kinetic aspects of the exchange process will be addressed using a combination of total energy changes as a function of cation position in the interlayer, and statistical thermodyanmics.

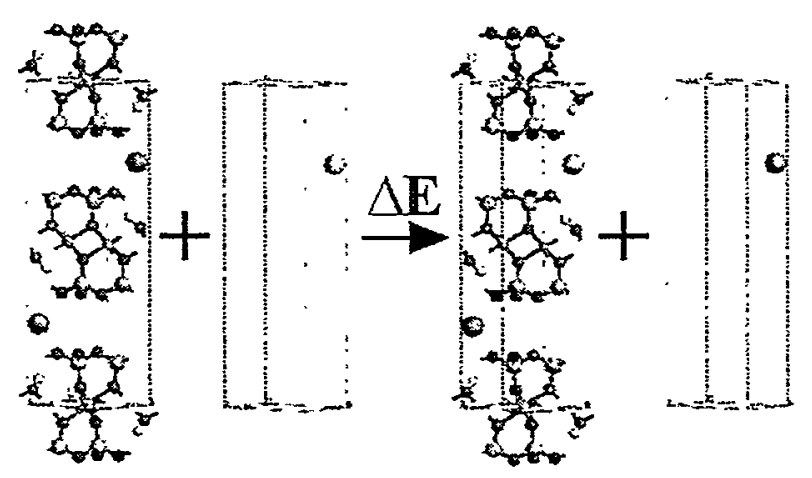

Figure 2.9. The total energy scheme for calculation of the gas phase energetics of cation exchange. Later corrections for the ionization of Cs (light grey sphere) and $\mathrm{K}$ (dark grey sphere) to cations and corrections for the heats of aqueous solvation were applied. 


\section{Molecular Simulation of Oxide Surface Chemistry}

\author{
J. R. Rustad, E. J. Bylaska, \\ D. A. Dixon, A. R. Felmy, and \\ K. M. Rosso
}

Supported by BES Geosciences.

Chemical interactions of aqueous species with minerals at solid-water interfaces can be highly complex. No single experimental method can fully define such processes, and conceptual molecular level understanding is usually pieced together using information from multiple experimental techniques. Understanding interfacial processes depends on information obtained from simpler systems, such as gas-phase molecules, aqueous species, vacuumterminated mineral surfaces and hydroxylated mineral surfaces. Molecular simulation can play an important role in organizing diverse experimental and theoretical studies on these simpler systems and focusing these results on interfacial problems. We outline a multidisciplinary approach to interfacial simulation studies involving interaction with theoretical quantum chemists. molecular spectroscopists, surface scientists, mineralogists. and aqueous solution chemists working on mineral-water interfaces. It is shown how molecular simulation can be used effectively to crosscorrelate data and calculations involving a) gas-phase and aqueous ions (especially metal ion hydrolysis and complexation), b) crystal structures of oxide and oxyhydroxide minerals, c) energetics and relaxation of bulk-terminated oxide surfaces, d) energetics and structure of hydroxylated and solvated surfaces, and e) acid base reactions and surface charging of oxides.

The model is based on the dissociating water potential described in (Halley et al. 1993). The original parameters were subsequently modified (Rustad et al. 1996) to obtain better agreement with the ab initio calculations of Xantheas (1994, 1995; Xantheas and Dunning 1993). Water potentials were also tested on bulk ice. Fe-O parameters were obtained by fitting the water model (Rustad et al. 1995) to the ab initio calculations of the iron-water potential surface of Curtiss et al. (1987). Using the water-water from Halley et al. (1993) and $\mathrm{Fe} 3^{+}$-water potential model in Rustad et al. (1995), the Fe-O distance in the hexaaquo complex is $207 \mathrm{pm}$. This compares well with non-local density functional calculations
(NLDFT), but is about $5 \mathrm{pm}$ longer than the experiment. The deprotonation energies for successive removal of protons from the hexaaquo complex correlates well with the known hydrolysis constants of ferric iron in aqueous solution, and also shows collapse to a tetrahedral structure for $\mathrm{Fe}(\mathrm{OH})^{4-}$ as is also observed in DFT calculations. Gas-phase deprotonation energies agree well with those determined through density functional theory by J. D. Kubicki (unpublished). Solution-phase MD calculations of hydrolysis reactions were also carried out (Rustad et al. 1995). These are the first self-consistent molecular dynamics calculations of hydrolysis reactions. Hydrolysis calculations have now been carried out on all the common trivalent metal ions using density functional electronic structure methods (Rustad et al. 1999).

Using the simple potential model derived from the $\mathrm{Fe}^{3+}$-water potential surface, $\mathrm{Fe}$ oxide/oxyhydroxide crystal structures are fully optimized with respect to lattice parameters a,b,c; $\alpha, \beta, \gamma ;$ and fractional coordinates (Rustad et al. 1996). As in case of the aqueous complex, Fe-O bond lengths are about $5 \%$ too long with a concomitant increase in the lattice constants. Stable structures are predicted for the polymorphs of $\mathrm{FeOOH}$ and $\mathrm{Fe}_{2} \mathrm{O}_{3}$. Recently we have been conducting plane-wave pseudopotential calculations on $\mathrm{Al}, \mathrm{Fe}$, and $\mathrm{Cr}$ oxyhydroxides (Rustad and Rosso submitted).

For vacuum-terminated surfaces, changes in interlayer separations upon surface relaxation are predicted (Wasserman et al. 1997) and used in the interpretation of x-ray photoelectron diffraction (XPD)

(Thevuthasan et al. 1999). Good agreement with experiment is obtained for relaxation of the (001) surface of hematite. These calculations also compare very well with FLAPW electronic structure calculations and were recently referenced in Wang et al. (1998). This work has also been extended to magnetite (001) (Rustad et al. 1999).

Water molecules are adsorbed at coordinatively unsaturated iron ions. For the hematite (012) surface, the extent of dissociation was determined by calculations of the 1296 possible tautomeric arrangements of protons on a neutral $(2 \times 2)$ surface using a 16-node Beowulf parallel computer (Rustad et al. 1999). The extent of water dissociation $(75 \%)$ on $-\mathrm{Fe}_{2} \mathrm{O}_{3}(012)$ is consistent with the temperature programmed 
desorption (TPD) and high-resolution electron energy loss system (HREELS) data (Henderson et al. 1998). The extent of water dissociation was also determined for two terminations of magnetite (001) (Rustad et al. 1999), as shown in Figure. 2.10.

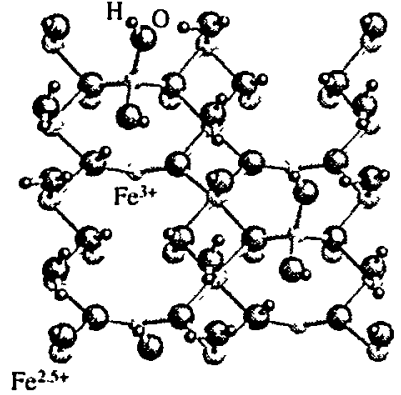

(a)

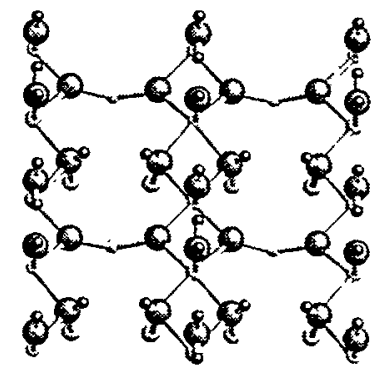

(b)
Figure 2.10. Minimum energy tautomeric forms for the hydroxylated " $A$ " (a) and " $B$ " (b) terminations. Note that in the minimum energy structure for " $A$ ", tetrahedral sites revert back to the unrelaxed configuration.

From the lowest-energy surface tautomers, protons are added and removed from surface oxide sites, resulting in a list of gas-phase acidities and proton affinities for surface sites. As a first approximation, a linear relationship found in the hydrolysis species is used to convert the calculated energy differences to surface pKa yielding a PZC of 8.9 for goethite (Rustad et al. 1996). The calculated charging curve of goethite (110) and (021) surfaces is in remarkable agreement with the experimental curves (Felmy et al. 1998). When the model resulting from the optimal fit to goethite is used to predict the hematite charging curve, the agreement with experiment is excellent, provided the Stern-layer capacitance is adjusted to a much lower value than that used for goethite (Rustad et al. 1999).

Extension to oxyanions $\left(\mathrm{H}_{2} \mathrm{SO}_{4}, \mathrm{H}_{2} \mathrm{CrO}_{4}, \mathrm{H}_{3} \mathrm{PO}_{4}\right.$, $\mathrm{H}_{4} \mathrm{SiO}_{4}$ ) is the logical next step in building up complexity. DFT calculations were carried out on protonated gas-phase oxyacid molecules (Rustad et al. 1999) as a basis for constructing the classical model. Criteria used to define the model include structure as a function of protonation state, proton affinity of $\mathrm{H}_{\mathrm{n}} \mathrm{TO}^{4-}, \mathrm{H}_{\mathrm{n}} \mathrm{TO}_{4}{ }^{2-}$, and the dipole moment. Proton affinities correlate well with solution $\mathrm{pK}_{\mathrm{a}}$. Models are tested through prediction of known ferric chromate, ferrous/ferric phosphate hydrate crystal structures. Gas-phase metal-ligand binding energies, calculated using the model, correlate well with known stability constants in aqueous solution. Future work will involve large-scale molecular dynamics simulation of sorption processes at the iron oxidewater interface. These simulations will yield new molecular-level ideas about what kinds of surface complexes can form on specific iron oxide surfaces, including information on possible proton stoichiometries, sorbate polymerization, and competitive sorption effects.

\section{References}

Curtiss, L. A., J. W. Halley, J. Hautman, and A. Rahman, J. Chem. Phys. 86, 2319 (1987).

Felmy, A. and J. Rustad, Geochimica et Cosmochimica Acta 62, 25 (1998).

Halley, J. W., J. R. Rustad, and A. J. Rahman, Chem. Phys. 98, 4110 (1993).

Henderson, M. A., S. A. Joyce, and J. R. Rustad, Surface Science 417, 66 (1998).

Rustad, J. R., A. R. Felmy, and B. P. Hay, Geochim. et Cosmochim. Acta 60, 1553 (1996).

Rustad, J. R., B. P., Hay, and J. W. Halley, J. Chem. Phys. 102, 427 (1995).

Rustad, J. R., D. A. Dixon, and A. R. Felmy, J. Am. Chem. Soc. 121, 3234 (1999).

Rustad, J. R., and K. M. Rosso, "Equation of state of diaspore $(\mathrm{AlOOH})$ from first principles calculations," submitted to Solid State Communications.

Rustad, J. R. and K. M. Rosso, "Energetics of Al and $\mathrm{Fe}$ oxyhydroxide minerals using plane-wave pseudopotential calculations," submitted to American Mineralogist.

Rustad, J. R., E. Wasserman, and A. R. Felmy, (1999) "The magnetite (001) surface: Insights from molecular dynamics calculations," Proceedings of the United Engineering Foundation Alloy Conference, in press.

Rustad, J. R., E. Wasserman, and A. R. Felmy, Surface Science 432, L583 (1999).

Rustad, J. R., E. Wasserman, and A. R. Felmy, Surface Science 424, 28 (1999).

Rustad, J. R., A. R. Felmy, and B. P. Hay, Geochim. et Cosmochim Acta 60, 1563 (1996).

Rustad, J. R., D. A. Dixon, J. D. Kubicki, and A. R. Felmy "The gas-phase acidities of tetrahedral oxyacids form ab initio electronic structure theory," in review, J. Phys. Chem. (1999). 
Thevuthasan, S., Y. J. Kim, S. I. Yi, S. A. Chambers, J. Morais, R. Denecke, C. S. Fadley. P. Liu, T. Kendelewicz, and G. E. Brown, Jr., Surface Science 425, 276 (1999).

Wang. X.-G., W. Weiss, Sh. K. Shaikhutdinov, M. Ritter, M. Petersen, F. Wagner, R. Schlögl, and M. Scheffler, Phys. Rev. Lett, 81, 1038 (1998).
Wasserman, E., J. R. Rustad, B. P. Hay, and J. W. Halley, Surface Science 385, 217 (1997). Xantheas, S. S., J. Chem. Phys. 100, 7523 (1994). Xantheas, S. S., J. Chem. Phys. 102, 4505 (1995). Xantheas, S. S. and T. H. Dunning, J. Chem. Phys. 99, 8774 (1993). 


\section{Molecular Dynamics}

\section{Simulations of Hydrated Silicate Liquids and Glasses}

\author{
F. J. Serpa ${ }^{(a)}$ and J. R. Rustad
}

Supported by BES Geosciences and EMSL.

(a) University of California at Santa Barbara.

The properties of water, either as a condensed low-temperature fluid or dissolved in crystalline, glassy, or molten silicates influences myriad geochemical phenomena extending from the earth's surface to its deep interior (Serpa 1999). The stability of glasses as nuclear waste storage media demands an understanding of the structure and properties of these materials as a function of water content. It is well known that $\mathrm{H}_{2} \mathrm{O}$ plays a dramatic role in the depolymerization of silicate liquids and glasses by destroying bridging oxygen, that is oxygen bonded to two $\mathrm{Si}$ or $\mathrm{Al}$ atoms, and creating non-bridging oxygen or oxygen that has only a single nearest $\mathrm{T}(\mathrm{T}=\mathrm{Si}, \mathrm{Al})$ neighbor. While extensive molecular dynamics simulations on aluminosilicate and some borosilicate compositions have been performed by various research groups, all compositions simulated to date are nominally anhydrous.

In the first phase of the work, we have produced a set of interaction potentials describing the system $\mathrm{Na}_{2} \mathrm{O}-\mathrm{H}_{2} \mathrm{O}-\mathrm{SiO}_{2}$. These potentials have been fit to 10-15 sodium hydroxide hydrate, sodium silicate hydrate, and sodium silicate crystal structures. The fundamental $\mathrm{Na}-\mathrm{OH} \mathrm{Na}-\mathrm{H}_{2} \mathrm{O}$ interactions have been obtained by fitting to sodium hydroxide hydrate crystals. The structures of these crystals are based on edge and face sharing $\mathrm{Na}\left(\mathrm{OH}_{2}\right)_{6}$ octahedra. The diverse arrangements of these octahedra are illustrated in Figures 2.11 through 2.14). Bond lengths and cell constants are reproduced to within $3 \%$ with stable minima found for all experimental crystal structures.

The interactions thus obtained were then tested on a variety of $\mathrm{Na}$ silicate hydrate crystals (Figures 2.15 through 2.21). There are two major families of such structures based on hydrogen-bound anionic chains of $\mathrm{H}_{2} \mathrm{SiO}_{4}{ }^{-2}$ and $\mathrm{HSiO}_{4}{ }^{3-}$. These structures include

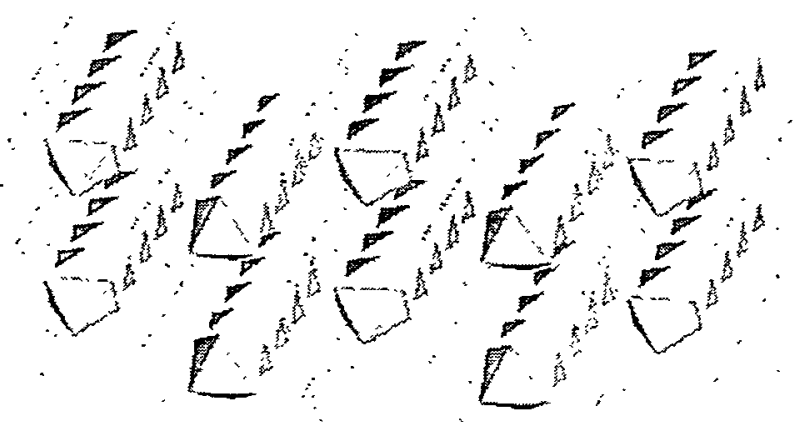

Figure 2.11. $\mathrm{NaOH} \cdot 7 \mathrm{H}_{2} \mathrm{O}$

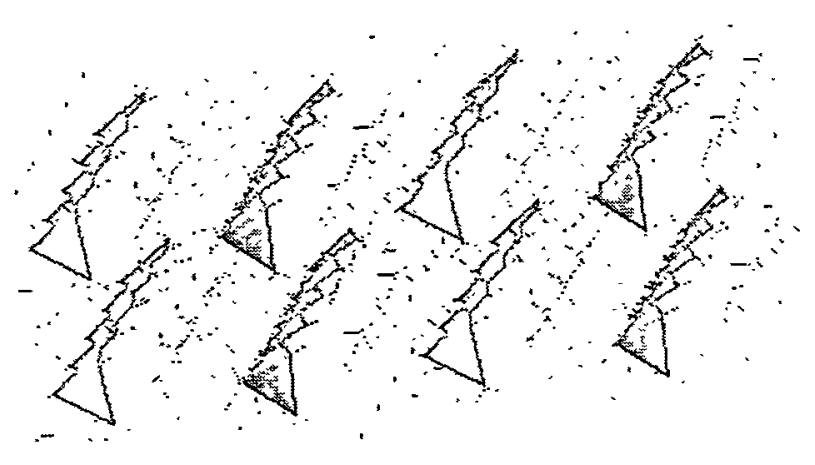

Figure 2.12. $\mathrm{NaOH} \bullet 4 \mathrm{H}_{2} \mathrm{O}$

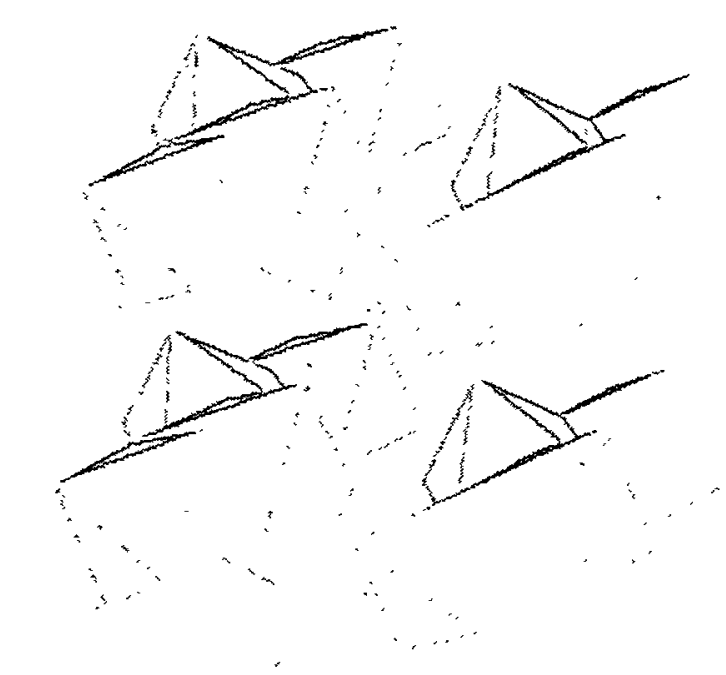

Figure 2.13. $\mathrm{NaOH} \cdot 3.5 \mathrm{H}_{2} \mathrm{O}$ 


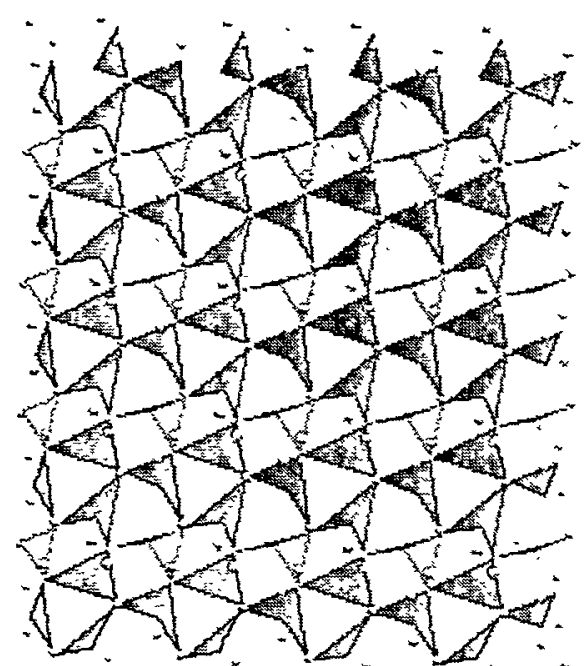

Figure 2.14. $\mathrm{NaOH} \cdot 1 \mathrm{H}_{2} \mathrm{O}$

Figure 2.15. $\mathrm{Na}_{2}\left(\mathrm{H}_{2} \mathrm{SiO}_{4}\right) .4 \mathrm{H}_{2} \mathrm{O}$

Figure 2.16. $\mathrm{Na}_{2}\left(\mathrm{H}_{2} \mathrm{SiO}_{4}\right) .5 \mathrm{H}_{2} \mathrm{O}$

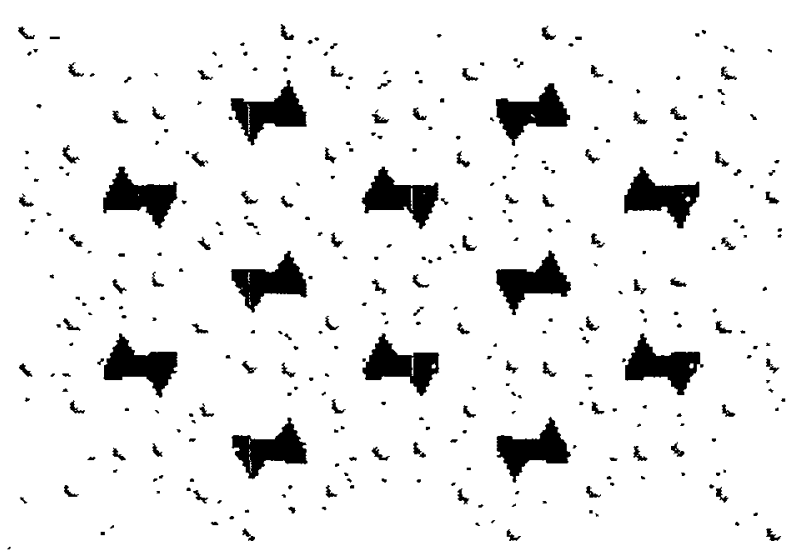

Figure 2.17. $\mathrm{Na}_{2}\left(\mathrm{H}_{2} \mathrm{SiO}_{4}\right) \cdot 7 \mathrm{H}_{2} \mathrm{O}$

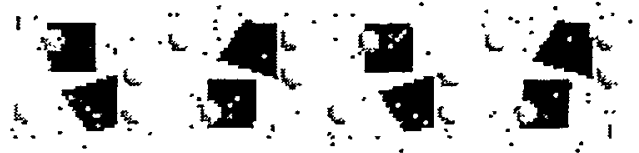

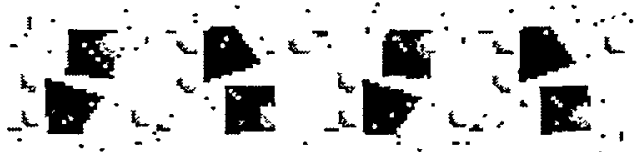

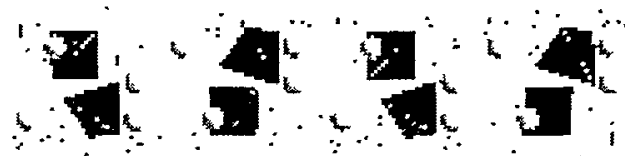

'

Figure 2.18. $\mathrm{Na}_{2}\left(\mathrm{H}_{2} \mathrm{SiO}_{4}\right) .8 \mathrm{H}_{2} \mathrm{O}$

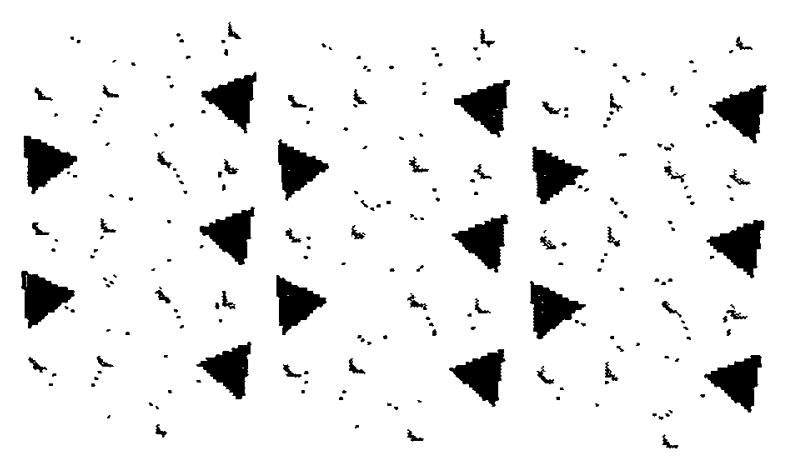

6

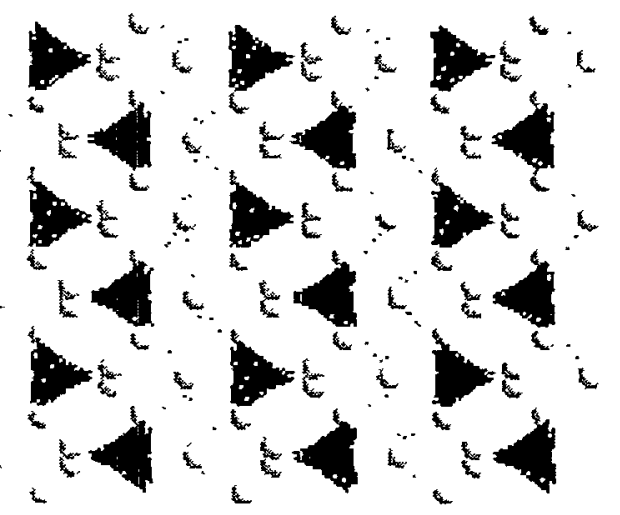

Figure 2.19. $\mathrm{Na}_{3}\left(\mathrm{HSiO}_{4}\right) \cdot \mathrm{H}_{2} \mathrm{O}$ 


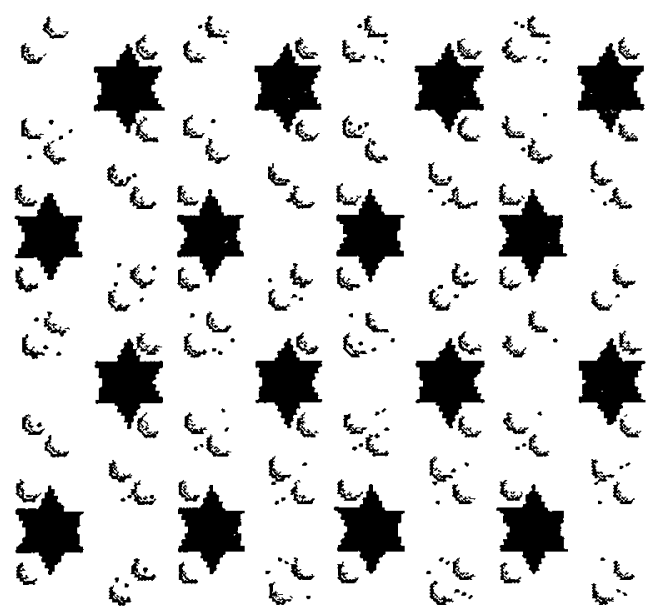

Figure 2.20. $\mathrm{Na}_{3}\left(\mathrm{HSiO}_{4}\right) \cdot 2 \mathrm{H}_{2} \mathrm{O}$

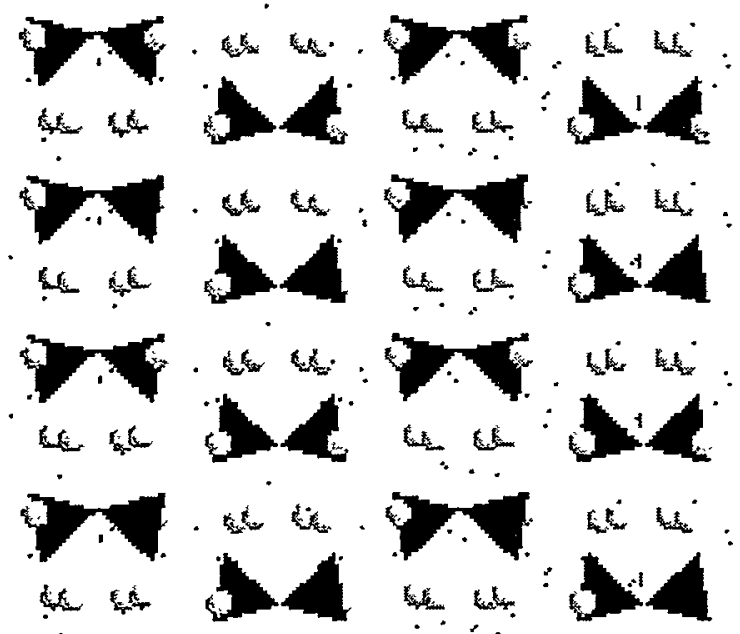

Figure 2.21. $\mathrm{Na}_{3}\left(\mathrm{HSiO}_{4}\right) \cdot 5 \mathrm{H}_{2} \mathrm{O}$

$\mathrm{Na}_{3}\left(\mathrm{HSiO}_{4}\right) \cdot(1,2,5) \mathrm{H}_{2} \mathrm{O}$ and $\mathrm{Na}_{2}\left(\mathrm{H}_{2} \mathrm{SiO}_{4}\right) \cdot(4,5,7,8) \mathrm{H}_{2} \mathrm{O}$. Additional sodium silicate hydrate crystal structures include the more polymerized species

$\mathrm{Na}\left(\mathrm{Si}_{2} \mathrm{O}_{4} \mathrm{OH}\right)\left(\mathrm{H}_{2} \mathrm{O}\right)$. Bond lengths and cell constants for the predicted group of crystals are reproduced to within $5 \%$, and the fragile hydrogen-bonded anionic chains remain intact and have the correct bond topology. These crystals provide an unusually rigorous test of the $\mathrm{Na}-\mathrm{H}_{2} \mathrm{O}-\mathrm{SiO}_{2}$ interaction potentials.

One of the key results of recent experimental investigations of hydrous silicate melts is the compositional independence of the partial molar volume of dissolved water. Ochs and Lange (1999) recently measured the partial molar volume of water over a range of silicate melt compositions. Ochs and Lange conclude that $\mathrm{VH}_{2} \mathrm{O}_{\text {total }}=22.9 \pm 0.6 \mathrm{~cm}^{3} / \mathrm{mol}$ at $1000^{\circ} \mathrm{C}$ and $1 \mathrm{bar}$ and that $\mathrm{VH}_{2} \mathrm{O}$ total is independent of silicate melt composition, the total water content, and the speciation $\left(\mathrm{OH}\right.$ or $\left.\mathrm{H}_{2} \mathrm{O}_{\text {mol }}\right)$. Our investigations of the sodium silicate hydrate crystal structures can be used to examine this concept in the crystalline state. In Figures 2.22 and 2.23 we plot the molar volume of $\mathrm{Na}_{3}\left(\mathrm{HSiO}_{4}\right) \cdot \mathrm{nH}_{2} \mathrm{O}$ and $\mathrm{Na}_{2}\left(\mathrm{H}_{2} \mathrm{SiO}_{4}\right) \cdot \mathrm{nH}_{2} \mathrm{O}$ as calculated using our interaction potential. The molar volumes obtained for the $\mathrm{Na}_{2}\left(\mathrm{H}_{2} \mathrm{SiO}_{4}\right) \cdot \mathrm{nH}_{2} \mathrm{O}$ system are $15.7 \mathrm{~cm}^{3} / \mathrm{mol}$ versus $14.2 \mathrm{~cm}^{3} / \mathrm{mol}$, from crystal structure data. For the $\mathrm{Na}_{3}\left(\mathrm{HSiO}_{4}\right) \cdot \mathrm{nH}_{2} \mathrm{O}$ system, we obtain $14.6 \mathrm{~cm}^{3} / \mathrm{mol}$ versus $12.3 \mathrm{~cm}^{3} / \mathrm{mol}$ from crystal structure data. Thus, while we overestimate the molar volume of water systematically, the sense of the

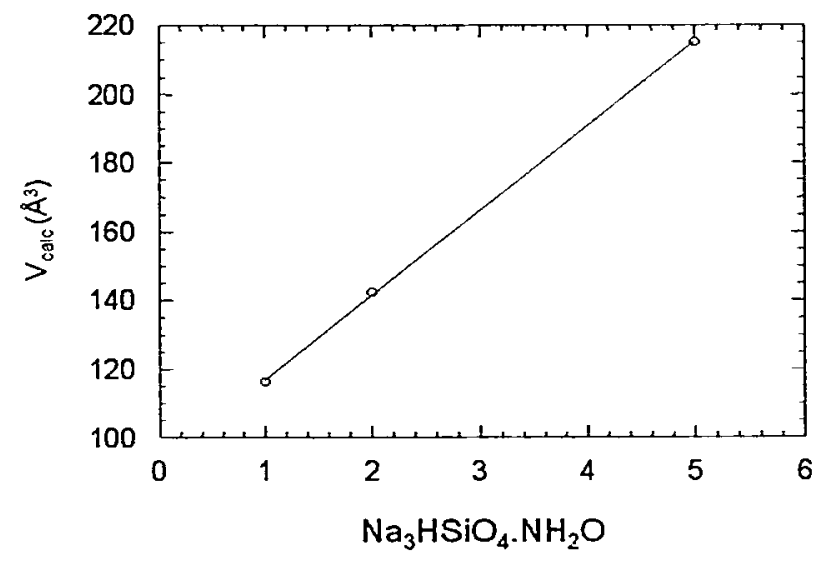

Figure 2.22. $\mathrm{Na}_{3}\left(\mathrm{HSiO}_{4}\right) \cdot \mathrm{NH}_{2} \mathrm{O}$

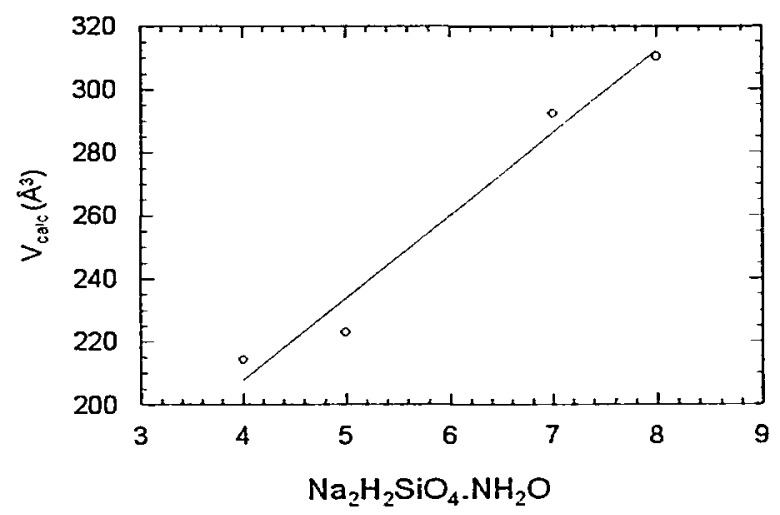

Figure 2.23. $\mathrm{Na}_{2}(\mathrm{H} 2 \mathrm{SiO} 4) \cdot \mathrm{NH}_{2} \mathrm{O}$ 
compositional variation is nearly the same as that observed experimentally. Additional experimental data over the wider range of water contents available in melt systems will be needed to further examine this relationship, however, the MD simulations will be extremely useful for investigating the speciation of water in silicate melts and will shed light on the molecular origins of the observed thermodynamic data.

\section{References}

Ochs, F. A. and R. A. Lange, The Density of Hydrous Magmatic Liquids, Science 283, 1314 (1999).

Serpa, F. J., A slippery problem with explosive consequences, Science 283, 1275 (1999). 


\section{Spectroscopy/Microscopy}




\section{A Spectroscopic Study of Phenanthrene Adsorption on Porous Silica}

\author{
Z. Wang, D. M. Friedrich, ${ }^{(a)}$ \\ M. R. Beversluis, ${ }^{(b)}$ A. G. Joly, \\ M. H. Huesemann, ${ }^{(c)}$ M. J. Truex, \\ R. G. Riley, ${ }^{(c)}$ and C. J. Thompson \\ and B. M. Peyton ${ }^{(a, d)}$
}

Supported by the Environmental Technology

Partnerships, DOE Office of Biological and

Environmental Research, DOE Office of Science.

(a) Optical Coating Laboratory, Inc. Santa Rosa, California.

(b) Associated Western Universities student.

(c) Marine Sciences Laboratory, Sequim, Washington.

(d) Washington State University, Pullman, Washington.

The slow desorption of hydrophobic organic carbon, such as alkylbenzenes, chlorobenzenes, and polycyclic aromatic hydrocarbons (PAHs), from soils and sediments directly affects the fate, transport, and degradation of these contaminants as well as the related risk assessment and remediation procedures in natural environments. Much recent work has been directed toward the elucidation of factors that are responsible for such slow desorption processes (Huang and Weber 1997; Luthy et al. 1997; Werth and Reinhard 1999; Wu and Gschwend 1986). It appears that the constrained diffusion of contaminants through soil organic matter and in the intraparticle mesopores and micropores may play a major role in these processes. At a molecular level, sorption and desorption processes involve direct chemical and physical interactions between sorbate and sorbent molecules at the solid surface. For nonionic compounds, sorption on ionic solids such as soils and silicas, the interaction forces may involve van der Waals or weak dipole-dipole interactions. Molecular spectroscopic techniques make it possible to directly observe the structural changes involved in the sorption/desorption processes.

In this work fluorescence spectroscopy and fluorescence lifetime measurements are used to study the sorption of phenanthrene in two types of porous silica particles with distinctly different pore size distributions. The objectives of this work are

1. demonstrate the effectiveness of molecular fluorescence spectroscopy and lifetime measurement in the determination of PAH sorption characteristics on porous silica

2. determine the effect of hindered diffusion of PAHs during its slow desorption based on the spectral changes of phenanthrene sorbed in porous silica with characteristic pore size distributions.

Two types of porous silica particles were used in the work. The first type is a commercial silica gel particle (Aldrich Davisil 150) with a surface area of $340 \mathrm{~m}^{2}$, particle diameter of $360 \mu \mathrm{m}$, and an average pore diameter of $150 \AA$. The second type of particle was synthesized and characterized in the laboratory following the procedure outlined by (Bruinsma et al. 1998). The latter (PNNL) particle has a surface area of greater than $800 \mathrm{~m}^{2}$, particle diameter of about $1 \mu \mathrm{m}$, and a narrow pore size distribution centered around $20 \AA$. Sorption of phenanthrene was initiated by passing a supercritical fluid $\mathrm{CO}_{2}$ solution of phenanthrene through a column packed with porous silica particles with phenanthrene loading levels between $4.7 \mu \mathrm{g} / \mathrm{g}$ (phenanthrene/silica) and $4.7 \mathrm{mg} / \mathrm{g}$. Sorption experiments were also conducted in aqueous solution by introduction of silica particles into aqueous phenanthrene solution. It was found that after 24 hours the amount of sorption only reached $0.47 \mu \mathrm{g} / \mathrm{g}$ (phenanthrene:silica). Two-photon excitation fluorescence profiles indicated that phenanthrene was sorbed throughout the silica particles.

At all loading levels the surface coverage of phenanthrene on the silica particles is below $1 \%$. Absorption spectra, fluorescence excitation and emission spectra, and fluorescence lifetime measurements were recorded on these phenanthreneloaded silica particles along with phenanthrene solid samples and dilute phenanthrene solutions in water and cyclohexane. The spectral characteristics of monomeric phenanthrene spectra recorded for dilute phenanthrene solutions are distinctively different from those of phenanthrene solid as demonstrated in Figure 3.1A and 3.1B. Spectral comparison indicates 
that the spectra of phenanthrene sorbed on PNNL silica particles at all loading levels and on Davisil silica particles below $2.3 \mathrm{mg} / \mathrm{g}$ (phenanthrene/silica) loading levels (Figure 3.1C) are identical to the spectra of the monomers. Under these loading levels, sorption of phenanthrene as monomers is thermodynamically more stable than formation of phenanthrene dimers, aggregates, or crystals. For Davisil particles at $4.7 \mathrm{mg} / \mathrm{g}$ (phenanthrene/silica) loading levels. spectral features similar to those of solid phenanthrene begin to appear. Phenanthrene sorbed from aqueous solution was found to be composed of only monomers.

The much lower sorption capacity of silica particles in aqueous solution compared with that in supercritical fluid suggests that the presence of water greatly changes the number of sorption sites and possibly the sorption site energy distribution. If sorption occurs in the micropores, increased hydration of the silica surface would cause desorption of phenanthrene. Since the pore size is close to the molecular diameter of phenanthrene, transport of phenanthrene through the pores will provide unequivocal evidence of hindered diffusion in the pores. Fluorescence spectra were recorded immediately after a small amount of water was added to the phenanthrene-contaminated silica particles (Figure 3.1D). As shown in Figure 3.1, for Davisil particles with loading levels $>4.7 \mu \mathrm{g} / \mathrm{g}$ (phenanthrene:silica), a majority of the sorbed phenanthrene converts from monomers to a crystallike phase immediately after the introduction of water. Clearly, the presence of bulk water drastically modifies the silica surface and causes a conversion of phenanthrene from monomeric form to the crystalline form. Such a conversion is in agreement with the expected decreasing hydrophobicity of the surface from a less hydrated state to a more hydrated state, which repels phenanthrene from the surface. The fact that $4.7 \mu \mathrm{g} / \mathrm{g}$ (phenanthrene:silica) phenanthrenecontaminated particles did not show the formation of crystalline phenanthrene is an indication that the true sorption capacity of phenanthrene on silica in water is much larger than that which is sorbed within 24 hours $(0.47 \mathrm{~g} / \mathrm{g}$, phenanthrene:silica). Therefore, SCF loading may be a way of simulating the aging process in natural soil and mineral environments.

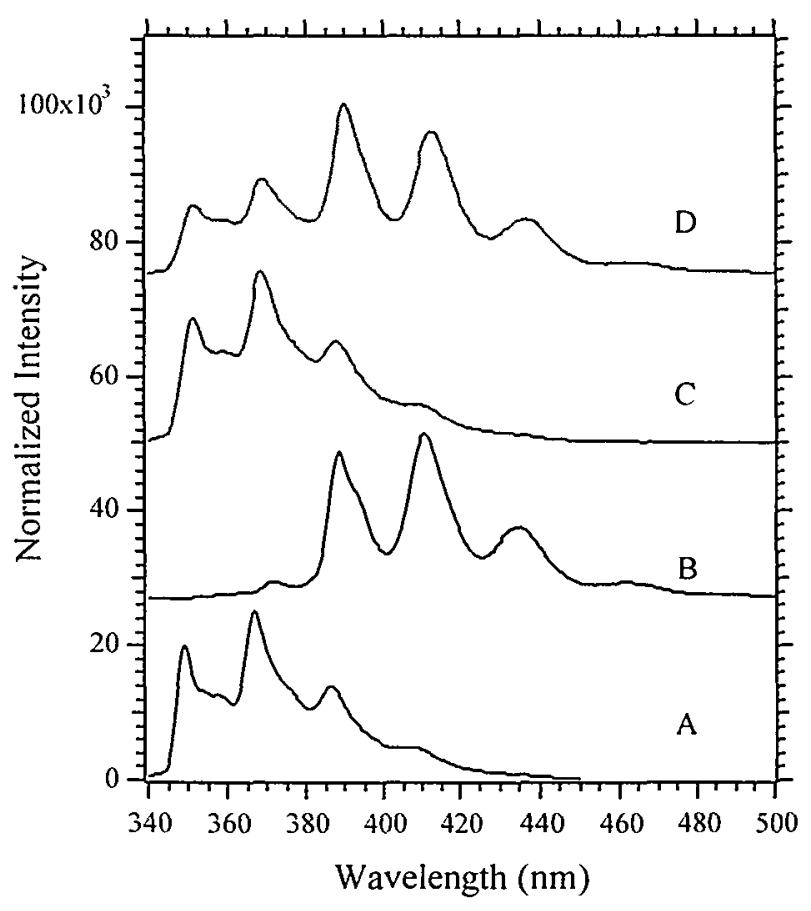

Figure 3.1. Fluorescence emission spectra of phenanthrene following excitation at $292 \mathrm{~nm}$. (A) $7 \times 10^{-6} \mathrm{M}$ solution of phenanthrene in cyclohexane; (B) as a crystalline film on a fused silica surface; (C) in PNNL silica particles at $47 \mu \mathrm{g} / \mathrm{g}$ (phenanthrene/silica) loading level; (D) in Davisil silica particles at (phenanthrene/silica) loading level in the presence of water. For clarity the spectra are normalized and offset in intensity.

In contrast to the Davisil particles, spectral changes were not observed for the $47 \mathrm{~g} / \mathrm{g}$ (phenanthrene:silica) phenanthrene-contaminated $20 \AA$ PNNL particles even after the particles had been in contact with water for more than a week. This indicates that sorption of phenanthrene monomers occurs in the $20 \AA$ micropores of the PNNL silica particles. Such a pore size is further reduced by a monolayer of hydration that normally occurs when the particles are exposed to the ambient conditions. Therefore the actual pore size is comparable with that of the molecular size of phenanthrene and its diffusion inside the pores is expected to be hindered. In the Davisil particles, pore sizes are much larger than the molecular diameter of phenanthrene so that phenanthrene can diffuse out of the pores without much resistance. Desorption causes a sudden increase of phenanthrene concentration 
beyond its solubility and results in the formation of phenanthrene crystals. Desorption experiments conducted in a liquid flow-through cell indicated that the phenanthrene microcrystals formed during desorption eventually dissolve in the presence of sufficient amounts of water.

\section{References}

Bruinsma, P. J., A. Y. Kim, J. Liu, and S. Baskaran, Chem. Mater., 9, 2507 (1998).
Huang, W., and W. J. Weber, Jr., Environ. Sci. Technol., 31, 3238 (1997).

Luthy, R. G., G. R. Aiken, M. L. Brusseau, S. D. Cunningham, P. M. Gschwend, J. J. Pignatello, M. Reinhard, S. J. Traina, W. J. Weber, Jr., and J. C. Westall, Environ. Sci. Technol., 31, 3341 (1997).

Werth, C. J., and M. Reinhard, Environ. Sci. Technol., 31, 697 (1999).

Wu, S. C., and P. M. Gschwend, Environ. Sci. Technol., 20, 717 (1986). 
Competitive Trace-Level

Sorption of Chromate and

Phosphate to Hematite

Surfaces: A Spectroscopic Approach

N. S. Foster-Mills, J. E. Amonette,

B. K. William, ${ }^{(a)}$ and A. E. Taylor ${ }^{(a)}$

Supported by DOE EMSP.

(a) Associated Western Universities student.

A fundamental understanding of specific mineral surface-site reactivities can help improve reactive transport models of contaminants in geologic systems and allow more effective remediation schemes to be devised. This project studied the thermodynamics and kinetics of the sorption of $\mathrm{Cr}(\mathrm{VI})$, a contaminant found in the groundwater at many DOE and industrial sites. on powdered hematite $\left(\alpha-\mathrm{Fe}_{2} \mathrm{O}_{3}\right)$, a common iron oxide mineral found in soils and sediments. Batch sorption experiments were performed to determine the maximum sorption capacities of the hematite for $\mathrm{Cr}(\mathrm{VI})$, phosphate, and sulfate oxyanions. Competitive sorption between $\mathrm{Cr}(\mathrm{VI})$ and phosphate oxyanions was examined using laser photoacoustic spectroscopy (LPAS).

\section{Batch Sorption Studies}

Batch sorption experiments with $20 \mathrm{mg}$ of hematite powder (specific surface of $9.7 \mathrm{~m}^{2} \mathrm{~g}^{-1}$ by BET-N $\mathrm{N}_{2}$ ) in $15 \mathrm{~mL}$ solution were conducted at room temperature with initial chromate, phosphate (P), or sulfate (S) concentrations ranging from 2.7 to $54, \mathrm{M}$ (i.e., $140 \mathrm{ppb}$ to $2.8 \mathrm{ppm}$ ). Preliminary experiments established that equilibration times of $1 \mathrm{~h}$ were sufficient. Concentrations of the anions remaining in solution after this time were determined by inductively coupled plasma mass spectrometry $(\mathrm{Cr})$ and ion chromatography $(\mathrm{P}, \mathrm{S})$. The sorption solutions were not buffered for $\mathrm{pH}$ to eliminate sorption interferences from the anions associated with buffering agents, and as a consequence, final sorption $\mathrm{pHs}$ ranged from 6.0 to 6.8. Despite the range in final $\mathrm{pH}$, the results of these sorption experiments (Figure 3.2a) could be described well by the linearized Langmuir isotherm equation:

$$
\mathrm{C}_{\text {final }} / \mathrm{C}_{\text {sorbed }}=\left(1 / \mathrm{C}_{\max }\right) \mathrm{C}_{\text {final }+} \mathrm{b}
$$

where $\mathrm{C}_{\text {final }}$ and $\mathrm{C}_{\text {sorbed }}$ are the equilibrium concentrations in solution and on the hematite surface, respectively, $\mathrm{C}_{\max }$ is the maximum sorption capacity of the mineral under the conditions of the experiment, and $b$ is a constant. Maximum sorption capacities of the hematite for sulfate, $\mathrm{Cr}(\mathrm{VI})$, and phosphate, were $3.5,8.3$, and $9.3 \mu \mathrm{mol} \mathrm{g}{ }^{-1}$, respectively, indicating that $\mathrm{Cr}(\mathrm{VI})$ and phosphate were sorbed more strongly than sulfate. In fact, $\mathrm{C}_{\max }$, which is an estimate of the relative sorption affinity of each of the three anions, was strongly correlated with $\mathrm{pK}_{2}$, the negative log of the second acid dissociation constant for each anion (Figure 3.2b). Such a relationship would be expected, as the protons are the charge-determining ions on the hematite surface and larger $\mathrm{pK}_{2}$ values indicate greater proton affinities on the part of the anions.

\section{Anion Sorption Model}

The correlation of $\mathrm{C}_{\max }$ with $\mathrm{pK}_{2}$ values suggests that only the divalent anion species (i.e., $\mathrm{SO}_{4}{ }^{2-}, \mathrm{CrO}_{4}{ }^{2-}$, and $\mathrm{HPO}_{4}{ }^{2-}$ ) contribute significantly to sorption. This premise can be tested by competitive sorption experiments, because the amounts of divalent anion available for sorption will vary differently for each anion when $\mathrm{pHs}$ close to the $\mathrm{pK}_{2}$ values are selected. Although experiments at $\mathrm{pHs}$ near the $\mathrm{pK}_{2}$ of sulfate are impractical, such experiments with $\mathrm{Cr}(\mathrm{VI})$ and phosphate are both practical and directly relevant to groundwater chemistry because the $\mathrm{pK}_{2}$ values for these anions are near 7. One would expect the relative sorption of $\mathrm{Cr}(\mathrm{VI})$ and phosphate to be directly proportional to the aqueous concentrations of $\mathrm{CrO}_{4}{ }^{2-}$ and $\mathrm{HPO}_{4}{ }^{2-}$. Speciation calculations show the ratio of these two species in solution (i.e., $\mathrm{HPO}_{4}{ }^{2-} / \mathrm{CrO}_{4}{ }^{2-}$ ) varies from about 0.2 to 1 in. going from $\mathrm{pH} 4$ to 9 (Figure 3.2c, solid curve) and suggest that sorption of $\mathrm{Cr}(\mathrm{VI})$ would be more favorable than phosphate over much of this range. We can estimate the relative amount of total phosphate needed to achieve 50\% sorption [i.e., equivalent sorption with $\mathrm{Cr}(\mathrm{VI})$ ] by

$$
\begin{gathered}
{\left[\mathrm{P}_{\text {total }} / \mathrm{Cr}(\mathrm{VI})_{\text {total }}\right]_{50 \%}=\left[\mathrm{C}_{\max (\mathrm{Cr}(\mathrm{VI})} / \mathrm{C}_{\max (\mathrm{P})}\right]} \\
{\left[\mathrm{CrO}_{4}{ }^{2-} / \mathrm{HPO}_{4}{ }^{2-}\right]}
\end{gathered}
$$

and this result is also plotted in Figure $3.2 \mathrm{c}$ (dotted curve, right axis). On this basis, we would predict that about 4.5 times as much phosphate as $\mathrm{Cr}(\mathrm{VI})$ would be needed at $\mathrm{pH} 5$ for equal sorption by the two anions on hematite, whereas equal sorption would occur at 
a)

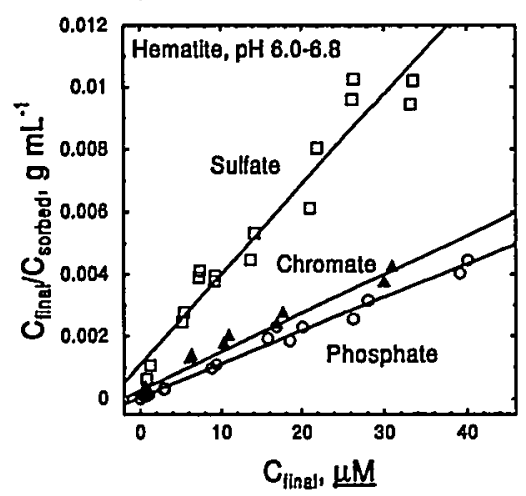

b)

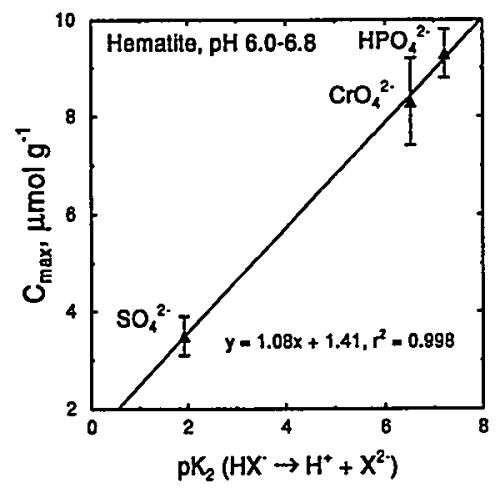

c)

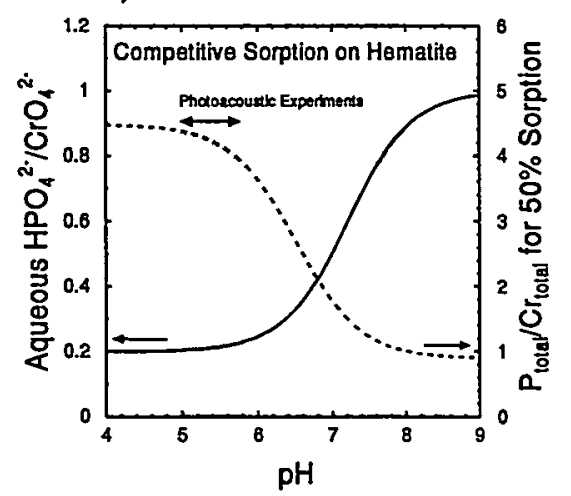

Figure 3.2. Results of hematite sorption studies with sulfate, chromate, and phosphate: a) linearized Langmuir isotherm plots of sorption of mono-anionic solutions; $b$ ) correlation between observed $C_{\max }$ values for monoanionic solutions and the acidities of the anions; c) influence of $\mathrm{pH}$ on aqueous speciation of phosphate and chromate (solid line, left axis) and the ratio of total phosphate to $\mathrm{Cr}(\mathrm{VI})$ needed to achieve equal sorption (dashed line, right axis).

$\mathrm{pH} 8$ with equal concentrations of $\mathrm{Cr}(\mathrm{VI})$ and phosphate. As shown below, the prediction at $\mathrm{pH} 5$ is in excellent agreement with the results of competitive sorption experiments carried out using LPAS.

\section{Spectroscopic Studies of Competitive Sorption}

Although the primary drinking water limit for $\mathrm{Cr}(\mathrm{VI})$ established by the U.S. Environmental Protection Agency (EPA) is $50 \mathrm{ppb}$, the levels of $\mathrm{Cr}(\mathrm{VI})$ in groundwater that are of concern range to as low as $11 \mathrm{ppb}$, where chronic contact can harm salmon fry. We selected LPAS to monitor sorption of $\mathrm{Cr}(\mathrm{VI})$ by the hematite because it provided the lowest detection limits (ca. $1 \mathrm{ppb}$ ) for $\mathrm{Cr}(\mathrm{VI})$ of any nondestructive measurement technique and would thus allow us to perform measurements of competitive sorption at realistic environmental levels. LPAS involves the absorption of light energy by a molecule and the subsequent detection of a pressure wave caused by heat energy released by the molecule upon return to the ground state. For aqueous $\mathrm{Cr}(\mathrm{VI})$, strong absorption of light occurs at $372 \mathrm{~nm}$, and so a pulsed Alexandrite laser $(50-n s$ pulses at $20 \mathrm{~Hz})$ tuned to this wavelength was used to provide the light pulse needed to make the LPAS measurement. Because the absorptivity of $\mathrm{Cr}(\mathrm{VI})$ is strongly dependent on solution $\mathrm{pH}$, this parameter was also monitored during the experiments.
For the competitive sorption experiments, we used a closed-loop system consisting of a photoacoustic measurement cell, two reaction/mixing chambers in parallel with valves to direct flow through one chamber or the other, a third chamber for sample introduction and monitoring of $\mathrm{pH}$, a peristaltic pump to circulate the solution through the system, and several filters to prevent particles from entering the photoacoustic cell. In a typical experiment, one reaction chamber was loaded with $4.3 \mathrm{mg}$ hematite and the other remained empty. A solution $(3 \mathrm{~mL})$ of $140 \mathrm{ppb} \mathrm{Cr}(\mathrm{VI})$ and $1 \mathrm{mM} \mathrm{KCl}$ with different amounts of phosphate was circulated through the system with the empty reaction chamber. After the photoacoustic signal stabilized, valves were switched so that the flow then circulated through the reaction chamber containing the hematite, thus initiating the sorption experiment. The integrated area of the photoacoustic waveform, laser power, and $\mathrm{pH}$ of the system were monitored continuously during the experiment by electronics.

Several competitive sorption experiments were performed in which the initial molar ratios of phosphate to $\mathrm{Cr}(\mathrm{VI})$ in solution were varied and reaction progress monitored by LPAS. Figure 3.3 shows the results of experiments carried out at initial $\mathrm{Cr}(\mathrm{VI})$ levels of $140 \mathrm{ng} \mathrm{mL}^{-1}$ and $\mathrm{P}: \mathrm{Cr}$ ratios of $0,2,4$, 8 , and 100 . The effects of phosphate were evident at a $\mathrm{P}: \mathrm{Cr}$ molar ratio of 2 (Figure 3.3, curve B). 


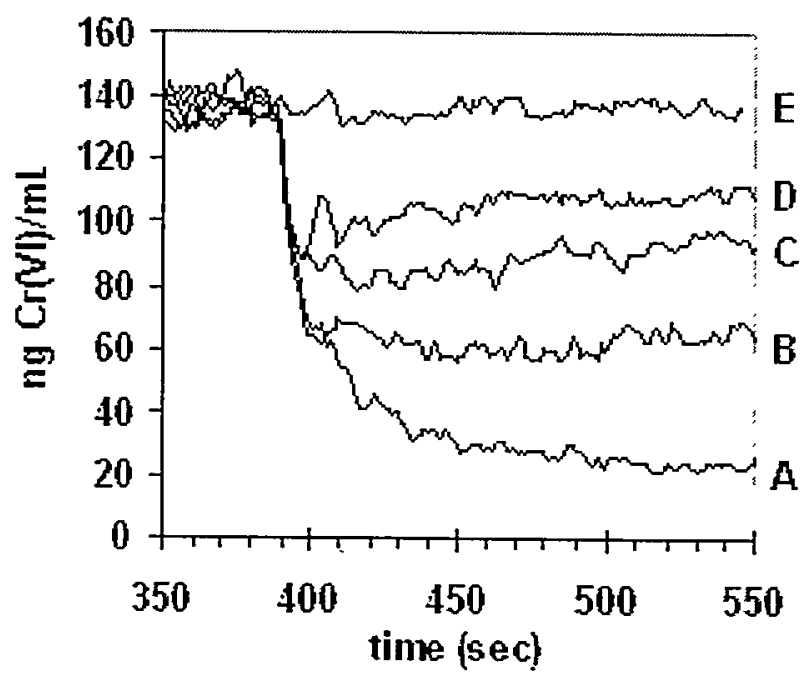

Figure 3.3. Changes in the concentrations of $\mathrm{Cr}(\mathrm{VI})$ in solution during adsorption experiments with hematite powders and different amounts of phosphate in solution. Solution was contacted with hematite at $\mathrm{t}=385 \mathrm{~s}$. Curves $\mathrm{A}$ through $\mathrm{E}$ correspond to initial $P: C r$ molar ratios of $0,2,4,8$, and 100 , respectively.

Approximately $50 \% \mathrm{Cr}$ sorption occurred at a $\mathrm{P}: \mathrm{Cr}$ ratio of 4 (Figure 3.3, curve $\mathrm{C}$ ), which agrees well with the sorption model prediction in Figure $3.2 \mathrm{c}$. At a $\mathrm{P}: \mathrm{Cr}$ ratio of 100 , no $\mathrm{Cr}(\mathrm{VI})$ sorption was observed indicating that all the sorption sites were occupied by phosphate.

Based on these results, we can draw the following conclusions. Sorption of $\mathrm{Cr}(\mathrm{VI})$ and phosphate species to hematite is dominated by divalent anions even at low pHs where monovalent anions predominate in solution. As a consequence, aqueous speciation (i.e., the fraction of the total species in solution available in the form of a divalent anion) is a more important determinant of the relative amount of $\mathrm{Cr}(\mathrm{VI})$ or phosphate sorbed than the intrinsic selectivity of the anions for the surface. In mixedanion systems typical of groundwater, significantly different sorption affinities may be observed than predicted solely on the basis of relative single-anion sorption constants.

An important outcome of this work is the development of a powerful new tool with which competitive adsorption of anions on minerals in suspension can be investigated in real time. We have demonstrated that nontoxic anions present in the subsurface environment, such as phosphate, may compete with toxic anions, such as $\mathrm{Cr}(\mathrm{VI})$, for sorption sites on redoxactive minerals to an extent that is highly $\mathrm{pH}$ dependent. Significantly, LPAS can be used for studies of pure mineral phases, such as hematite in the present experiments, as well as for multi-component soil mixtures. Thus, controlled and "real-world" experiments can be carried out to determine the extent to which competing nontoxic anions can prevent adsorption and reduction of toxic anions by minerals or redox-active remediation agents, such as zero-valent iron. 


\section{Mössbauer Spectroscopic Study of Iron Redox in Silicate Glasses}

R. K. Kukkadapu, G. L. Smith, ${ }^{(a)}$

H. Li, ${ }^{(a)}$ J. V. Crum, ${ }^{(a)}$

M. C. Weinberg, ${ }^{(b)}$ and H. Poisl ${ }^{(b, c)}$

Supported by DOE Office of Science, DOE

Environmental Management Science Program, and EMSL Operations.

(a) Environmental Technology Division, PNNL.

(b) University of Arizona.

(c) Postdoctoral Research Fellow.

High-level waste (HLW) glasses contain significant quantities of iron. Vitrification processing conditions and waste glass composition can affect the iron oxidation state in glass, which in turn can influence the tendency of liquid-liquid immiscibility, or phase separation, of the final glass waste formed. An understanding of the effects of the iron redox ratio on liquid-liquid immiscibility is important for immobilization of HLW because glass phase separation can adversely impact chemical durability of the final waste form (Tomozawa 1990; Taylor 1990). The objective of this study was to determine the nature of the Fe species, and the Fe oxidation state in glasses employing colorimetery and complementary spectroscopic techniques, such as UV-VIS-NIR and ${ }^{57} \mathrm{Fe}$-Mössbauer. The results will be correlated with glass phase separation work currently being conducted at the University of Arizona (Tucson).

The ${ }^{57} \mathrm{Fe}-\mathrm{Mössbauer}$ spectroscopy is an iron specific technique with greater sensitivity than $\mathrm{x}$-ray diffraction (XRD); Fe oxidation states and the local environment are identifiable by Mössbauer for samples with iron concentrations as little as $0.5 \mathrm{wt} \%$. The ${ }^{57} \mathrm{Fe}-\mathrm{Möss} b a u e r$ technique provides information on the valence and coordination state, crystal field strengths (e.g., low spin and high spin Fe(II)), magnetic ordering temperatures, etc. In contrast to $\mathrm{XRD}$, it also provides information on compounds that do not exhibit long-range order (poorly crystalline or amorphous materials). Common iron oxide phases such as magnetite and hematite, are readily distinguished from each other and from ferrous compounds.
Transmission ${ }^{57} \mathrm{Fe}-\mathrm{Mössbauer}$ spectra were collected at room temperature (about $25^{\circ} \mathrm{C}$ ) and liquid $\mathrm{He}$ temperature $(4.2 \mathrm{~K})$ using a $50-\mathrm{mCi}(1.85-\mathrm{MBq})$ ${ }^{57} \mathrm{Co} / \mathrm{Rh}$ single-line thin source. The velocity transducer (Wissel, Germany) was operated in the constant-acceleration mode $(23 \mathrm{~Hz}, \pm 10 \mathrm{~mm} / \mathrm{sec})$. Data were acquired on 1024 channels and then folded to 512 channels to give a flat background and a zerovelocity position corresponding to the center shift (CS or $\delta$ ) of a metallic-Fe foil at room temperature.

Calibration spectra were obtained with a $20-\mu \mathrm{m}$ thick $\alpha-\mathrm{Fe}$ foil (Amersham, England) placed in exactly the same position as the samples to minimize any error due to changes in geometry. The transmitted radiation was recorded with an $\mathrm{Ar}-\mathrm{Kr}$ proportional counter. Approximately $180 \mathrm{mg}$ of powder sample (particle size $<75 \mu \mathrm{m}$ ) was mixed uniformly with petroleum jelly in a 0.5 -inch thick and 0.5 -inch diameter $\mathrm{Cu}$ holder sealed at one end with clear tape. The amount of sample chosen corresponded to the ideal absorber thickness that provided the largest signal-to-noise ratio in the given collection time. For the $4.2 \mathrm{~K}$ analyses, an oxygen impermeable film, which would be stable at $4.2 \mathrm{~K}$ (Arlon, Inc., California) was used instead of tape. Petroleum jelly was used to fill the sample space volume, and the end was sealed with tape or Arlon film. The 4.2K Mössbauer measurements were performed using a top-loading Janis exchange-gas cryostat. The temperature was continuously monitored with a Nichrome thermocouple and was within $\pm 0.5 \mathrm{~K}$. A Lakeshore Model DRC-93CA temperature controller was used to control the temperature. The measured isomer shifts were quoted relative to the $\mathrm{Fe}$ foil at room temperature. The entire drive-source assembly was external to the cryostat. In other words, only the absorber (sample) was cooled to $4.2 \mathrm{~K}$.

The unfolded spectra obtained were folded and evaluated with the MOSMOD and Recoil programs (University of Ottawa, Canada) using the Voigt-based hyperfine parameter distribution method (Rancourt and Ping 1999). The Voigt-based method assumes a certain number $(\mathrm{V})$ of generalized sites (quadrupole splitting distributions (QSD) and/or hyperfine field distributions (HFD)), each having their own continuous distribution (QSD or HFD). Each normalized site-specific QSD or HFD is composed of a certain number of Gaussian components $(\mathrm{C})$ being 
the sum of more than one Voigt line. The center shift $(\delta)$ of each QSD site is related to its quadrupole splitting, $\Delta$ or QS. as $\delta=\delta_{0}+\delta_{1} \Delta$ where $\delta_{0}$ is the value of $\delta$ when the distributed hyperfine parameter is zero, and $\delta_{1}$ is the coupling of $\delta$ to the distributed hyperfine parameter. For the HFD site, the $\delta$ is related to its Zeeman splitting, $z$, as $\delta=\delta_{0}+\delta_{1} z$; and its quadrupole shift parameter, $\varepsilon$, site is related to its $z$, as $\varepsilon=\varepsilon_{0}+\varepsilon_{1} z$, where $\varepsilon_{0}$ is the value of $z$ when $z$ (which is distribution) is zero and $\varepsilon_{1}$ is the coupling of $\varepsilon$ to the distributed hyperfine parameter.

Liquid-liquid immiscibility in sodium silicates has been extensively studied (Hammel 1965; PoraiKoshits and Averjanov 1968). From the data available in the literature, a composition of $18.56 \mathrm{~mol} \% \mathrm{Na}_{2} \mathrm{O}$ and $81.44 \mathrm{~mol} \% \mathrm{SiO}_{2}$ is expected to be outside the immiscibility dome at and above glass transition temperature. Therefore, the effect of an iron oxidation state on this baseline composition can be investigated. The effects of iron concentration and oxidation state on the glass phase separation is part of the overall research objective. In this study, the silicate glass doped with $0.5 \mathrm{~mol}_{0} \mathrm{Fe}_{2} \mathrm{O}_{3}$ (UA-3) was prepared at $1600^{\circ} \mathrm{C}$ at ambient conditions.

Figure 3.4 shows Mössbauer spectra collected at room temperature (RT) and $4.2 \mathrm{~K}$. The RT spectrum shows an asymmetric doublet (in the region -2 to $3 \mathrm{~mm} / \mathrm{sec}$ ) with a non-linear background. The outer peak ( 2.2 to $2.5 \mathrm{~mm} / \mathrm{sec}$ ) of the doublet is characteristic of high field components of paramagnetic Fe(II) (Ono 1964), while the inner peak is a mixture of low field components of Fe(II) and both the doublets of Fe(III) (Greenwood and Gibb 1971). A shoulder to this effect is evident at the high-energy (higher velocity) end of the peak. The non-linear background, which is uncommon in this type of glass; indicates the presence of magnetic Fe species or clusters that are amorphous in nature. The $\mathrm{Fe}(\mathrm{II}) / \mathrm{Fe}$-total ratio of the sample can be derived by fitting the spectrum. provided the valence of $\mathrm{Fe}$ contributing to the non-linear background is known. Cooling down the sample to lower temperatures, usually to those of liquid nitrogen or liquid helium. would resolve this ambiguity. At low temperatures (usually below $30 \mathrm{~K}$ for Fe-minerals), the spin-spin and spin-lattice relaxation processes slow down, such that their $t_{1 / 2}$ become longer than that of the ${ }^{57} \mathrm{Fe}$ excited state, and magnetic spectra can be observed (Hawthorne 1988). For paramagnetic Fe materials, the magnetic field normally changes due to

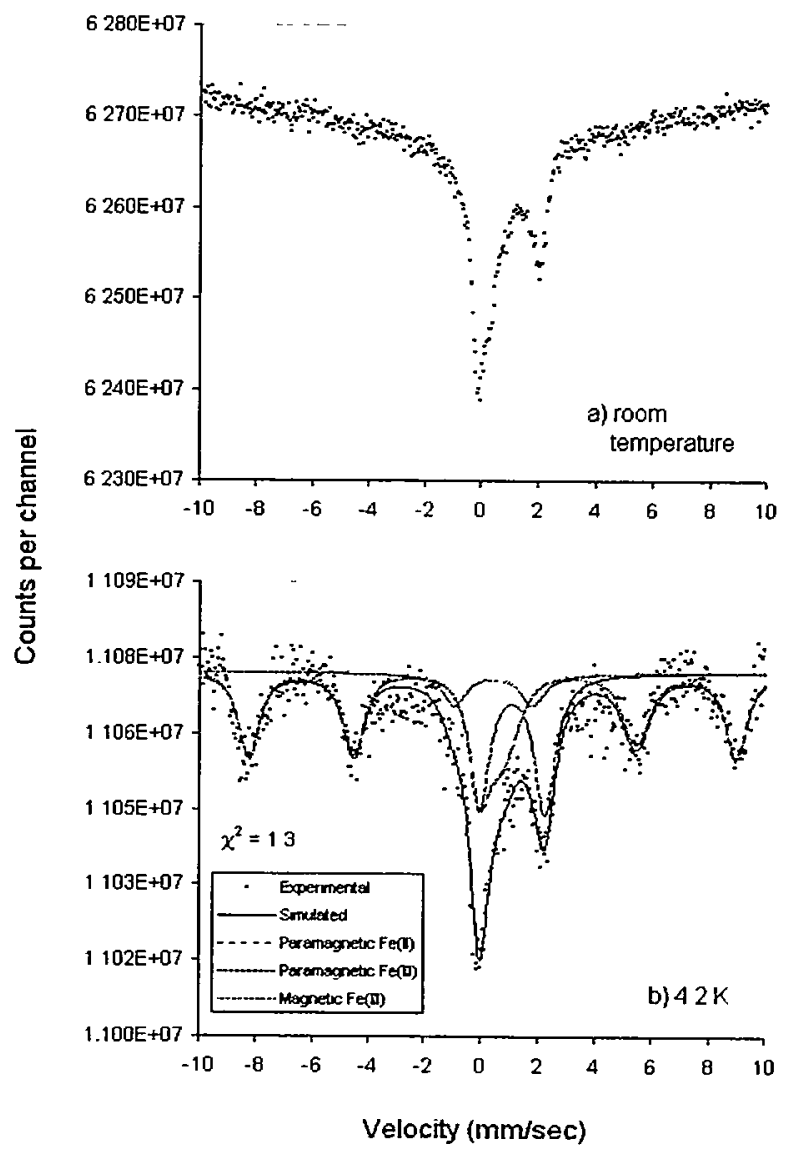

Figure 3.4. Room temperature and 4.2K Mössbauer spectra.

these relaxation effects; with the changes being fast compared to the lifetime of the ${ }^{57} \mathrm{Fe}$ excited state.

Experimental and simulated spectra of the sample at $4.2 \mathrm{~K}$ are shown in Figure 3.4. The experimental spectrum exhibited apart from the asymmetric doublet due to paramagnetic Fe sites a sextet characteristic of magnetic Fe. Simulation of the pattern yielded the following parameters for the sextet: $\delta=0.42 \mathrm{~mm} / \mathrm{sec}$; $\Delta=-0.05 \mathrm{~mm} / \mathrm{s}$; magnetic hyperfine field (HF) $=$ $53.5 \mathrm{~T}$. The derived $\delta$ and $\Delta$ parameters are characteristic of $\mathrm{Fe}(\mathrm{III})$; $\mathrm{Fe}(\mathrm{II})$ sites exhibit larger $\Delta$ values. The $\mathrm{HF}$ value of $53.5 \mathrm{~T}$ and other Mössbauer parameters are similar to hematite $\left(\alpha-\mathrm{Fe}_{2} \mathrm{O}_{3}\right)$; for example, a weakly ferromagnetic hematite exhibits a $\mathrm{HF}$ of $53.3 \mathrm{~T}$ at $4.2 \mathrm{~K}$, (Murad et al. 1985) whereas magnetite $\left(\mathrm{Fe}_{3} \mathrm{O}_{4}\right)$ and other commonly occurring $\mathrm{Fe}$ oxides exhibit lower HFs. We invoked a hyperfine distribution model to fit the spectrum: the derived fullwidth at half maximum was $0.40 \mathrm{~mm} / \mathrm{sec}$ versus 
$0.20 \mathrm{~mm} / \mathrm{sec}$ (natural line width) expected for an elemental sextet, suggesting that a distribution of local chemical environments exists in the sample. Additional studies will be performed to investigate the origin of the magnetic behavior of the glass with such low $\mathrm{Fe}$ concentration.

The asymmetric doublet at $4.2 \mathrm{~K}$ is similar to the one at RT. Fit parameters indicated that paramagnetic $\mathrm{Fe}$ (II) and $\mathrm{Fe}$ (III) contributed to this signal. The derived parameters for $\mathrm{Fe}(\mathrm{II})(\delta=1.13 \mathrm{~mm} / \mathrm{sec}$; $\Delta=2.27 \mathrm{~mm} / \mathrm{s})$ and $\mathrm{Fe}$ (III) $(\delta=0.76 \mathrm{~mm} / \mathrm{sec}$; $\Delta=0.37 \mathrm{~mm} / \mathrm{s}$ ) are similar to those reported in the literature. A comparison of $\mathrm{RT}$ and $4.2 \mathrm{~K}$ spectra shows that the ratio of the areas of the high-energy peak to the low-energy peak is similar in both, suggesting that the non-linear background present at $\mathrm{RT}$ is solely due to magnetic Fe(III).

The $\mathrm{Fe}(\mathrm{II}) / \mathrm{Fe}$-total ratio was calculated from the relative areas of the different $\mathrm{Fe}$ sites of the $4.2 \mathrm{~K}$ spectrum. In the literature, the iron redox ratio in glass is conventionally determined by the ratio of the area under the spectrum for $\mathrm{Fe}$ (II) over the total area of the spectrum, (Levy et al. 1976; Mysen et al. 1980) assuming that the ratio of $f_{\mathrm{Fe}(\mathrm{II})} / f_{\mathrm{Fe}(\mathrm{III})}$ is not substantially different from unity (where $f$ is the fraction of these atoms that is recoil-free). The spectral area percentages derived from the $4.2 \mathrm{~K}$ spectrum due to different Fe components are as follows: magnetic $\mathrm{Fe}(\mathrm{III})$ is $46.4 \%$, paramagnetic $\mathrm{Fe}(\mathrm{III})$ is $23.4 \%$, and paramagnetic $\mathrm{Fe}(\mathrm{II})$ is $30.2 \%$. Based on these values, the ratio of $\mathrm{Fe}(\mathrm{II}) / \mathrm{Fe}$-total was calculated. The ratio obtained $(0.30)$ was slightly higher than 0.22 determined by using a calorimetric method. In the calorimetric method, $\mathrm{Fe}$ (II) could be oxidized during the dissolution of glass in acid at ambient temperature, resulting in a slightly lower measured $\mathrm{Fe}(\mathrm{II})$ concentration.

Magnetic behaviors of low and high iron (1 to $4 \mathrm{~mol} \%$ $\mathrm{Fe}_{2} \mathrm{O}_{3}$ ) glasses with a different iron redox ratio will be further studied using Mössbauer in a collaboration with the glass phase separation study. Because of the use of a powder sample with large surface area for the measurement, it is important to accurately determine the surface (top $100 \mathrm{~nm}$ or so) iron oxidation states, especially for the glasses partially reduced; a conversion electron Mössbauer spectroscopy setup, currently being developed at EMSL, would be employed for a surface study. In addition, synchrotron Mössbauer spectroscopy studies are planned to gather information on $f$-factors and relaxation phenomena. The use of transmission electron microscopy to characterize the glass microstructures at a nanoscale is also planned, which could provide further understanding of the origin of the magnetic behaviors in glass with iron partially reduced.

\section{References}

Greenwood, N. N., and T. C. Gibb, Mössbauer Spectroscopy, Chapman and Hall Ltd., London, (1971).

Hammel, J. J., $7^{\text {th }}$ International Congress on Glass, (1965).

Hawthorne, F. C., Reviews in Mineralogy, Miner. Soc., 18, Chelsea, Michigan (1988).

Levy, R. A., C. HJ. P. Lupis, and P. A. Flinn, Phys. Chem. Glasses, 17, 94 (1976).

Murad, E., Iron in Soils and Clay Minerals, J. W. Stucki, B. A. Goodman, U. Schwertmann, Eds. Reidel Publishing company: Dordrecht, Holland, 309 (1985).

Mysen, B. O., F. Seifert, and D. Virgo, Am. Mineral., 65, 867 (1980).

Ono, K., and A. Ito, J. Phys. Chem., 19, 899 (1964).

Porai-Koshits, E. A., and V. I. Averjanov, J. NonCrystalline Solids, 1, 29 (1968).

Rancourt, D. G., and J. Y. Ping, Nucl. Inst. Meth. Phys. Res., B58, 85 (1999).

Taylor, P. A., Review of Phase Separation in Borosilicate Glasses with Reference to Nuclear Fuel Waste Immobilization. AECL-10173. Atomic Energy of Canada Limited, AECL Research, Whiteshell Laboratories, Pinawa, Manitoba, Canada (1990).

Tomozawa, M., Phase Separation in Glass, In Treatise on Materials Science and Technology, Tomozawa, M., and R. H. Doremus, Eds.; Academic Press, New York, 71 (1990). 


\section{Mineralization Processes Associated with the Bacterial Reduction of $\mathrm{Fe}$ (III) Oxides}

\section{J. M. Zachara. J. K. Fredrickson, \\ Y. A. Gorby, S. C. Smith, and}

R. K. Kukkadapu

Supported by the Natural and Accelerated

Bioremediation Research Program and

BES Geosciences

The subsurface biogeochemical cycle of iron is intimately linked with those of trace metals and polyvalent radionuclides, as the latter commonly associate with the surfaces of Fe(III) oxides or participate in electron transfer reactions with $\mathrm{Fe}(\mathrm{II})$. The reductive arm of the iron biogeochemical cycle is driven by dissimilatory iron reducing bacteria (DIRB) that use $\mathrm{Fe}$ (III) as the terminal electron acceptor in the respiration of organic matter or $\mathrm{H}_{2(\mathrm{~g})}$. ED\&S researchers and other PNNL collaborators have been investigating the mechanisms of bacterial electron transfer to $\mathrm{Fe}$ (III) oxide surfaces through BES-Geosciences supported research and the solubilization of $\mathrm{Fe}$ (III) oxide-entrained trace metals as part of OBER-NABIR support research. These studies are providing fundamental new insights into

1. biogeochemical function of subsurface water systems

2. biologic processes useful to the remediation of subsurface metal and radionuclide contamination on DOE lands.

A range of hematite $\left(\mathrm{Fe}_{2} \mathrm{O}_{3}\right)$ crystallite morphologies was synthesized to investigate the influence of crystal face distribution and surface area on bacterial Fe(III) oxide reduction. The morphologies include tabular, thick tabular, and cubic hematite which differ markedly in ratios of faces 001 and 012 . The electron transfer process from bacteria to oxide is believed to occur through the formation of a surface complex(s) between electron transducing proteins on the membrane surface and hydroxyl sites on the oxide surface. Different crystal faces are populated with different concentrations of hydroxyl sites with different coordination environments, and these factors are speculated to influence the rate and extent of bacterial electron transfer to the oxide. Shown in Figure 3.5 is bacterial dissolution data for large and
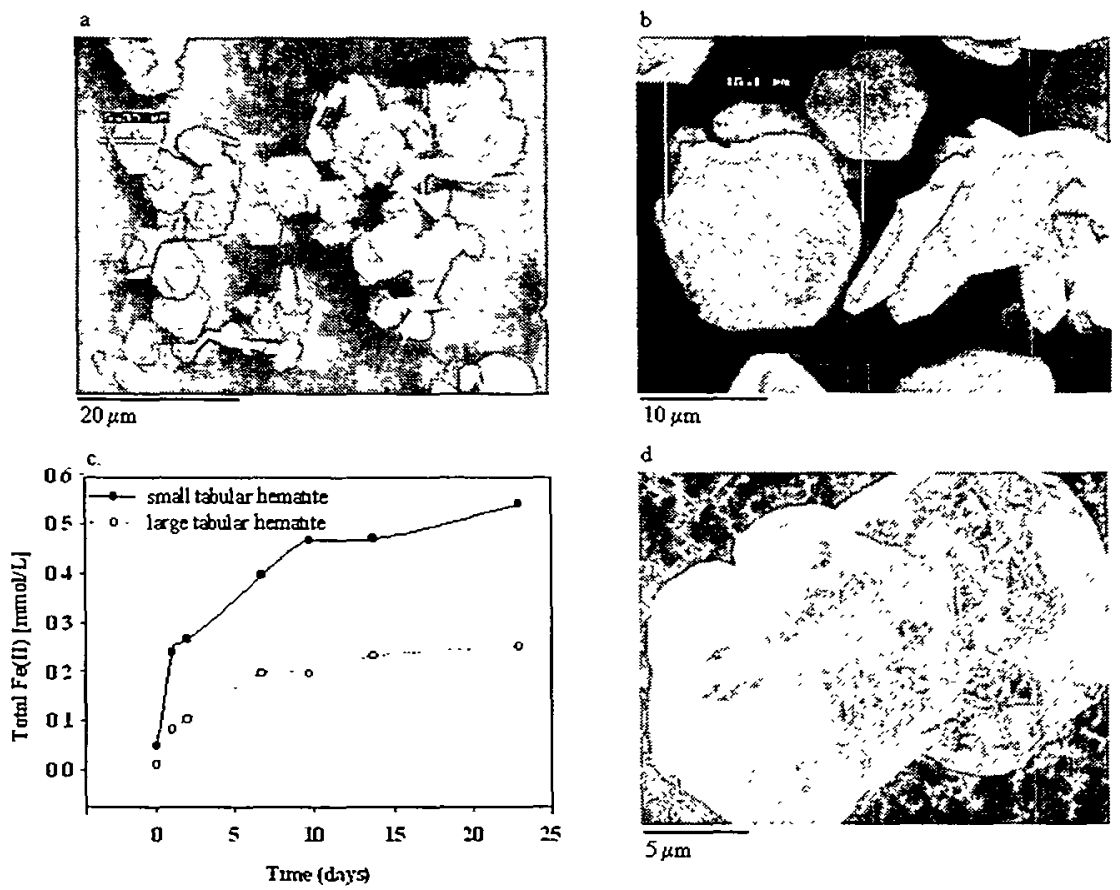

Figure 3.5. Small(a) and large(b) tabular hematite used in biologic dissolution experiments. DIRB populate the extensive c-plane (001) and promote dissolution features (lower right, center). The small tabular hematite is more rapidly reduced because of higher surface area. 
small tabular hematite. Dissolution extent correlates with surface area and the proton promoted dissolution rate. The bacterial dissolution of these tabular hematites was anomalously slow because of the predominant contribution of the non-reactive face 001 to the total surface area.

Much work has been performed on the bioreduction of amorphous hydrous ferric oxide ( $\mathrm{HFO} ; \mathrm{Fe}_{2} \mathrm{O}_{3} \bullet \mathrm{nH}_{2} \mathrm{O}$ ) and its crystallization products. $\mathrm{HFO}$ is a primary iron oxide form in soil, sediments, and aquifer materials that serves as a sorbent for trace metals and radionuclides. HFO is thermodynamically unstable with respect to goethite and hematite, and it slowly transforms to these phases in the environment unless poisoned by adsorbed or coprecipitated constituents. Shown in Figure 3.6a-f are Mössbauer spectra for $\mathrm{HFO}, \mathrm{Ni}-\mathrm{HFO}$, and $\mathrm{Co}-\mathrm{HFO}$ that have been heated to $70^{\circ} \mathrm{C}$ to induce crystallization. The $\mathrm{Ni}$ and Co were co-precipitated with the HFO to concentrations of 5 mole \%. Heating induced partial crystallization of the $\mathrm{HFO}$ to a mixture of $\mathrm{HFO}$, goethite, and hematite; a phase association commonly observed in soil. The presence of both $\mathrm{Ni}$ and Co retarded crystallization. The inoculation and incubation of the HFO samples with DIRB and an electron donor (lactate) induced change to the heated HFO and the Co-HFO. The iron reducing bacteria selectively reduced HFO from the mixture of goethite and hematite (Figure 3.6b) and transformed $\mathrm{Co}-\mathrm{HFO}$ to $\mathrm{Co}$-substituted magnetite $\left(\mathrm{Co}_{x} \mathrm{Fe}_{3-\mathrm{x}} \mathrm{O}_{4}\right)$. The presence of co-precipitated $\mathrm{Ni}$ prevents bioreduction of HFO by blocking HFO surface sites and preventing interfacial electron transfer. Polyvalent $\mathrm{Co}$ (II/III) has the opposite effect and enhances HFO bioreduction.

The biotransformation of the metal substituted HFOs has marked effects on trace metal flux, in some cases inducing mobilization from the solid phase and in others, immobilization. We are currently studying the mechanisms of these bio-mineral transformations and are investigating their role in the sorptive immobilization of metals and radionuclides in anoxic subsurface environments. 

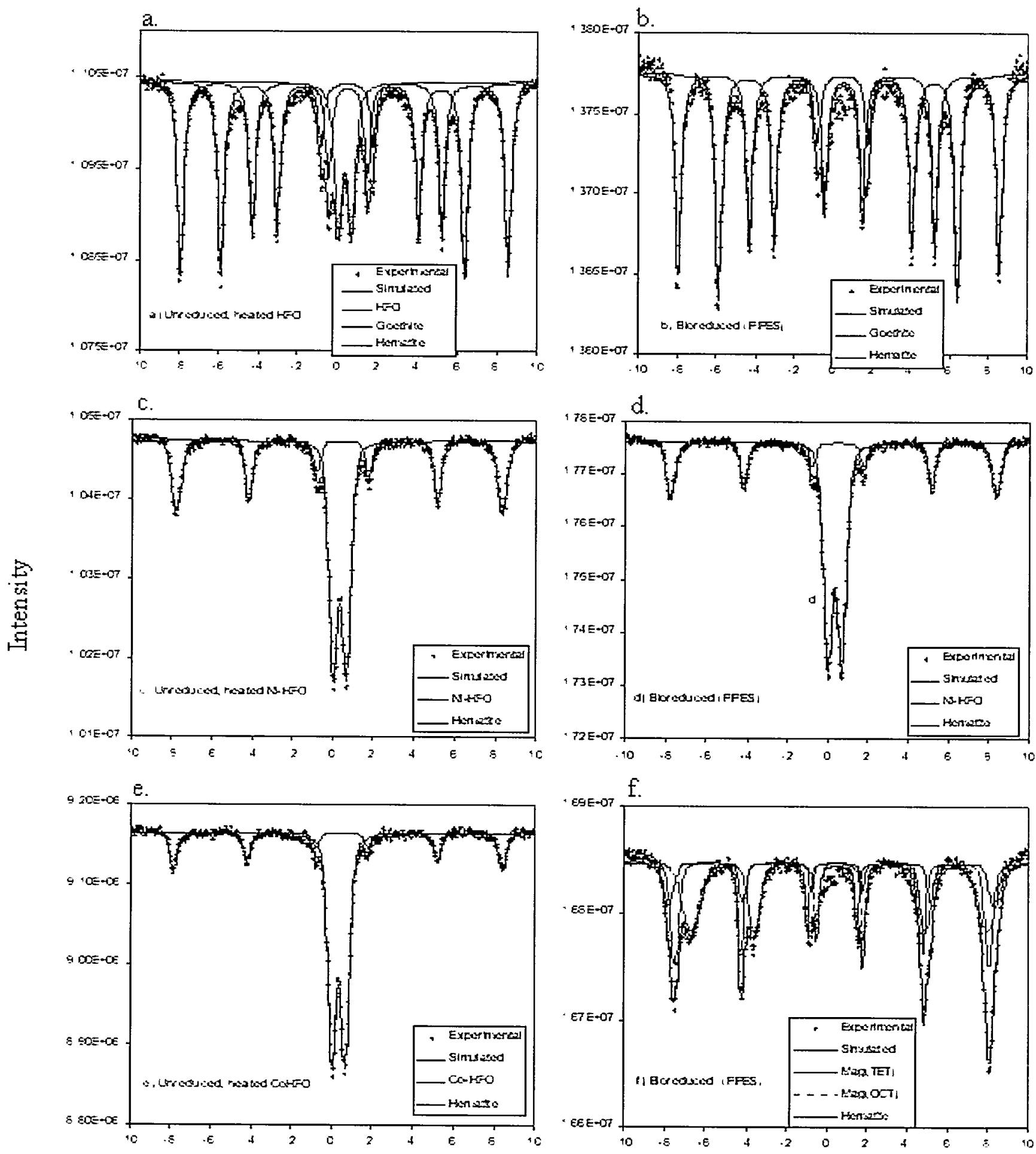

Velocity $(\mathrm{mm} / \mathrm{sec})$

Figure 3.6. RT Mössbauer spectra of $70^{\circ} \mathrm{C}$-heated HFO and Ni/Co-HFO before and after bioreduction by CN32. 


\section{Redox Chemistry at Mineral Surfaces}

J. E. Amonette, K. M. Rosso,

Y. A. Gorby, H. R. Divanfard, ${ }^{(a)}$

J. F. Marquez, ${ }^{(a)}$ E. A. Rodriguez,

and C. K. Russell

Supported by PNNL Laboratory Directed Research and Development, EMSL Operations, and DOE/OBER/NABIR.

(a) Heritage College.

Minerals may serve as large reservoirs of electronbuffering capacity in soils and their surfaces catalyze reactions that may proceed only slowly, if at all, in bulk solution. However, little is known about how these reactions occur on a molecular scale. With recent advances in instrumentation for microscopicscale investigation, however, we are making steady progress in uncovering the intricacies of mineral surface reactions. In this report we summarize some of the new techniques we have developed and insights we have gained into the role minerals play in the redox chemistry of soils.

\section{Imaging Reduced Zones on Mineral Surfaces}

Although one of the key parameters in any mineralwater reaction is the reactive surface area of the mineral, accurate measurements are difficult to obtain. The difficulty is further compounded when one attempts to measure the surface coverage of the reduced form of a bulk constituent such as $\mathrm{Fe}$. Surficial $\mathrm{Fe}(\mathrm{II})$ is subject to oxidation by atmospheric oxygen and does not yield a spectroscopic signature significantly different from that of Fe(III) in the bulk. To overcome this difficulty, we employed a reactive probe, $\mathrm{Ag}(\mathrm{I})$, to oxidize surface-accessible $\mathrm{Fe}(\mathrm{II})$ and precipitate $\mathrm{Ag}(\mathrm{m})$ in place, thereby preserving the spatial distribution of reactive surface sites in a form that is more stable to atmospheric oxidation and amenable to measurement. Furthermore, the K-edge $\mathrm{X}$-ray properties of Ag (high-energy [25.4 keV], high fluorescence yield [83\%], negligible absorption by air/water) make surface analysis by $\mathrm{x}$-ray microscopy (XRM) practical.

We prepared small specimens of biotite and hematite by reacting them with $0.01 \mathrm{M} \mathrm{Fe}\left(\mathrm{NH}_{4}\right)_{2} \mathrm{SO}_{4}$ or a
$\mathrm{HCO}_{3}$-buffered $0.25 \mathrm{mM} \mathrm{Na}_{2} \mathrm{~S}_{2} \mathrm{O}_{4}$ solution, washing them three times with $\mathrm{DI} \mathrm{H}_{2} \mathrm{O}$, reacting them with $0.01 \mathrm{M} \mathrm{AgF} / \mathrm{HF}$, washing them three times with $\mathrm{DI}$ $\mathrm{H}_{2} \mathrm{O}$, and then drying them rapidly with a stream of inert gas. Specimens that had contacted only water or $0.01 \mathrm{M} \mathrm{AgF} / \mathrm{HF}$ were also prepared. With the exception of the drying step, all preparation was performed under strictly anoxic conditions. Once the specimens were dry, they were mounted on holders. The XRM analyses were performed using $25.6 \mathrm{KeV}$ light focused with a glass capillary having a $0.7-\mu \mathrm{m}$-diameter exit. Spot size on the specimen varied with distance from the capillary tip and was adjusted to be approximately equal to the step size of the scan (typically $2.5-5 \mu \mathrm{m}$ ). In addition to transmission measurements, a 13-element $\mathrm{Ge}$ detector was used to detect $\mathrm{Ag}$ fluorescence produced by the sample.

The biotite specimens routinely yielded $\mathrm{Ag}$ on the surface as would be expected from the Fe(II) content of the mineral. Typical images (Figure 3.7a) suggested narrow contiguous zones of reaction suggestive of step edges with occasional high concentrations at defect sites. Large areas of the biotite yielded no measurable $\mathrm{Ag}$. The hematite specimens showed reactive sites only after treatment with $\mathrm{Na}_{2} \mathrm{~S}_{2} \mathrm{O}_{4}$ and then yielded patterns suggesting small independent etch pits (Figure 3.7b). X-ray absorption near edge spectroscopy (XANES) spectra collected at the reactive sites were identical to those for $\mathrm{Ag}(\mathrm{m})$ and significantly different from that for $\mathrm{AgCl}$

(Figure 3.7c) thus showing that the $\mathrm{Ag}$ accumulations were clearly the result of reduction of $\mathrm{Ag}$ by the mineral surface. Perhaps the most interesting feature is the highly localized nature of the reactions. For biotite, the reactive sites are predominately at the frayed edges of the particles and steps (Figure 3.7d). The similar ionic radii of $\mathrm{Ag}^{+}$and $\mathrm{K}^{+}$(the main interlayer cation in biotite) may account for the reactivity of these sites. Given the low solubility of $\mathrm{Ag}_{2} \mathrm{~S}$, this technique likely can also be used to image reduced zones produced by sulfate-reducing bacteria.

\section{Contaminant Degradation Studies}

A variety of oxidized contaminants can be altered or destroyed by reductive processes. In soils and sediments, $\mathrm{Fe}$ is the dominant redox-active element by virtue of its abundance and favorable reduction potential located midway in the aqueous regime. 


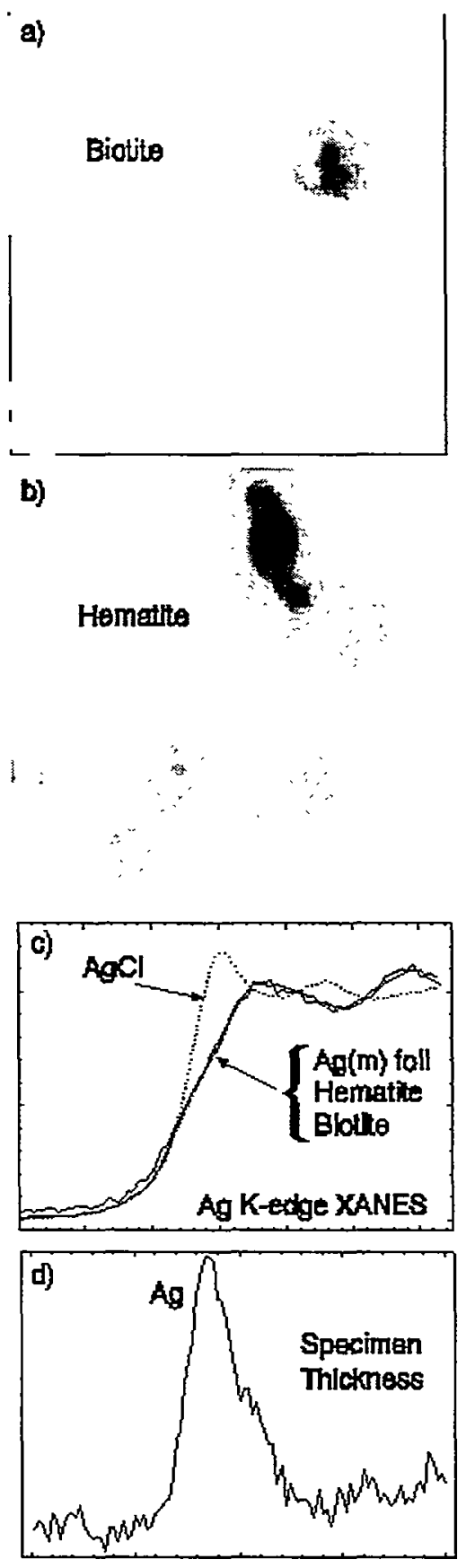

Figure 3.7. SXRM images $(170 \times 170 \mu \mathrm{m})$ of reduced zones (Ag density) on surfaces of a) biotite and b) hematite; c) normalized Ag-K-edge XANES spectra of reduced zones, $\mathrm{Ag}(\mathrm{m})$, and $\mathrm{AgCl}(\mathrm{s})$; and d) lateral scan $(200 \mu \mathrm{m})$ across edge of reduced biotite showing Ag accumulation in frayed-edge sites.

While most of the Fe in contact with soil surfaces is $\mathrm{Fe}(\mathrm{III}), \mathrm{Fe}(\mathrm{II})$ moieties can be produced by microbial activity or chemical treatment. Manipulation of the redox state of $\mathrm{Fe}$ in soils and sediments forms a potential in situ remediation technique for chlorinated hydrocarbons, nitroaromatics, and oxyanion contaminants. A typical remediation scheme involves addition of a soluble reductant such as dithionite ion to a soil system containing a mixture of layer silicates and iron oxides. This treatment leaves several possible reductants in the system, including structural $\mathrm{Fe}(\mathrm{II})$ in smectites, adsorbed $\mathrm{Fe}(\mathrm{II}), \mathrm{FeCO}_{3}$ precipitates and, possibly, residual sulfide species from the dithionite. These solid-phase reductants are then available to react with soluble contaminants carried by groundwater to the reduced zone.

\section{Reduction by $\mathrm{Fe}(I I)$ Associated with Clay Minerals}

In this work, we studied the reductive degradation of tetrachloromethane $\left(\mathrm{CCl}_{4}\right)$, trichloroethylene (TCE), and trinitrotoluene (TNT) by $\mathrm{Fe}$ (II) associated with a dithionite-treated smectite clay alone and in combination with zerovalent $\mathrm{Fe}(0)$ colloids. In addition to assessing the overall rates and products of the reaction. the relative contributions of several possible reductants associated with the smectite were studied.

A series of batch experiments with a smectite from Panther Creek, Mississippi, were conducted under anoxic conditions in sealed headspace vials using synthetic groundwater and excess reductant. The smectite was pre-reduced using buffered dithionite solutions and then was washed to remove excess reductant. Experiments were conducted with bulk smectite samples and with samples that had been fractionated to remove particles $>2 \mu \mathrm{m}$ and then treated with $0.1 \mathrm{M} \mathrm{HCL}$ for $2 \mathrm{~h}$ to completely remove sulfide precipitates. Some of the acid-treated samples also had their exchange sites saturated with $\mathrm{Fe}^{2+}$ cations. For comparison of $\mathrm{Fe}(\mathrm{II})$ and $\mathrm{Fe}(0)$ efficacy, experiments were also conducted with colloidal $\mathrm{Fe}(0)$ particles alone, or mixed 50:50 with smectite. In all initial experiments, reductant concentrations were far in excess of those needed to completely reduce the contaminants (i.e., pseudo-first-order [PFO] conditions with respect to the contaminant). Initial contaminant concentrations were $10 \mathrm{ppm}$ for $\mathrm{CCl}_{4}$, $2.5 \mathrm{ppm}$ for TCE, and $25 \mathrm{ppm}$ for TNT. Individual vials were sacrificed at specified times for analysis of headspace concentrations by GC-MS ( $\mathrm{CCl}_{4}$ and TCE) or solution concentrations by HPLC with UV detection (TNT). 
Dithionite-treated smectite clay degraded $\mathrm{CCl}_{4}$ by stepwise removal of $\mathrm{Cl}$ atoms to yield trichloromethane and dichloromethane species. No chloromethane was identified, but one long-term experiment showed production of methane (data not shown). In contrast to the experiments with bulk smectite, experiments with $<2 \mu \mathrm{m}$ acid-treated smectite showed little reaction with $\mathrm{CCl}_{4}$ and essentially no difference between highly reduced $[2.0 \% \mathrm{Fe}(\mathrm{II})]$ and slightly reduced smectite $[0.2 \% \mathrm{Fe}(\mathrm{II})]$. When the exchange sites of the same two reduced smectite samples were saturated with $\mathrm{Fe}(\mathrm{II})$, however, a significant increase in reactivity was seen (Figure 3.8, top), particularly for the highly reduced smectite. Because the original acid-treated smectite contained only structural Fe(II)

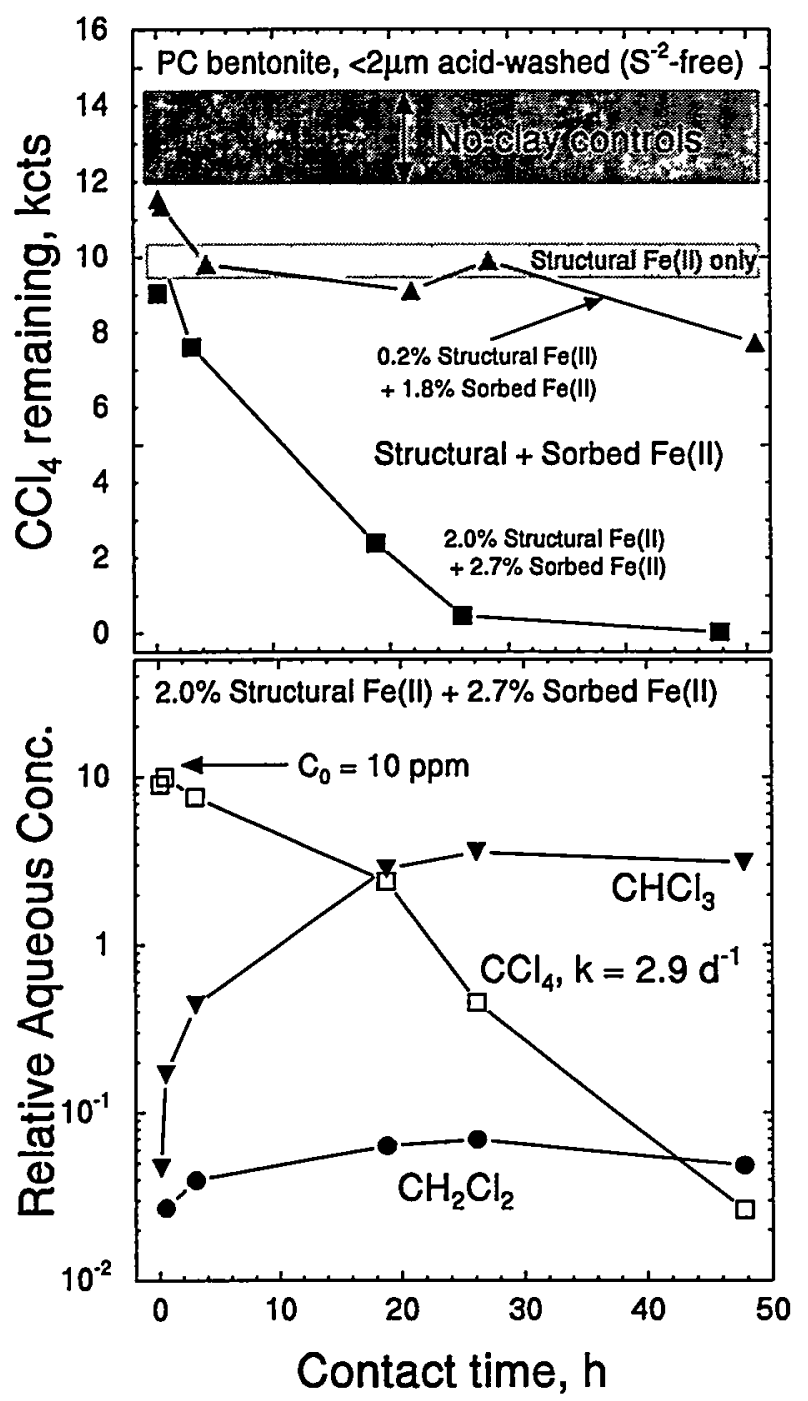

Figure 3.8. Dechlorination of $\mathrm{CCl}_{4}$ by smectite with different amounts of structural and sorbed $\mathrm{Fe}(\mathrm{II})$. as a source of electrons, it seems that surface-adsorbed $\mathrm{Fe}(\mathrm{II})$ is essential to the reaction with $\mathrm{CCl}_{4}$. Furthermore, the relatively small increase in reactivity when the slightly reduced smectite was saturated with $\mathrm{Fe}$ (II) suggests that the $\mathrm{Fe}(\mathrm{II})$ that was adsorbed reacted with the structural $\mathrm{Fe}$ (III), thus depleting the pool of surface $\mathrm{Fe}(\mathrm{II})$ available for reaction with $\mathrm{CCl}_{4}$. In short, the surface $\mathrm{Fe}(\mathrm{II})$ is a stronger reductant than the structural $\mathrm{Fe}$ (II) and will actually reduce structural $\mathrm{Fe}(\mathrm{III})$.

Analysis of reaction products for the acid-treated and bulk smectite clays also suggests that different reduction mechanisms are involved. With the acidwashed clay (Figure 3.8, bottom), mass balance shows only about $25 \%$ of the $\mathrm{CCl}_{4}$ is converted to chloroform whereas for the bulk smectite, essentially $100 \%$ conversion to chloroform was observed. This result suggests that when surface-sorbed $\mathrm{Fe}(\mathrm{II})$ is the only reactant (i.e., sulfides are absent) a pathway involving either polymerization of free radical species or conversion to formic acid via a carbene intermediate is followed. The presence of sulfide and possible ferrous carbonate phases, on the other hand, seems to promote the step-wise dechlorination pathway. The PFO rate constants $\left(\mathrm{k}_{\mathrm{PFO}}\right)$ for these two pathways also differ by a factor of about 2 , with the bulk smectite yielding a rate constant of about $6.6 \mathrm{~d}^{-1}$.

Experiments with $\mathrm{Fe}(0)$ and mixtures of $\mathrm{Fe}(0)$ and reduced smectite also yielded interesting results. No reaction was observed when $\mathrm{Fe}(0)$ colloids were used in the absence of smectite. However, a 50:50 mixture of $\mathrm{Fe}(0)$ colloids and reduced smectite yielded degradation rates that exceeded those of the reduced clay alone or a 50:50 mixture with nonreduced smectite. These results suggest that the smectite surface promotes corrosion of the $\mathrm{Fe}(0)$ surface, which is essential for $\mathrm{Fe}(0)$ to be an effective reductant. Furthermore, the enhanced reactivity achieved when both smectite and $\mathrm{Fe}(0)$ are present likely stems from the steady supply of Fe(II) ions by the corrosion process which then sorb to the clay surface. Product analysis shows that stepwise dechlorination is the only pathway when $\mathrm{Fe}(0)$ is present and $k_{\text {PFO }}$ values of about $7.1 \mathrm{~d}^{-1}$ were observed.

Experiments involving mixtures of reduced smectite and $\mathrm{Fe}(0)$ were also conducted with TCE. The degradation rates were much slower than for $\mathrm{CCl}_{4}$ 
and, as with the $\mathrm{CCl}_{4}$, a mixture of smectite and $\mathrm{Fe}(0)$ proved most effective. The $\mathrm{k}_{\mathrm{PFO}}$ obtained for the 50:50 mixture for TCE degradation was about $0.3 \mathrm{~d}^{-1}$, more than 20 times slower than for $\mathrm{CCl}_{4}$.

Initial experiments with reduced bulk smectite and TNT under PFO conditions yielded reduction rates that were too fast to measure by the batch technique. Dilution of the reduced smectite to yield Fe(II) concentrations that were about 1.5 times higher than the initial TNT concentrations, however, yielded a measurable degradation rate. Unidentified intermediate degradation products were also observed in the course of the reaction.

The results of these experiments suggest that

- surface adsorbed Fe(II) is essential for degradation of organic species by clays and that sulfide residues from dithionite treatment may also be important

- structural Fe(III) in smectites is reduced by adsorbed $\mathrm{Fe}(\mathrm{II})$ and will decrease proportionally the amount of sorbed $\mathrm{Fe}$ (II) available to react with contaminants

- mixtures of $\mathrm{Fe}(0)$ and $\mathrm{Fe}(\mathrm{II})$ associated with smectite surfaces are the most effective reductants. presumably due to the large supply of surface-adsorbed $\mathrm{Fe}(\mathrm{II})$ and $\mathrm{Fe}(\mathrm{OH})_{2}$ provided when clay corrodes the $\mathrm{Fe}(0)$ surface.

Taken in total, the generation of solid-phase reductive capacity in sediments by dithionite treatment is very effective for remediation of contaminated groundwater.

\section{Reduction by $\mathrm{Fe}(\mathrm{II})$ Adsorbed to Goethite}

We also examined the factors influencing the rates of $\mathrm{CCl}_{4}$ dechlorination by $\mathrm{Fe}$ (II) that was sorbed to the surface of goethite (Gorby et al. in review). Several experiments were conducted in which the total amount of $\mathrm{Fe}(\mathrm{II})$ in the system, the amount of sorbed Fe(II), and the density of sorbed Fe(II) were varied. The results showed the overall reaction to be first order with respect to $\mathrm{CCl}_{4}$ and second order with respect to the volumetric concentration of sorbed $\mathrm{Fe}(\mathrm{II})$. The rate constant was determined to be $67 \pm 8 \underline{\mathrm{M}}^{-2} \mathrm{~s}^{-1}$ for the overall reaction. Of the $\mathrm{CCl}_{4}$ degraded, $83-90 \%$ was converted to chloroform, which accumulated in the reaction vial.

\section{Interactions of Sulfate-Reducing Bacteria with Mineral Surfaces}

In situ bioremediation can be used to convert hazardous metals in groundwater from mobile forms to immobile or nonhazardous forms. While the initial treatment may be effective in removing the metal from solution, in many instances, a real potential for remobilization exists.

The focus of this project, which is part of a collaborative effort with researchers at Washington State University and Montana State University, is on identifying and quantifying the fundamental factors that control the remobilization rates of metals that have been precipitated by bioreductive processes. We have selected sulfate-reducing bacteria (SRB) as our biological system and will begin by looking at the remobilization of $\mathrm{Pb}$ precipitated as the sulfide.

Our premise is that the long-term stability of bioimmobilized metals is primarily controlled by 1) the spatial distribution and chemical form of the metal precipitates that form, 2) the amount and type of reduced iron produced during the treatment, and 3 ) the oxygen flux past the immobilized metals. The relative influence of these factors on the rate of remobilization can be quantified by correlating fundamental sediment-surface, groundwater-chemical, and contaminant properties with measurements of metal-remobilization rates. Secondary factors that can impact the rate of remobilization are 4) the flux and chemistry of the groundwater (e.g., ligand type and concentration, $\mathrm{pH}$ ), 5) the presence and activity of sulfur and iron-oxidizing bacteria, and 6) aquifer temperature.

Our approach involves detailed surface analysis of mineral surfaces to determine the chemical and morphological forms of the immobilized contaminant and the relation between contaminant and microbial spatial distributions. Ultimately, we will relate these primary surface data to observed contaminant resolubilization rates. These rate data may then be used by others to develop more accurate flow and transport models for predicting the fate of metal and radionuclide plumes after biological treatment. 
Much of our work this year has involved the development of a fluidized-bed reactor system for treatment of mono-mineralic powders (Figure 3.9). The reactor, which is currently in the final stages of testing, is designed to allow recirculation of the reaction medium through the cell, thus closely simulating groundwater conditions in a reducing aquifer. The mineral particles and SRBs remain suspended and constantly mixed by the flow of solution into the bottom of the $\mathrm{V}$. Flow rates are maintained by a constant-head feed reservoir with a UV-transparent top to prevent microbial growth. The materials in the reactor are isolated from other reservoirs in the system by replaceable filter membranes on the inlet and outlets and judicious use of UV radiation external to the cell to minimize biofilm formation. Thin walls in the flat sides of the reactor allow spectroscopic studies of solid-phase chemical properties (Fe by Mössbauer spectroscopy; $\mathrm{Pb}$ and $\mathrm{U}$ by $\mathrm{x}$-ray absorption spectroscopy) under controlled atmospheric conditions. Ports for sampling the filtered medium and solid-phase specimens are used for periodic ex situ measurements of solution properties and mineral surface features with other spectroscopic and microscopic tools.

In addition to the reactor deyelopment effort, we have conducted a number of batch incubation studies to ascertain the acceptable media for SRB growth in groundwater matrices and to determine the effects of different mineral types on this growth. The results of this work show that the presence of mineral surfaces exerts a significant positive effect on SRB growth. However, the mineral type (quartz, feldspar, or smectite) seems to have little effect on this growth. Rather, the minerals seem to serve mainly as a physical means of support. Mineral type, however, is

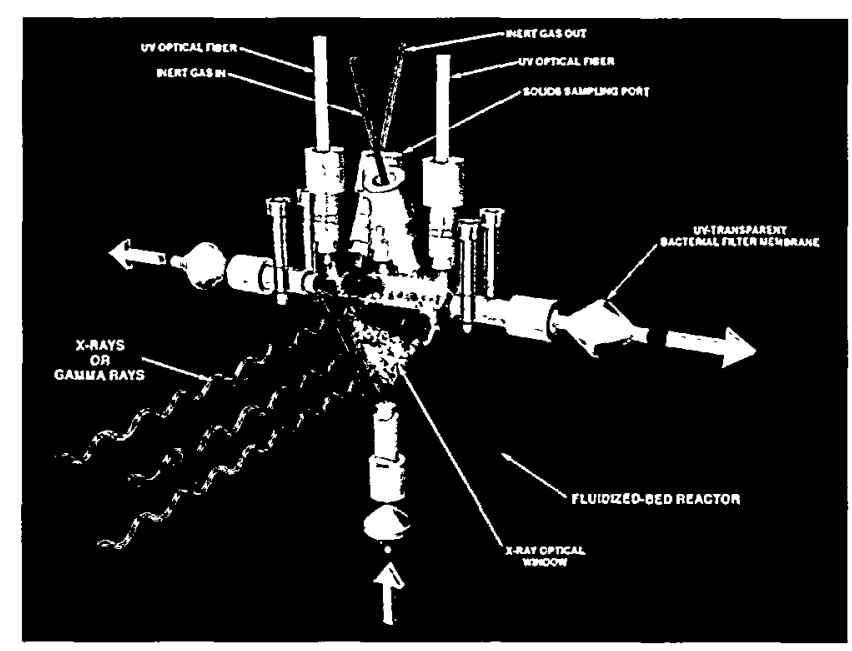

Figure 3.9. Fluidized-bed reactor for in situ studies of bacterial-mineral reactions.

expected to be important when toxic metals, such as $\mathrm{Pb}$, are present because of differences in the minerals' ability to buffer the aqueous metal concentrations through sorption.

\section{Acknowledgments}

We thank R. C. Nelson for design assistance, and J. L. Killinger and $M$. Townsend for machining the fluidized-bed reactor cells. D. J. Workman and D. W. Kennedy provided laboratory assistance in the $\mathrm{CCl}_{4}$ degradation studies with goethite.

\section{Reference}

Gorby, Y. A., J. E. Amonette, D. J. Workman, D. W. Kennedy, J. S. Fruchter, Environ. Sci. Technol. (in review). 


\section{Electron Paramagnetic Resonance Studies of Mineral Surface Chemistry}

\author{
J. E. Amonette, R. K. Kukkadapu, \\ A. S. Lea, C. J. Matocha, ${ }^{(a)}$ \\ D. L. Sparks, ${ }^{(a)}$ W. F. Bleam, ${ }^{(b)}$ and \\ S. J. Yoon ${ }^{(b)}$
}

Supported by EMSL Operations, Du Pont Graduate Fellowship.

(a) University of Delaware.

(b) University of Wisconsin-Madison.

By revealing the local electronic environments of atoms with unpaired electrons, electron paramagnetic resonance (EPR) spectroscopy provides information about the aqueous environmental surface chemistry of minerals and organo-mineral composites found in soils and sediments. Specific types of measurements include 1) the environments of transition metal ions present in crystal structures and on the surfaces of inorganic hydroxides and oxides, clays, and soil particles, and 2) measurements of the rates of transientfree-radical and metal-ion redox reactions induced by rapid mixing of reactants or laser photochemistry. This report describes the collaborative research performed on the multi-frequency continuous-wave EPR system located in the Environmental Spectroscopy Laboratory. An X-band pulsed EPR system is also located in EMSL and that work is described separately (Bowman et al. 2000).

\section{Spectroscopic Fundamentals}

Electron paramagnetic resonance spectroscopy is a type of absorption spectroscopy, in which molecules containing unpaired electrons (typically transitionmetal ions and organic radicals) absorb microwave radiation. Typically, samples are placed in a resonating cavity between the poles of a magnet and radiated by monochromatic microwave radiation while scanning through the magnetic field. The magnetic field splits electronic energy levels of the magnetic dipoles. When the energy splitting induced by the magnetic field corresponds to the energy of the microwave radiation, absorption (i.e., resonance) occurs. Because the exact magnetic field at which resonance occurs depends on the local environment of the electrons, valuable information about that environment is obtained including the nature of ligands around the absorbing center and the degree of metal-ligand covalency.

The EPR technique is applicable to 1) transition-metal ions (primarily $3 \mathrm{~d}$ and $4 \mathrm{~d}$ ions) with partly filled inner-electron shells having up to 5 unpaired electrons, 2) trivalent lanthanide ions, 3) actinide ions, 4) organic and inorganic free-radical species, 5) metals and semiconductors, and 6) solid defects. It is primarily used to characterize ions in magnetically dilute environments. In concentrated paramagnetic specimens, spectral resolution is lost (i.e., broad spectra are obtained) due to significant dipolar interactions between the adjacent paramagnetic centers (e.g., nontronite, Mn-oxides, Fe-oxides).

Under the right conditions, EPR spectroscopy has the ability to characterize the local chemical environment of paramagnetic transition-metal and rare-earth ions present in the lattice, in the interlayer region, or adsorbed to the surface of clays. The technique also provides information on minor structural substitutions and interactions of clays with other adsorbates, water, and a variety of organic molecules. Manganese oxides [e.g., $\mathrm{MnO}_{2}, \mathrm{MnO}(\mathrm{OH})$ ] exhibit broad EPR spectra due to magnetic dipolar interactions. Consequently, the EPR information is not very useful. However, $\mathrm{Mn}$ ions in dilute specimens or solutions exhibit spectra that provide information about the local environment of the ion. Unlike $\mathrm{Fe}^{3+}, \mathrm{Mn}^{2+}$ exhibits hyperfine structure mainly due to its higher magnetic moments. The technique has been used to probe chemisorption and precipitation of $\mathrm{Mn}^{2+}$ on carbonate surfaces and partitioning into dolomite, to speciate the forms and amounts of $\mathrm{Mn}$ in aqueous samples, and to determine the kinetics of sorption reactions of $\mathrm{Mn}^{2+}$ ions on $\mathrm{Mn}$ oxide surfaces. Other applications include sorption of transition metal ions by humic acids, decay of organic free radicals generated by ionizing radiation, study of reaction intermediates on oxide surfaces (heterogeneous catalysis), identification of impurities and defects in minerals and semiconductor materials, and studies of radiation damage.

\section{Birnessite Reduction by Catechol}

Behavior of $\mathrm{Mn}$ in soils and geochemical sediments is generally assumed to be mediated by redox reactions. Oxides and hydroxides containing Mn(III) and $\mathrm{Mn}$ (IV) can oxidize organic ligands more rapidly than 
$\mathrm{O}_{2}$ (Luther 1990). Aromatic and nonaromatic ligands have been reported to reductively dissolve $\mathrm{Mn}(\mathrm{III}, \mathrm{IV})$ (hydr)oxides with the formation of polymeric reaction products that resemble soil humic substances (Stone and Morgan 1984). Thus, redox cycling of $\mathrm{Mn}$ is dynamic and coupled to geochemical cycling of other metals, $\mathrm{C}$ turnover in soils, and $\mathrm{N}$ transformations in soils and marine sediments.

To adequately understand these interactions, a simple model system comprising birnessite $\left(\delta-\mathrm{MnO}_{2}\right)$ and catechol (1,4-dihydoxybenzene) was studied employing in situ electron paramagnetic resonance stopped-flow (EPR-SF) spectroscopic and stirredbatch techniques. Birnessite is a suitable mineral because it is one of the most commonly identified Mn oxides in soils and geochemical environments, (McKenzie et al. 1989) while catechol is a suitable model organic ligand because ortho-type semiquinones have been identified in soil humic substances (Steelink 1964).

The EPR-SF technique was used to measure paramagnetic $\mathrm{Mn}(\mathrm{II})$ release and detect possible semiquinone intermediates; a six-line EPR signal is expected for $\mathrm{Mn}(\mathrm{II})$. Figure 3.10 shows an EPR spectrum recorded within $10 \mathrm{~s}$ of a reaction between birnessite and catechol. The six-line spectrum confirmed that birnessite was reduced to $\mathrm{Mn}(\mathrm{II})$. Spectra were recorded at room temperature $\left(23^{\circ} \pm\right.$ $0.5 \mathrm{C}$ ) and a microwave frequency of $9.55 \mathrm{GHz}$ (X-band) using the Bruker ESP $300 \mathrm{E}$ spectrometer. Mixed samples were injected by the stopped-flow unit (Update Instruments, Inc., Madison, Wisconsin) into a flow-through quartz flat aqueous cell (Wilmad Glass Co., Buena, New Jersey) inserted in a $\mathrm{TE}_{102}$ resonator. Stopped-flow kinetic measurements were made with ms time resolution in time-sweep mode by centering on the increase in intensity of the fourth downfield resonance peak $\left(\mathrm{H}_{0}\right.$ in Figure 3.10$)$ at $0.3435 \mathrm{~T}$ ( $g=1.98)$ during the reaction sequence. This approach has been used by others in EPR-SF studies (Fendorf et al. 1993). When the entire six-line spectrum for $\mathrm{Mn}$ (II) was desired, field-sweep mode was used $( \pm 0.05 \mathrm{~T})$. The EPR technique yielded a linear response to $\mathrm{Mn}$ (II) between 5 and $200 \mu \mathrm{M}$.

A series of stopped-flow "flooding" experiments were conducted to determine the reaction orders with

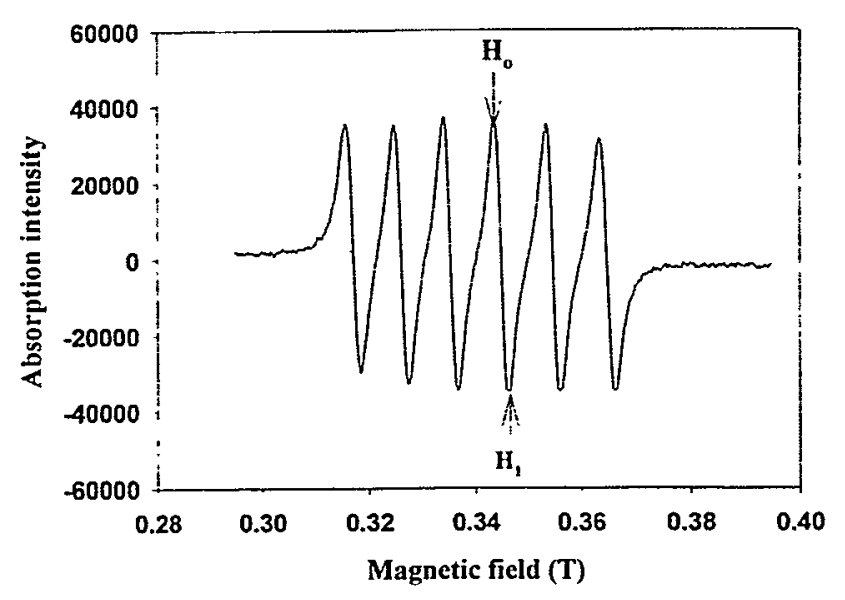

Figure 3.10. Representative room temperature EPR specta of $100 \mu M \mathrm{Mn}_{\mathrm{T}}$ as birnessite $\left(0.45 \mathrm{~m}^{2} \mathrm{~L}^{-1}\right)$ reacted with $5 \times 10^{-3} \mathrm{M}$ catechol concentration (CAT) depicting the characteristic six-line spectra of the $\mathrm{Mn}(\mathrm{II})$ product. $\mathrm{HO}$ and $\mathrm{H} 1$ indicate the peak and valley used to quantify $\mathrm{Mn}$ (II) concentrations.

respect to the concentrations of catechol and birnessite (i.e., surface area). In these experiments, either catechol or birnessite was present in excess and thus the reaction was pseudo-first-order with respect to the other reactant. Reaction progress was monitored with the EPR by the levels of $\mathrm{Mn}^{2+}$ released. The results of these experiments showed the reaction to be firstorder with respect to both reactants and yielded an overall empirical second-order rate constant of $4( \pm 0.5) \times 10^{-3} \mathrm{~L} \mathrm{~m}^{-2} \mathrm{~s}^{-1}$. Experiments were conducted at $\mathrm{pHs}$ ranging from 4 to 6 , with no change in rate. These results are consonant with the low point of zero charge for the birnessite surface (ca. 2-3) and the very weak acid nature of the catechol $\left(\mathrm{pK}_{\mathrm{a} 1}=9.7 ; \mathrm{pK}_{\mathrm{a} 2}\right.$ $=13.7$ ). Thus, in the $\mathrm{pH}$ region of 4 to 6 , little change in either the surface or solute properties would be expected.

In combination with other results obtained with this system (Matocha et al. submitted) the results of this study suggest that the rate-limiting step in the reaction between aqueous catechol and birnessite is an associative ligand substitution mechanism. The rapid rate of the reaction suggests that catechol could serve as an alternative soil extractant for easily reducible $\mathrm{Mn}$ between $\mathrm{pH} 4$ and 6 , and that large concentrations of catechol or similar humic materials in soils containing Mn oxides could possibly lead to Mn toxicity in susceptible plants. 


\section{Manganese Precipitated on Calcite}

The interactions of trace metals with carbonate surfaces may be a significant attenuation mechanism for a variety of contaminants in arid soils. As part of a basic research program into the surface chemistry of carbonates, we investigated atomic-scale processes involving dissolution and growth on single-crystal calcite surfaces using atomic-force microscopy. The impact of carbonate, $\mathrm{Sr}^{2+}$, and $\mathrm{Mn}^{2+}$ levels on calcite dissolution rates (i.e., etch-pit formation rates) was determined under a range of concentrations (Lea et al. submitted). At the highest $\mathrm{Mn}^{2+}$ levels, we observed the nucleation and growth of a phase on the calcite surface while the calcite was still dissolving. The lath-shaped phase grew in specific crystallographic directions relative to the calcite, reached a fixed width and height while continuing to elongate, and stopped growing when the active ends encountered a single atomic step on the calcite surface. It seemed probable that the phase contained $\mathrm{Mn}$, but several possible $\mathrm{Mn}$ solids could have been formed including $\mathrm{MnCO}_{3}$ (rhodochrosite), (Mn, $\mathrm{Ca}) \mathrm{CO}_{\mathfrak{3}}$ (kutnahorite), $(\mathrm{Ca}, \mathrm{Mn}) \mathrm{Mn}_{4} \mathrm{O}_{9} 3 \mathrm{H}_{2} \mathrm{O}$ (rancieite), $\mathrm{Mn}_{3} \mathrm{O}_{4}$ (hausmanite), $\mathrm{MnOOH}$ (manganite), and perhaps even an $\mathrm{MnO}_{2}$ phase (e.g., vernadite or birnessite). Because the total amount of precipitate was extremely small, conventional techniques such as $\mathrm{x}$-ray diffraction could not be used.

As discussed in the previous section, EPR is very sensitive to $\mathrm{Mn}(\mathrm{II})$ species. Isolated ions ( $>20 \mathrm{~nm}$ apart) yield a narrow 6-line spectrum due to mag-netic hyperfine splitting, but when the atoms are closer, their magnetic fields interact and magnetic ordering swamps the fine spectrum to yield a broad signal. We used this property to determine whether the precipitates on the calcite surface contained Mn(II). Powdered samples of calcite before and after a treatment identical to that in the AFM experiments were analyzed by EPR spectroscopy at room temperature and a microwave frequency of $9.4 \mathrm{GHz}$ (X-band). The results of the analysis (Figure 3.11) showed a distinct effect of the Mn treatment on the EPR signal. Before treatment, isolated $\mathrm{Mn}$ ions in the bulk calcite structure yielded a complicated 6-line spectrum (Figure 3.11, top). After treatment, this spectrum was largely obliterated and replaced by a broad single-line spectrum (Figure 3.11, bottom). These results clearly identify the presence of $\mathrm{Mn}$ (II) in the precipitate and also establish that the ions are close enough to order magnetically, as would be expected in a solid phase. Separate analyses using $x$-ray photoelectron spectroscopy (XPS) yielded a Mn 2p signal that was consistent with rhodochrosite. The XPS data, while definitively eliminating Mn(IV) species, could not completely rule out the possible inclusion of $\mathrm{Mn}(\mathrm{III})$. Thermodynamic speciation of $\mathrm{Mn}, \mathrm{Ca}$, and carbonate concentrations in solution established that the solutions were supersaturated with respect to both rhodochrosite and kutnahorite, but we were unable to further distinguish between these two possibilities. On the combined basis of these surface-chemical and EPR analyses, then, we were able to narrow the range of possible Mn phases to two.

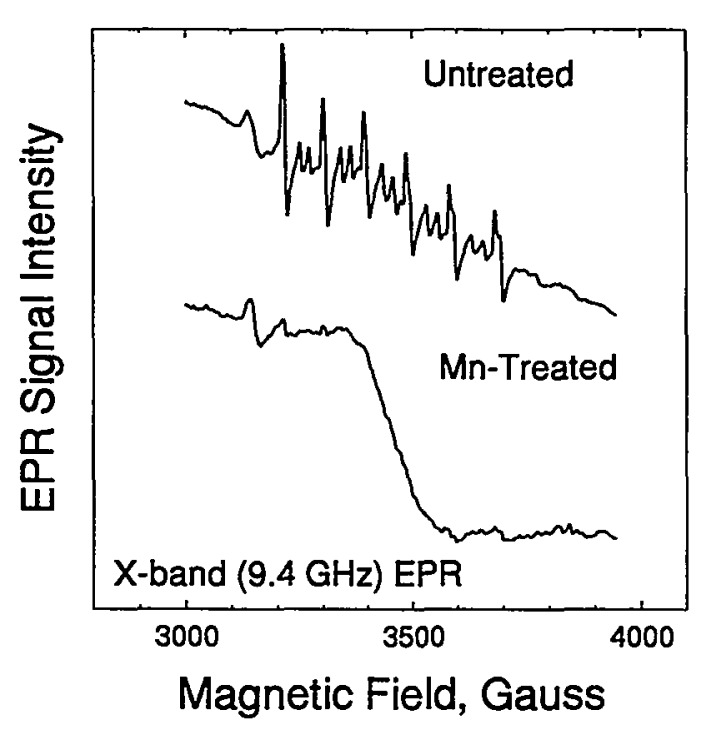

Figure 3.11. Continuous-wave $X$-band EPR spectra of powdered calcite before and after treatment with a dilute $\mathrm{Mn}$ solution under conditions identical to those under which the surface precipitate formed in AFM studies of single-crystal surfaces.

\section{Lanthanide Precipitates on Boehmite}

Lanthanide species, though of little environmental concern on their own merits, can serve as surrogates for actinide species that are of great concern. Identification of the forms by which these species are retained by mineral surfaces is a critical and essential step in the effort to predict their movement in soils and sediments. The low concentrations typically involved limit the techniques that can be used and favor those with the greatest sensitivity, such as EPR. 
Toward this end, we selected Gd(III) as a surrogate for the trivalent actinide species [e.g., $\mathrm{Pu}$ (III), $\mathrm{Am}(\mathrm{III})]$ and endeavored to identify the nature of the sorbed species formed during reaction with synthetic boehmite $(\alpha-\mathrm{AlOOH})$, which has the same structure as the more common $\mathrm{Fe}$ oxyhydroxide, lepidocrocite. Low-concentration sorption experiments were conducted at $\mathrm{pH} 4$ and 5 on pristine boehmite and that treated with phosphate to yield a phosphate surface coverage of $1 \mu \mathrm{mol} \mathrm{m}{ }^{-2}$. The solids thus produced were analyzed by extended $\mathrm{x}$-ray absorption fine structure (XAFS) spectroscopy, magnetic susceptibility, and EPR. The EPR experiments included temperature-dependent measurements of Gd(III) treated boehmite conducted at several points between 58 and $287 \mathrm{~K}$.

With pristine boehmite, very low levels of sorption occurred and analyses by magnetic susceptibility and EXAFS were not possible. The temperaturedependent EPR data, however, showed a linear relationship between temperature and the reciprocal of the EPR signal intensity (Figure 3.12). Extrapolation of this relation to $0 \mathrm{~K}$ yielded a y intercept that was not significantly different from zero indicating superparamagnetic ordering of clusters of Gd(III) on the surface. These clusters are likely ultra-fine hydroxide precipitates. Magnetic susceptibility measurements of an equivalent $\mathrm{Eu}$ (III) system (data not shown) also found superparamagnetism (i.e., no magnetic hysteresis combined with magnetic saturation at high fields). The precipitates are likely antiferromagnetic in the bulk phase and thus could be described as superantiferromagnetic.

With phosphate, dramatic increases in the degree of Gd adsorption were observed, thus allowing analysis by all three techniques. The magnetic susceptibility (Eu) and EPR data (Figure 3.12) yielded results similar to those for the pristine boehmite samples (i.e., superparamagnetic/superantiferromagnetic Gd clusters). The XAFS (Gd- $\mathrm{L}_{3}$ edge) data (not shown) indicated that these clusters were Gd-phosphate rather than hydroxide.

In general, it is known that lanthanide ions tend to form ultra-fine clusters upon sorption to oxide surfaces. Hydrous oxide clusters, however, will not

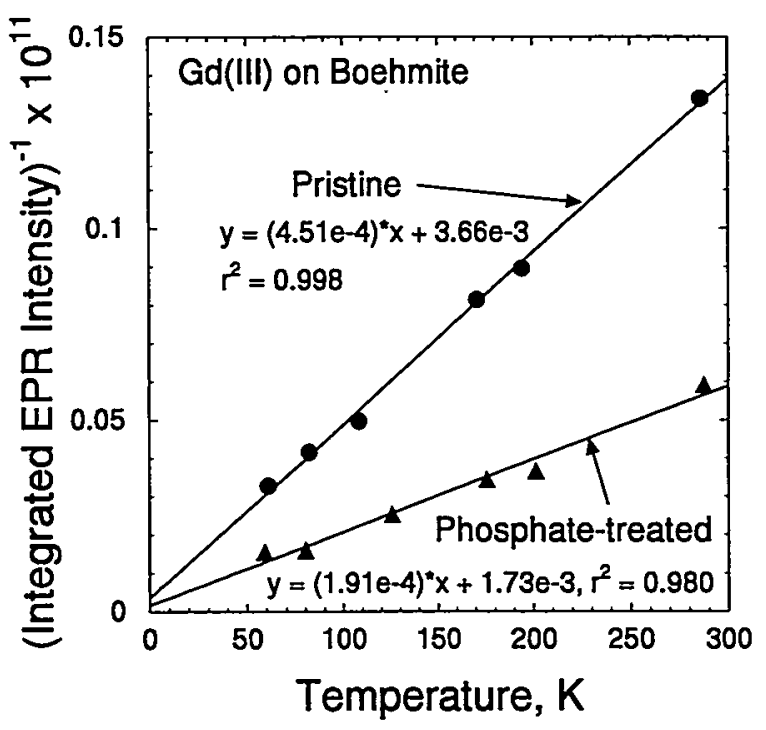

Figure 3.12. Temperature dependency of reciprocal EPR signal intensity for $\mathrm{Gd}(\mathrm{III})$ sorbed to pristine boehmite and to boehmite treated with phosphate to a surface density of $1 \mu \mathrm{mol} \mathrm{m^{-2 }}$.

form in the presence of phosphate. Our data show that when phosphate is present, as is typically the case, the surface becomes even more reactive with respect to lanthanide sorption. In part, this reactivity is facilitated by the formation of lanthanide phosphate clusters analogous to the hydrous oxide clusters. Thus, even at concentrations below the solubility limits, clustered surface precipitates are formed rather than single-ion adsorption complexes. The presence of these precipitates likely makes trivalent lanthanides and, by analogy, trivalent actinides, much less likely to be transported in soils and sediments. Further research into the exact nature of the precipitates and whether they serve as transitory phases in the development of crystalline phases could greatly aid our knowledge of the behavior of lanthanide and actinide species in soil systems.

\section{References}

Bowman, M. K., D. M. Kramer, U. Diebolt, L. Kispert, and A. M. Tyryshkin, "High-Resolution Spectroscopy." In Annual Report 1999 Macromolecular Structure and Dynamics. PNNL-13191, Pacific Northwest National Laboratory, Richland, Washington. 
Fendorf, S. E., D. L. Sparks, J. A. Franz, and

D. M. Camaioni, Soil Sci. Soc. Am. J., 57, 57 (1993).

Lea, A. S., J. E. Amonette, D. R. Baer, and Y. Liang, Geochim Cosmochim Acta (submitted).

Luther, G. W., III, "Frontier Molecular Orbital Theory in Geochemical Processes." In Aquatic Chemical

Kinetics: Reaction Rates of Processes in Natural Water. W. Stumm, Ed.; Wiley-Interscience, New York (1990).

Matocha, C. J., D. L. Sparks, J. E. Amonette, and R. K. Kukkadapu, Soil Sci. Soc. Am. J. (submitted).
McKenzie, R. M., "Manganese Oxides and Hydroxides." In Minerals in Soil Environments. Dixon, J. B., and S. W. Weed, Eds.; $2^{\text {nd }}$ ed. SSSA Book Series 1. SSSA, Madison, Wisconsin, 439 (1989).

Steelink, C., Geochim. Cosmochim. Acta., 28, 1615 (1964).

Stone, A. T., and J. J. Morgan, Environ. Sci. Technol. $18,450(1984)$. 


\section{Geochemical Mechanisms in Terrestrial Carbon Sequestration}

\author{
J. E. Amonette, J. A. Capp, ${ }^{(a)}$ \\ A. Lüttge, ${ }^{(b)}$ D. R. Baer, and \\ R. S. Arvidson ${ }^{(b)}$
}

Supported by DOE/OBER/Center for Carbon Sequestration in Terrestrial Ecosystems, BES-Geosciences.

(a) Associated Western Universities student.

(b) Rice University.

Concern over the potential climate changes associated with increasing levels of atmospheric $\mathrm{CO}_{2}$ has focused new research on the pathways and processes that enhance $C$ sequestration. In this report we summarize the research initiated this year on key aspects of organic- and inorganic- $C$ sequestration processes in soils. We also describe our exploration of a new microscopic technique for imaging changes in mineral surface topography resulting from precipitation and dissolution reactions such as might occur during $\mathrm{C}$-sequestration.

\section{Formation of Humic Materials at Oxide Surfaces}

Restoration of organic soil C to levels typical of pre-agricultural soils (as much as twice the current levels) can be a significant sink for atmospheric $\mathrm{C}$ over the next 20-50 years and thereby help stabilize atmospheric levels during the transition to non-fossil sources of energy. For example, an increase of I $\mathrm{wt} \% \mathrm{C}$ in the top $15 \mathrm{~cm}$ of a soil would sequester about 23 metric tons of $\mathrm{Cha}^{-1}$. Whereas most of the $\mathrm{C}$ in soils is turned over quite rapidly by the activity of microbes, a small fraction can be retained in a recalcitrant form (i.e., humified) through the partial oxidation and polymerization of organic molecules such as hydroxybenzoic acids, amino acids, and polyphenols. Humification is believed to be catalyzed by phenol oxidase enzymes secreted by fungi (Martin and Haider 1969; Nelson et al. 1979) demonstrated this process by bubbling air through a mixture of tyrosinase (an oxidase extracted from mushrooms) and several of the organic monomers just listed. In the present work, we sought to determine the influence of other solid-phase oxidants, such as the common $\mathrm{Fe}(\mathrm{III})$ and $\mathrm{Mn}$ (IV) oxide minerals, on the humification process. If these minerals further catalyzed the humification reaction, then agricultural management practices that promote their formation in soils (e.g., fertilization with $\mathrm{Fe}$ and $\mathrm{Mn}$ ) might increase the amounts of $\mathrm{C}$ sequestered by this process.

We prepared a mixture of organic monomers $(2 \mathrm{mM}$ orcinol, resorcinol, p-hydroxybenzoic acid, L-glycine, $\mathrm{L}-$ serine, and vanillic acid) in a $100 \mathrm{mM}$ phosphate solution buffered at $\mathrm{pH} 6.5$. Separate $1 \mathrm{mg} / \mathrm{mL}$ suspensions of goethite $(\alpha-\mathrm{FeOOH})$, hematite $\left(\alpha-\mathrm{Fe}_{2} \mathrm{O}_{3}\right)$, birnessite $\left(\gamma-\mathrm{MnO}_{2}\right)$, an Fe-rich smectite (Panther Creek bentonite), and tyrosinase were also prepared. To a series of $7.5 \mathrm{~mL}$ polystyrene $1 \mathrm{~cm}$ cuvettes, we added $3.5 \mathrm{~mL}$ of the buffered organic monomer solution, $1 \mathrm{~mL}$ of the mineral suspension, and $0.5 \mathrm{~mL}$ of the tyrosinase solution. The mineral treatments were run in duplicate. Solutions with $1 \mathrm{~mL}$ of $\mathrm{H}_{2} \mathrm{O}$ added in place of the mineral suspension were also run as controls. Each cuvette was then capped and incubated at $22^{\circ} \mathrm{C}$ while continuously bubbling the mixture with house air using a small tube passed through the cap. At selected intervals after mixing, the absorbance of the mixture in the cuvette was measured using an HP 8452 diode-array UV-Vis spectrometer. The change in absorbance at $486 \mathrm{~nm}$ was used to measure reaction progress.

The solid-phase oxidants all yielded increases in the apparent reaction rate and extent (Figure 3.13). In

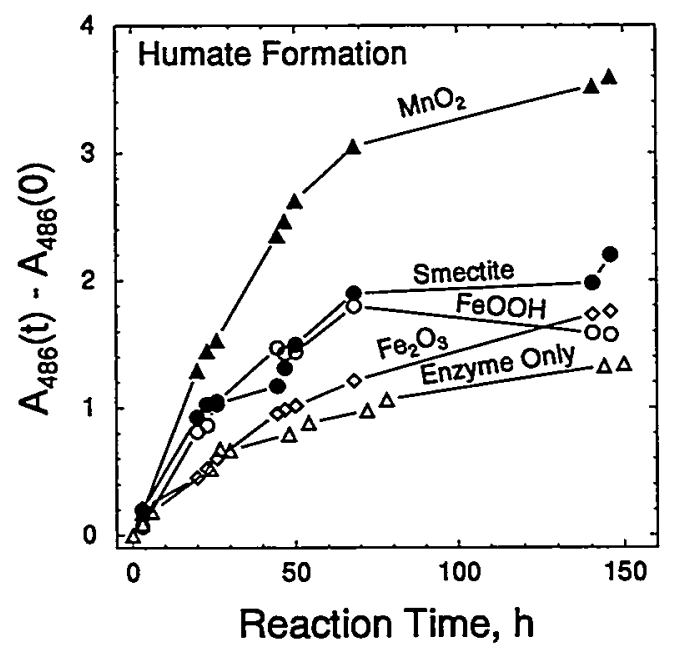

Figure 3.13. Rates of enzyme-catalyzed humification induced by $\mathrm{Fe}$ (III) and $\mathrm{Mn}$ (IV) mineral suspensions and by a solution containing no additional mineral oxidant. 
general, the Fe(III)-bearing minerals increased the humification rate by as much as twofold, with smectite and goethite having a stronger effect than hematite. These results may stem from the greater surface area offered by the smectite $\left(635 \mathrm{~m}^{2} \mathrm{~g}^{-1}\right)$ and goethite $\left(87 \mathrm{~m}^{2} \mathrm{~g}^{-1}\right)$ than the hematite $\left(6 \mathrm{~m}^{2} \mathrm{~g}^{-1}\right)$. The $\mathrm{Mn}$ (IV) oxide increased the humification rate by a factor of about 3 . Although the surface area of the $\mathrm{Mn}$ (IV) oxide was not measured, it was certainly no more than that of the smectite, suggesting that the higher reduction potential of $\mathrm{Mn}(\mathrm{IV})\left(\mathrm{E}^{\circ}=1.20 \mathrm{~V}\right)$ relative to $\mathrm{Fe}(\mathrm{III})\left(\mathrm{E}^{\circ}=0.77 \mathrm{~V}\right)$ was the key factor in the higher humification rate.

These results suggest that the presence of $\mathrm{Mn}(\mathrm{IV})$ and $\mathrm{Fe}$ (III) minerals can aid the polymerization of humic materials in soils and that management practices that foster the presence of these minerals can have a significant impact on the overall rates of $\mathrm{C}$ sequestration achieved.

\section{Stoichiometry of Calcite Precipitation}

On a geologic time scale, precipitation of inorganic carbonate minerals is the main mechanism by which $\mathrm{CO}_{2}$ has been removed from the atmosphere. At the $\mathrm{pHs}$ typical of the ocean and groundwater, the $\mathrm{HCO}_{3}^{-}$ ion is the dominant carbonate species in solution and the stoichiometry of the reaction can be written as

$$
\begin{aligned}
\mathrm{Ca}^{2+}+ & +2 \mathrm{HCO}_{3}^{-} \rightarrow \mathrm{CaCO}_{3}(\mathrm{~s}) \\
& +\mathrm{H}_{2} \mathrm{O}+\mathrm{CO}_{2}(\mathrm{~g})
\end{aligned}
$$

This reaction implies that 1 mole of $\mathrm{CO}_{2}$ is released to the atmosphere for each mole of $\mathrm{CaCO}_{3}$ formed, suggesting that precipitation of carbonate invariably increases the short-term supply of atmospheric $\mathrm{CO}_{2}$ (Schlesinger 1999). A simpler general form of the reaction can also be written in which no direct release of $\mathrm{CO}_{2}$ is involved:

$$
\mathrm{Ca}^{2+}+\mathrm{HCO}_{3}^{-} \rightarrow \mathrm{CaCO}_{3}(\mathrm{~s})+\mathrm{H}^{+}
$$

Rather. precipitation of a mole of $\mathrm{CaCO}_{3}$ consumes one mole of alkalinity (or creates one mole of acidity). The loss in alkalinity can come from the dissolved bicarbonate species to yield $\mathrm{CO}_{2}$ as in the first reaction or from reaction with solid-phase $\mathrm{pH}$ buffers including organic matter and silicate minerals like plagioclase to yield other products as in:

$$
\begin{aligned}
& \mathrm{NaAlSi}_{3} \mathrm{O}_{8}+\mathrm{H}^{+}+7 \mathrm{H}_{2} \mathrm{O} \\
\rightarrow & \mathrm{Na}^{+}+\mathrm{Al}(\mathrm{OH})_{3}+3 \mathrm{H}_{4} \mathrm{SiO}_{4}
\end{aligned}
$$

As the pH-buffering capacity of soil solids is several orders of magnitude larger than that provided by groundwater species alone, it does not necessarily follow that one mole of $\mathrm{CO}_{2}$ would be released for each mole of $\mathrm{CaCO}_{3}$ that precipitates. The actual amount of $\mathrm{CO}_{2}$ released will depend on the kinetics of the various possible $\mathrm{pH}$-buffering reactions and the fluxes of water and gas through the soil. Furthermore, even in a strictly carbonate-buffered system, release of $\mathrm{CO}_{2}$ in response to generation of $\mathrm{H}^{+}$would not be expected to be significant at $\mathrm{pHs}$ above about 8 , due to the $\mathrm{pK}_{1}$ of 6.35 for the carbonic acid-bicarbonate pair.

To demonstrate these points, we conducted experiments in which we measured the $\mathrm{CO}_{2}$ released by $\mathrm{CaCO}_{3}$ precipitation at a typical groundwater $\mathrm{pH}$. As variables, we selected 1) the presence or absence of a solid-phase pH buffer (finely ground feldspar), and 2) the rate of removal of dissolved $\mathrm{CO}_{2}(\mathrm{~g})$ from the sample (headspace purging versus suspension sparging). Results of our most recent experiments are reported here.

The experimental apparatus consisted of two plastic gas-washing bottles connected in series that were continually flushed with a stream of $\mathrm{CO}_{2}$-free $\mathrm{N}_{2}(\mathrm{~g})$ at about $32 \mathrm{~cm}^{3} \mathrm{~min}^{-1}$. In one set of experiments, a sparging tube was immersed in the suspension. In the other set of experiments, the sparging tube was suspended above the suspension so that only the headspace was flushed, and $\mathrm{CO}_{2}$ produced in the aqueous phase needed to diffuse to the gas-liquid surface to be collected in the $\mathrm{N}_{2}(\mathrm{~g})$ stream. The precipitation reactions were conducted in the first flask and the $\mathrm{CO}_{2}$ evolved was trapped by $200 \mathrm{~mL}$ of $0.1 \mathrm{M} \mathrm{NaOH}$ in the second flask and subsequently measured by a total- $\mathrm{C}$ analyzer. Four apparatus were used simultaneously and purged with the same source of $\mathrm{N}_{2}(\mathrm{~g})$. The four reaction flasks initially contained $1 \mathrm{mmol}$ of $\mathrm{NaHCO}_{3}$ adjusted with $\mathrm{HCl}$ to $\mathrm{pH} 7.5$ in a volume of $50 \mathrm{~mL}$. Two flasks received an equivalent amount of $\mathrm{CaCl}_{2}$, which was added by syringe after the gas flow had started, to yield a final volume of 
$100 \mathrm{~mL}$; one of these flasks also contained $1 \mathrm{~g}$ of a powdered feldspar standard (NBS $99,<75 \mu \mathrm{m}$ ). The two remaining flasks also had final volumes of $100 \mathrm{~mL}$ and one of them contained $1 \mathrm{~g}$ of the feldspar. Thus, for a given experiment, $\mathrm{CaCO}_{3}$ was precipitated in two apparatus, in the presence and absence of feldspar. Conditions in the other two apparatus served as $\mathrm{CaCO}_{3}$-free controls. The $\mathrm{pH}$ of the reaction flasks was measured at the beginning and end of the precipitation experiments. In addition to $\mathrm{CO}_{2}$ evolved during precipitation, a total $\mathrm{C}\left(\mathrm{C}_{\mathrm{T}}\right)$ balance was also made by acidifying the contents of the first flask to $\mathrm{pH} 2$ at the end of the experiment and measuring the $\mathrm{CO}_{2}$ evolved under the same sparging conditions. As flow rates varied slightly from one apparatus to the next, the $C_{T}$ recovery data were used to normalize the data for $\mathrm{CO}_{2}$ evolution during the precipitation. Experiments were conducted with reaction times of 16 or $64 \mathrm{~h}$ after addition of $\mathrm{CaCl}_{2}$.

The results of these experiments yielded several insights into the stoichiometry of the $\mathrm{CaCO}_{3}$ precipitation reaction. First, the final $\mathrm{pHs}$ varied with the type of gas flushing (solution or headspace, Figure 3.14). With solution sparging, the final $\mathrm{pH}$ in the $\mathrm{CaCO}_{3}$ flasks increased from 7.5 to $7.8-7.9$, as would be expected by removal of $\mathrm{CO}_{2}$ from the system. With headspace flushing, the final $\mathrm{pH}$ in the $\mathrm{CaCO}_{3}$ flasks decreased to final values of 7.3-7.4. With both gas-flushing systems, increases in $\mathrm{pH}$ to 8.3-8.9 were seen with the $\mathrm{CaCO}_{3}$-free controls (data not shown).

Second, the presence of feldspar decreased the change in $\mathrm{pH}$ (Figure 3.14). That is, the feldspar buffered the $\mathrm{pH}$ of the solution closer to its initial value. The overall buffering capacity of the feldspar was low, however, as expected from the high solution:solid ratio employed.

Third, the net amounts of $\mathrm{CO}_{2}$ evolved during $\mathrm{CaCO}_{3}$ precipitation varied from essentially nil to as much as $23 \%$ of $\mathrm{C}_{\mathrm{T}}$ (Figure 3.14 ). The maximum amount evolved, however, was slightly less than half the amount expected assuming the stoichiometry of the first equation and precipitation of all inorganic $\mathrm{C}$ as $\mathrm{CaCO}_{3}$. With the exception of the lowest-pH data point, the amount of $\mathrm{CO}_{2}$ evolved was inversely correlated $\left(\mathrm{r}^{2}>0.999\right)$ with the final $\mathrm{pH}$ of the suspension. The outlying data point at $\mathrm{pH} 7.27$

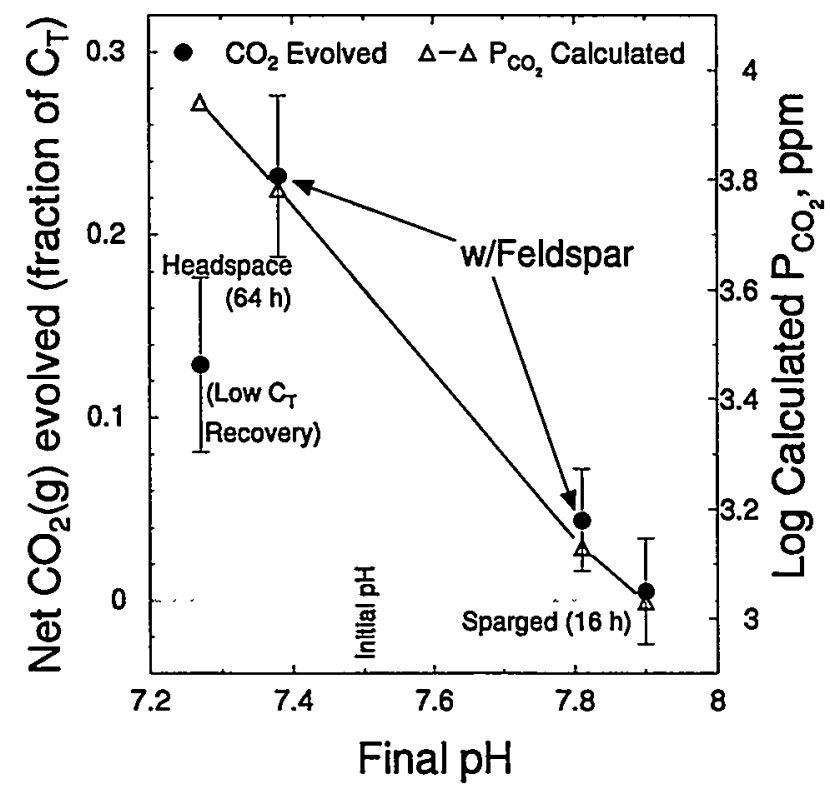

Figure 3.14. Net amounts of $\mathrm{CO}_{2}$ evolved during $\mathrm{CaCO}_{3}$ precipitation experiments (left axis) and calculated $\mathrm{P}_{\mathrm{CO} 2}$ in equilibrium with suspensions at final $\mathrm{pH}$ of experiments (right axis).

probably represents a leak in the gas flushing system as only $58 \%$ of the $C_{T}$ was recovered during the acidification procedure for this sample. In all other samples, $\mathrm{C}_{\mathrm{T}}$ recovery was $80-90 \%$.

Taking the final $\mathrm{pH}$ values and the initial composition of each system as inputs to the MINTEQA2 thermodynamic speciation code ( $\mathrm{v} 3.10$, USEPA Environmental Research Laboratory, Athens, Georgia), we calculated the $\mathrm{P}_{\mathrm{CO} 2}$ in equilibrium with the precipitated $\mathrm{CaCO}_{3}$ at the end of the experiment. A line with a negative slope of 1.47 is obtained when $\log \mathrm{P}_{\mathrm{CO} 2}$ is plotted against $\mathrm{pH}$, as expected from the equilibrium constant used in the calculation (Figure 3.14). What is striking, however, is the direct correspondence between the calculated $\mathrm{P}_{\mathrm{CO} 2}$ data and the evolved $\mathrm{CO}_{2}$ data. These results suggest that each of the reactions had reached a steady state with respect to the $\mathrm{P}_{\mathrm{CO} 2}$ levels maintained in the reaction flask. Even though the systems are "open" in a thermodynamic sense, calcite is known to equilibrate rapidly with the surrounding fluid.

Thus, the primary factor influencing the calcite precipitation stoichiometry in these experiments seems to be the rate of gas removal and its influence 
on the $\mathrm{P}_{\mathrm{CO} 2}$. A secondary influence seems to be the degree of $\mathrm{pH}$ buffering by the solid phase. In all experiments where $\mathrm{CaCO}_{3}$ was precipitated, the calculated steady-state $\mathrm{P}_{\mathrm{CO} 2}$ levels were higher than atmospheric levels (ca. $380 \mathrm{ppm}$ ). In soils and sediments, low gas exchange rates would tend to promote higher $\mathrm{P}_{\mathrm{CO} 2}$ levels, but this influence would be offset by the massive $\mathrm{pH}$-buffering capacity of the solid phase, which is only hinted at in these experiments. For example, the solution:solid ratio in these experiments was 100 , whereas in a typical groundwater, a ratio of about 0.3 would be expected. Ultimately, then, soil $\mathrm{pH}$ would control $\mathrm{P}_{\mathrm{CO} 2}$ and the amounts of $\mathrm{CO}_{2}$ evolved during $\mathrm{CaCO}_{3}$ precipitation.

In summary, our experiments suggest that the risk of $\mathrm{CO}_{2}$ emission from $\mathrm{CaCO}_{3}$ precipitation is inversely related to the $\mathrm{pH}$ maintained by a soil. At $\mathrm{pHs}$ above 7.9 , little or no $\mathrm{CO}_{2}$ evolution would occur. Extrapolation of the relation between $\mathrm{CO}_{2}$ evolution and $\mathrm{pH}$ suggests that soils at pHs of about 6.8 or lower would stoichiometrically release 1 mole of $\mathrm{CO}_{2}$ for each mole of $\mathrm{CaCO}_{3}$ precipitated. From the standpoint of inorganic- $\mathrm{C}$ sequestration, the best soil management practices seem to be those that maintain soil $\mathrm{pH}>7.9$ and certainly no lower than 6.8 . Further experimentation is under way to confirm and refine these observations.

\section{Interferometric Microscopy of Calcite Surfaces}

In the past decade, optical phase-shift interferometry has found increasing use in the topographical characterization of semiconductor and optic material surfaces (Onuma et al. 1994). Recent work at Yale University (Lüttge et al. 1999) has extended this technique to directly measure reactive surface area and dissolution rates of feldspar (abiotic) and apatite (microbial) ex situ. As applied by Lüttge and coworkers, the technique uses a closed-path Mirau double-beam interferometer objective attached to an optical microscope to measure the path length differences between white light reflected by the sample and light reflected by a reference surface. Transformation of the interferogram, which is collected in a matter of a second or two by moving the surface of the sample vertically using piezoelectric ceramics, results in a topographical map of the surface with absolute vertical resolution as small as a few nm and horizontal resolution of 1 um. Changes in the topography of the surface as a result of reaction can be monitored over time by masking part of the surface, which then serves as a reference for later measurements.

Key attributes of phase-shift interferometry (in addition to rapid data collection) are 1) the large depth of focus ( $100 \mathrm{um}$ at $\mathrm{nm}$-scale resolution, $1 \mathrm{~mm}$ at lower resolution), 2) the large field of view (up to $1 \mathrm{~mm}^{2}$ ), and 3 ) the noninvasive nature of the technique.

Because these attributes allow nm-scale information to be collected quickly on relatively large areas of rough surfaces, phase-shift interferometry is well-suited to the analysis of reaction rates on minerals and other heterogeneous surfaces having high environmental significance.

In our initial application of the technique, we examined the cleavage surface of calcite after cleaning and drying with ethanol. After this observation, we removed the specimen, which was mounted on a special orienting stub, subjected it to a 5-minute "etching" treatment with deionized $\mathrm{H}_{2} \mathrm{O}$, and remounted it in the instrument after drying the surface with ethanol. The spatial registration provided by the stub allowed us to easily find and examine the exact same portion of the specimen surface. We then let the specimen sit overnight in contact with humid air (typical of Houston in August) before examining it for a third time the next morning.

The results (Figure 3.15) clearly demonstrate the ease with which the calcite surface reconstructs itself. In Figure 3.15a, a deep etch pit located at the foot of a high terrace is shown along with a line indicating where a cross section of the pit was extracted. Numerous other shallow pits are also seen on the same level as the deep pit. The initial image of the deep pit taken after cleaning with ethanol yielded a cross section (Figure $3.15 \mathrm{~b}$ ) that was about $72 \mathrm{~nm}$ deep and $5.5 \mu \mathrm{m}$ wide at the top. Immediately after etching with $\mathrm{H}_{2} \mathrm{O}$, the pit had enlarged to a $250-\mathrm{nm}$ depth and a $7.3-\mu \mathrm{m}$ width at the top (Figure 3.15c). However, upon equilibrating the surface overnight with humid air (Figure 3.15d), reconstruction of the calcite surface occurred to partly fill in the pit and eliminate the sharp features seen immediately after etching. The overall width at the top of the pit remained constant at about $7.3 \mu \mathrm{m}$. 

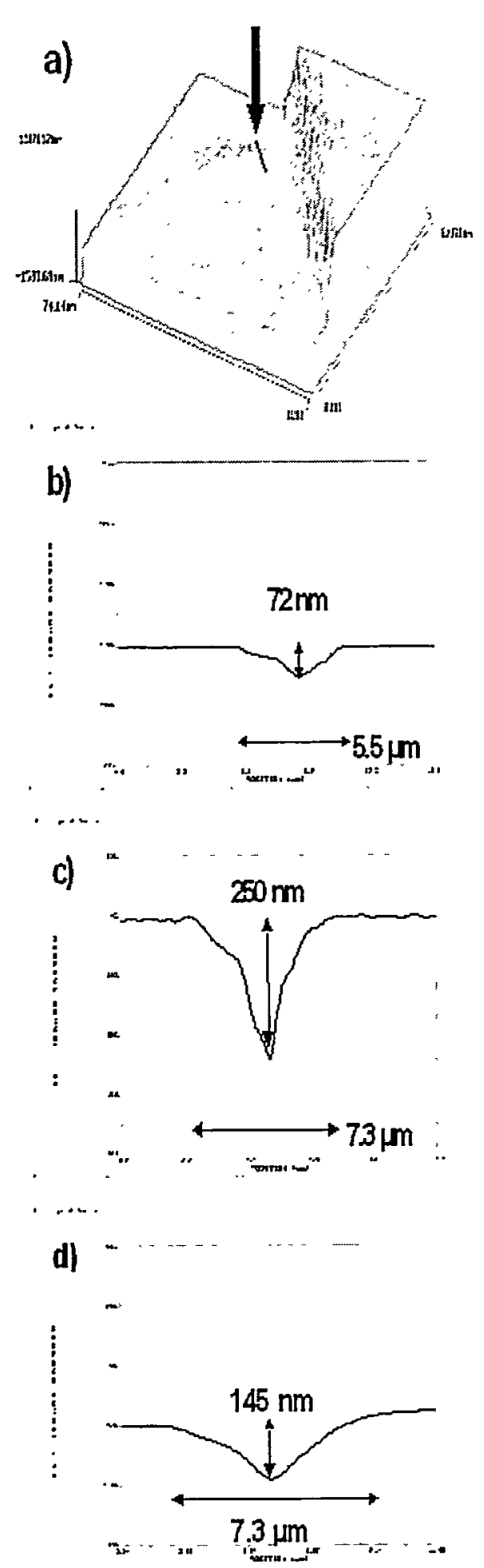

Figure 3.15. a) Interferometric microscope image of etch pit and step edge on calcite cleavage surface. Next three sections show cross sections of the pit (at arrow) measured b) before, c) immediately after, and d) 14-h after dissolution treatment with DI water.
Evidently the pit is located along a line defect perpendicular to the cleavage surface. The higher energy of sites located at this point cause it to dissolve more readily than the rest of the calcite surface. In humid air, however, the pit reconstructs to minimize the surface energy. Immediately after the etching process, the slopes of the sides of the pit are different (Figure $3.15 \mathrm{c}$ ) yielding an asymmetric shape. This feature is well known from our atomic-force microscopy (AFM) studies and reflects the two main types of double-kink sites (obtuse and acute) exposed on the calcite surface (Liang et al. 1996). The ratio of the slopes is inversely proportional to the step velocity during the etching process.

This simple experiment demonstrates how interferometric microscopy can be used to collect information about dissolution and reconstruction processes on mineral surfaces. It is but a short step to apply the technique to the precipitation of coatings, whether organic or inorganic in nature, on mineral surfaces. In ongoing research, we are examining the impact of metal ions such as $\mathrm{Mn}^{2+}$ and $\mathrm{Sr}^{2+}$ on the calcite dissolution process to confirm earlier results we obtained with AFM (Lea et al. in review). Experiments examining the interactions of humic polymers with feldspar surfaces are also under way. These experiments should yield insights as to how attachment and polymerization of humics on the surface occurs and the degree to which it affects subsequent weathering of minerals to yield the alkalinity. Both of these mineral surface processes are key to the sequestration of atmospheric $\mathrm{CO}_{2}$ by soils.

\section{References}

Lea, A. S., J. E. Amonette, D. R. Baer, and Y. Liang, Geochim Cosmochim Acta (in review).

Liang, Y., D. R. Baer, J. M. McCoy, J. E. Amonette, and J. P. LaFemina, Geochim Cosmochim Acta, 60, 4883 (1996).

Lüttge, A., E. W. Bolton, and A. C. Lasaga, Am. J. Sci., 299, 1 (1999).

Martin, J. P., and K. Haider, Soil Sci., 107, 260, (1969).

Nelson, D. W., J. P. Martin, and J. O. Ervin, Soil Sci. Soc. Am. J., 43, 84 (1979).

Onuma, K., T. Karneyama, and K. Tsukamoto, J. Crystal Growth, 137, 610 (1994).

Schlesinger, W. H., Science, 284, 2095 (1999). 


\section{Corrosion Products of Mild Steel in High lonic Strength Brines and the Effect on $\mathrm{Pu}(\mathrm{VI})$ Reduction}

\author{
Z. Wang, R. C. Moore, ${ }^{(a)}$ \\ A. R. Felmy, M. Mason, and \\ R. K. Kukkadapu
}

Supported by DOE WIPP program and EMSL Operations.

(a) Sandia National Laboratories.

In the United States, the majority of wastes targeted for disposal in the Waste Isolation Pilot Plant (WIPP) and other planned salt dome repositories will be contained in mild steel drums. Possible contact of the drums with high ionic strength brines located underneath and above the disposal room can result in corrosion of the drum steel and produce reducing conditions in the disposal room (Brush 1990). Reducing conditions can result in the reduction of hexavalent heavy radionucides, such as $\mathrm{Pu}(\mathrm{VI})$ and $\mathrm{U}(\mathrm{VI})$. to lower oxidation states, +III and +IV, which have very low water solubility (Grambow et al. 1995). Corrosion studies in the past have focused on corrosion rates of drum steel. Little information is available about the identification of the corrosion products. the mechanism of corrosion, or the effects of the corrosion process on the reduction of high oxidation state heavy radionuclides, such as $\mathrm{Pu}$.

In this study, the mechanism of iron corrosion in WIPP brines under simulated repository conditions and the effect of corrosion on actinide oxidation state are being examined. The results presented in this report document the first phase of the work: characterization of the corrosion layer and reduction of $\mathrm{Pu}(\mathrm{VI})$ in WIPP brine with drum steel present. Chemical composition, thickness, and. where possible, the phase composition of the corrosion layer on steel surfaces and iron powders immersed in both dilute $\mathrm{NaCl}$ solutions and WIPP brines were determined under controlled atmosphere conditions using a combination of in situ AFM. XPS, Mössbauer spectroscopy, and chemical analysis techniques. Preliminary plutonium reduction results are briefly discussed.

Cleaned ASTM A36 cold-rolled sheet steel coupons (0.5 inch diameter and $1 / 16$ inch thickness) and iron powder (325 mesh, 99.9\%) were placed individually in sealed plastic test tubes containing GSEEP brine, ERDA 6 brine, or dilute $\mathrm{NaCl}$ solution to initiate the corrosion process at $25^{\circ} \mathrm{C}$ in a controlled atmospheric chamber under $\operatorname{Ar}$ (oxygen concentration $<5 \mathrm{ppm}$ ). After three months of reaction, the majority of the steel coupons reacted in brines and dilute $\mathrm{NaCl}$ solution showed only a barely noticeable darkening of the surface and some scattered tiny dark spots. Iron powder reacted in both ERDA 6 and GSEEP brines caused a color change of the solution from colorless to light green, indicating the presence of $\mathrm{Fe}(\mathrm{II})$. In dilute $\mathrm{NaCl}$ solutions, however, the iron powder turned black, and the material displayed magnetic properties. XRD data of the powder confirmed the presence of magnetite. AFM images of the dry surfaces of the cleaned bare steel coupons (Figure 3.16a) show features that mostly reflect the marks generated during the machining and polishing process with approximately $\mu \mathrm{m}$-level roughness. However the AFM images of the corroded steel surfaces (Figures $3.16 \mathrm{~b}$, $3.16 \mathrm{c}, 3.16 \mathrm{~d}$ ) indicate that the corrosion film is highly inhomogeneous forming granules with sizes between tens to hundreds of nanometers at the surface. Although no measurable corrosion products

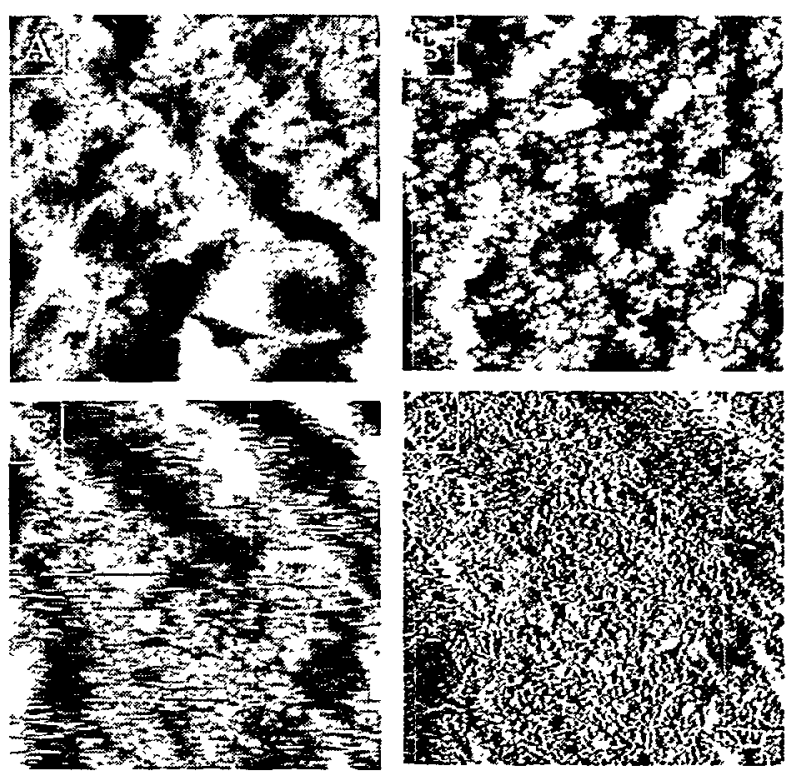

Figure 3.16. AFM images of steel coupon surface. a) uncorroded dry sample, topography signal; b) ERDA6 brine corroded dry sample, topography signal; c) ERDA6 brine corroded sample in diluted hydrochloric acid, topography signal; d) ERDA6 brine corroded sample in diluted hydrochloric acid, deflection signal. 
accumulated at the bottom of the test tubes during the leaching process, the brine solution did develop a colloid-like appearance with a noticeable tyndall effect, indicating that the corrosion film slowly dissociated from the steel surface preventing complete passivation. Once the steel coupons were subjected to aqueous solution, the AFM images became blurred and streaky even after leaching with $40 \mathrm{~mL}$ of dilute hydrochloric acid (Figure 3.16c and 3.16d for topography and deflection respectively). The streakiness of the images is an indication that small particles are being easily detached from the surface and moved by the very light resistance of the AFM tip. After prolonged leaching, clear indications of crystallinity of the steel was evident, indicating that the corrosion layer had been removed.

The elemental composition of the corrosion film was determined by ICP-MS and IC analysis of the effluent solutions generated during the hydrochloric acid leaching process while the AFM images were taken in situ. The results indicate that leaching with a dilute $\mathrm{NaCl}$ solution at near neutral $\mathrm{pH}$ and with dilute $\mathrm{HCl}$ resulted in essentially no removal of $\mathrm{Fe}$ from the surface until the $\mathrm{pH}$ decreased to relatively low levels (i.e., 3.0). This suggests that the surface film does not contain significant amounts of pure $\mathrm{Fe}$ (II) oxides, such as $\mathrm{Fe}(\mathrm{OH})_{2}(\mathrm{c})$, that are soluble at near neutral $\mathrm{pH}$ values. Small amounts of soluble $\mathrm{Mg}$ and $\mathrm{SO}_{4}$ are leached out even at $\mathrm{pH} 3.0$, indicating that at least some of these salts are associated with the oxide coating. XPS spectra of the corroded steel coupons after rinsing with DDI water further confirmed these results. In addition, a strong $\mathrm{Cl}^{-}$peak also appeared on the XPS spectra. These anion peaks vanished after the corrosion film was removed. XPS depth profiles indicate that the corrosion film thickness is nonuniform, varying between a few nanometers to a few hundred nanometers.

A more detailed analysis of the XPS spectra $\left(\mathrm{Fe} 2 \mathrm{P}_{3 / 2}\right.$ spectra, electron binding energy around $707 \mathrm{eV}$ ) suggests that iron is present in the corrosion film as both $\mathrm{Fe}^{2+}$ and $\mathrm{Fe}^{3+}$. Mossbauer spectra (Figure 3.17) of the powder samples indicate two doublets with isomer shifts of $0.45 \mathrm{~mm} / \mathrm{sec}$ and $1.25 \mathrm{~mm} / \mathrm{sec}$ and quadruple splittings of $0.42 \mathrm{~mm} / \mathrm{sec}$ and $2.88 \mathrm{~mm} / \mathrm{sec}$, respectively. The relative ratio of $\mathrm{Fe}$ (II) to $\mathrm{Fe}$ (III) is 1.91:1. These spectral characteristics are almost identical to the $\mathrm{SO}_{4}{ }^{2-}$ - bearing green rust obtained by

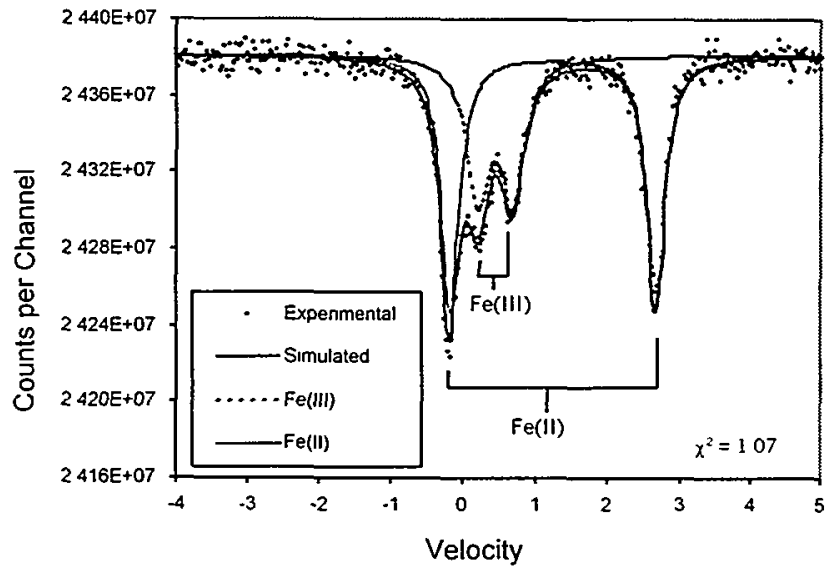

Figure 3.17. Mössbauer spectrum of ERDA6 brine corroded iron powder sample at $77 \mathrm{~K}$.

microbially induced corrosion of steel (Génin et al. 1998). The formation of such compounds involves in situ incorporation of water and anions, such as $\mathrm{Cl}^{-}$, $\mathrm{CO}_{3}{ }^{2-}$, and $\mathrm{SO}_{4}{ }^{2-}$, from the solution into the empty interlayers of brucite-like $\mathrm{Fe}(\mathrm{II})$ hydroxide sheets with a corresponding partial oxidation of the Fe(II) ions from oxidation $2+$ to $3+$.

Different steel planchets that had been leached in brine solutions or recently cleaned of oxide coatings were immersed in WIPP brines and $\mathrm{Pu}$ introduced into the planchet/brine solutions as $\mathrm{Pu}(\mathrm{VI})$ at an initial concentration of $0.00015 \mathrm{M}$. The planchet/brine solutions were then sampled after 15 days of contact. As expected, the "blank" solutions did not show any noticeable decrease in soluble $\mathrm{Pu}$ concentration indicating the lack of precipitation or adsorption reactions with the sample containers. In addition, the soluble $\mathrm{Pu}$ in these solutions was predominantly nonextractable by TTA, indicating the $\mathrm{Pu}$ remained in the oxidized form (i.e., either as Pu(VI) or Pu(V)). The total soluble $\mathrm{Pu}$ concentrations decreased significantly in all solutions in which steel planchets were added, indicating that some $\mathrm{Pu}$ was removed from solution either as a precipitate or adsorbed to the planchets or corrosion products. This effect was more pronounced in the solutions that had planchets having considerable build up of corrosion products than in the solutions with planchets with all corrosion products removed by acid leaching. Future work is directed toward the understanding of the exact nature of the corrosion products on steel surfaces on $\mathrm{Pu}$ reduction or adsorption. 


\section{References}

Brush, L. H., "Test Plan for Laboratory and Modelling Studies of Repository and Radionuclide Chemistry for the Waste Isolation Pilot Plant," DAND90-0266, Sandia National Laboratories, Albuquerque, New Mexico (1990).
Génin, J. M.-R., Ph Refait, A. A. Olowem, M. Abdelmoula, I. Fall, and S. H. Drissi, Hyperfine Interactions, 112, 47 (1998).

Grambow, B., E. Samailos, H. Geckeis, R. Müller, and H. Hentschel, Radiochimica Acta, 74, 149 (1995). 


\section{Mineral Structure Controls on Cs Adsorption in Hanford Sediments}

\section{J. M. Zachara, J. P. McKinley,}

R. J. Serne, S. C. Smith, and

P. L. Gassman

Supported by the Environmental Management Science Program.

${ }^{137} \mathrm{Cs}$ is a major radioactive contaminant in high-level nuclear waste at Hanford. Single-shell tanks holding these wastes have leaked, discharging over 1 million curies of ${ }^{137} \mathrm{Cs}$ into the Hanford vadose zone. While Cs is strongly sorbed to phyllosilicate minerals, Hanford field studies have indicated Cs migration to greater depths than predicted by current transport models that use simplified, empirical descriptions of the mineral adsorption process. We are exploring geochemical causes for expedited migration, focusing on the impacts of high $\mathrm{Na}^{+}, \mathrm{OH}^{-}$, and $\mathrm{Al}(\mathrm{OH})_{4}{ }^{-}$which may each act to destabilize surface complexes of $\mathrm{Cs}$ by different mechanisms.

Thermodynamic studies of highly selective Cs ion exchange are being linked with microscopic studies of the micaceous sorbing fraction to develop insights on Cs adsorption to Hanford vadose zone sediments in the presence of high-level waste (HLW) components. Exchange selectivity functions measured for the Hanford sediment in different electrolytes (Figure 3.18) show that $\mathrm{Cs}$ is adsorbed in great preference to other cations. These thermodynamic functions allow multicomponent ion exchange modeling of $\mathrm{Cs}$ retention in the presence of mixed $\mathrm{Na}^{+}, \mathrm{Ca}^{2+}$, and $\mathrm{K}^{+}$electrolyte. The large increase in $\mathrm{Cs}$ adsorption selectivity with decreasing fractional site occupation [equivalent fraction on the exchange complex; $\mathrm{E}(\mathrm{CsX})]$ indicates the presence of multiple site types with different adsorption energies. The low affinity sites are swamped by the high concentration of $\mathrm{Na}(>5 \mathrm{~mol} / \mathrm{L})$ in HLW supernatant. Under such extreme conditions, only the high affinity sites, which are present at relatively low concentration (i.e., $<\log$ $E=-3$ ), contribute to Cs adsorption.

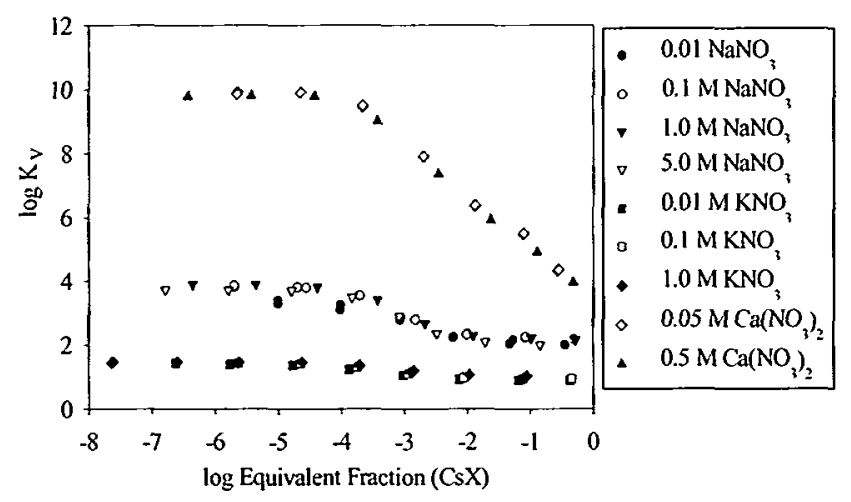

Figure 3.18. Dependence of the conditional thermodynamic equilibrium constant on surface saturation (CsX) and electrolyte concentration. $K_{v}=\left[A^{u+t}\right]^{v}\left[N_{C s x}\right]^{u} /\left[C^{t}\right]^{u}\left[N_{A x u}\right]^{v}$ where $A^{u+}$ is the electrolyte cation $\left(\mathrm{Na}^{+}, \mathrm{K}^{+}, \mathrm{Ca}^{2+}\right)$ and $\mathrm{N}$ is mole fraction. Equivalent fraction (CsX) - adsorbed Cs $(\mathrm{eq} / \mathrm{g}) / \mathrm{cation}$ exchange capacity (eq/g).

Micaceous mineral solids (including biotite, muscovite, and vermiculite) were picked from Hanford sediments, contacted with $\mathrm{Cs}$ in high salt solutions, and interrogated with electron and $\mathrm{x}$-ray microspectroscopy to identify the structural regions of the mineral sorbents where the high affinity sites exist (Figure 3.19). Cs preferentially adsorbed around the periphery of weathered biotite grains (Figure 3.19a) and in intragrain microchannels (Figure 3.19b). The weathered edges of micas have long been implicated in high affinity Cs sorption, ours is the first observation that intragrain channels may be equally or more important structural regions for Cs retention. Cs adsorbed in the microchannels may become irreversibly bound as particles and become armored with $\mathrm{Al}$ and Si precipitates resulting from HLW-rock interaction. Field evidence suggests that this immobilization process is an important one beneath leaked HLW tanks. Current laboratory and spectroscopic studies are evaluating these phenomena.

Other research underway that is supported by the Hanford Science and Technology Program is determining the mineralogic amount of ${ }^{137} \mathrm{Cs}$ in contaminated sediments from beneath leaked singleshell, HLW tanks. The high radioactivity of these samples precludes their study in the EMSL. 

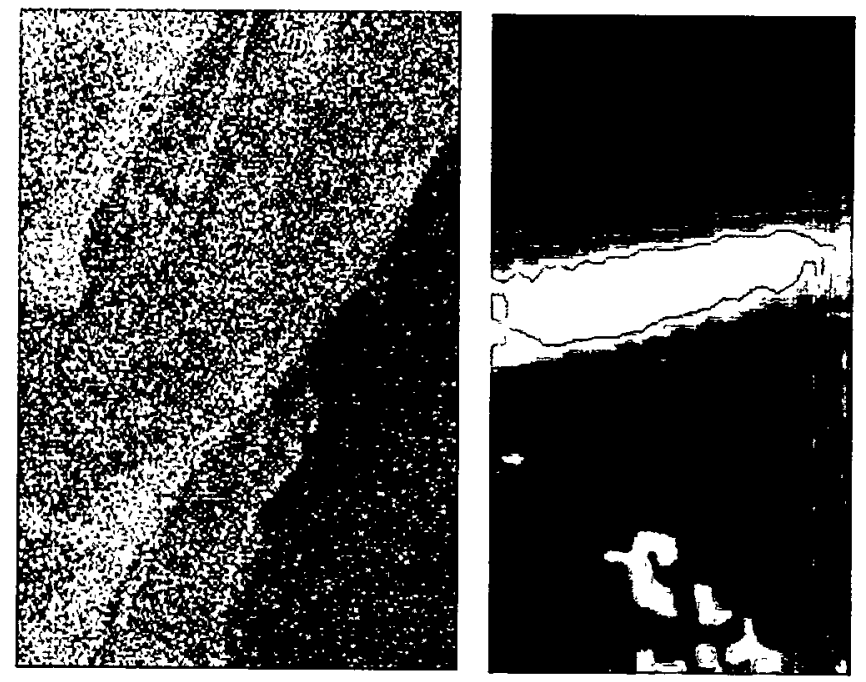

Figure 3.19. Adsorbed $\mathrm{Cs}^{+}$distribution maps for Hanford Site biotite exposed to a solution of $10^{-2} \mathrm{M}$ $\mathrm{Cs}$ for 3 months. The left image is by EMP analysis of a plan-view specimen (200 micrometers across) and the right is by $\mathrm{x}$-ray microprobe of a thin section (100 micrometers across). White intensity is proportional to $\mathrm{Cs}^{+}$concentration. $\mathrm{Cs}^{+}$is preferentially bound at platelet edges in plan-view (left image) and within internal, structural channels (right image). 


\section{Capability Reviews}




\section{Laser Photoacoustic}

\section{Spectroscopy: Basic}

\section{and Applied Research}

N. S. Foster-Mills,

J. E. Amonette, T. Autrey,

J. R. Small, ${ }^{(a)}$ Y. Chen, ${ }^{(b)}$ and

E. Small ${ }^{(b)}$

Supported by EMSL Operations, PNNL Laboratory Directed Research and

Development, National Science Foundation, and National Institutes of Health.

(a) Eastern Washington University.

(b) Quantum Northwest (Spokane).

Laser photoacoustic spectroscopy (LPAS) is a versatile and highly sensitive absorption-spectroscopic technique limited mainly by the absorptivity of the specimen and the availability of pulsed-laser light at a suitable wavelength. We are developing the technique because of the tremendous potential it has for nondestructive measurements of analytes in environmental samples at real-world concentrations. This report summarizes the ongoing collaborative research on LPAS in EMSL.

\section{Spectroscopic Fundamentals}

(Foster et al. 1998)

In the simplest terms, LPAS involves the absorption of light energy by a molecule and the subsequent detection of heat energy released by the molecule upon return to the ground state. The versatility of LPAS stems from the many processes that give rise to volumetric changes after photoexcitation of a sample. The sensitivity of LPAS arises from the inherently high efficiency of thermal conversion that occurs in most of these light-absorption processes coupled with a similar efficiency in the piezoelectric devices that convert the pressure wave into a voltage pulse. In addition to a laser, the essential elements of a laser photoacoustic detector consist of 1) a cell to hold the sample, 2) an ultrasonic transducer acoustically coupled to the cell to convert pressure to a voltage pulse, and 3) electronics for triggering data collection and for digitizing and storing the output from the transducer.

Table 4.1 summarizes six types of events that contribute to photoacoustic signal generation. No photoacoustic signal is possible without initial absorption of light by a molecule, $\mathrm{M}$, to generate an

Table 4.1. Summary of events contributing to photoacoustic signal generation.

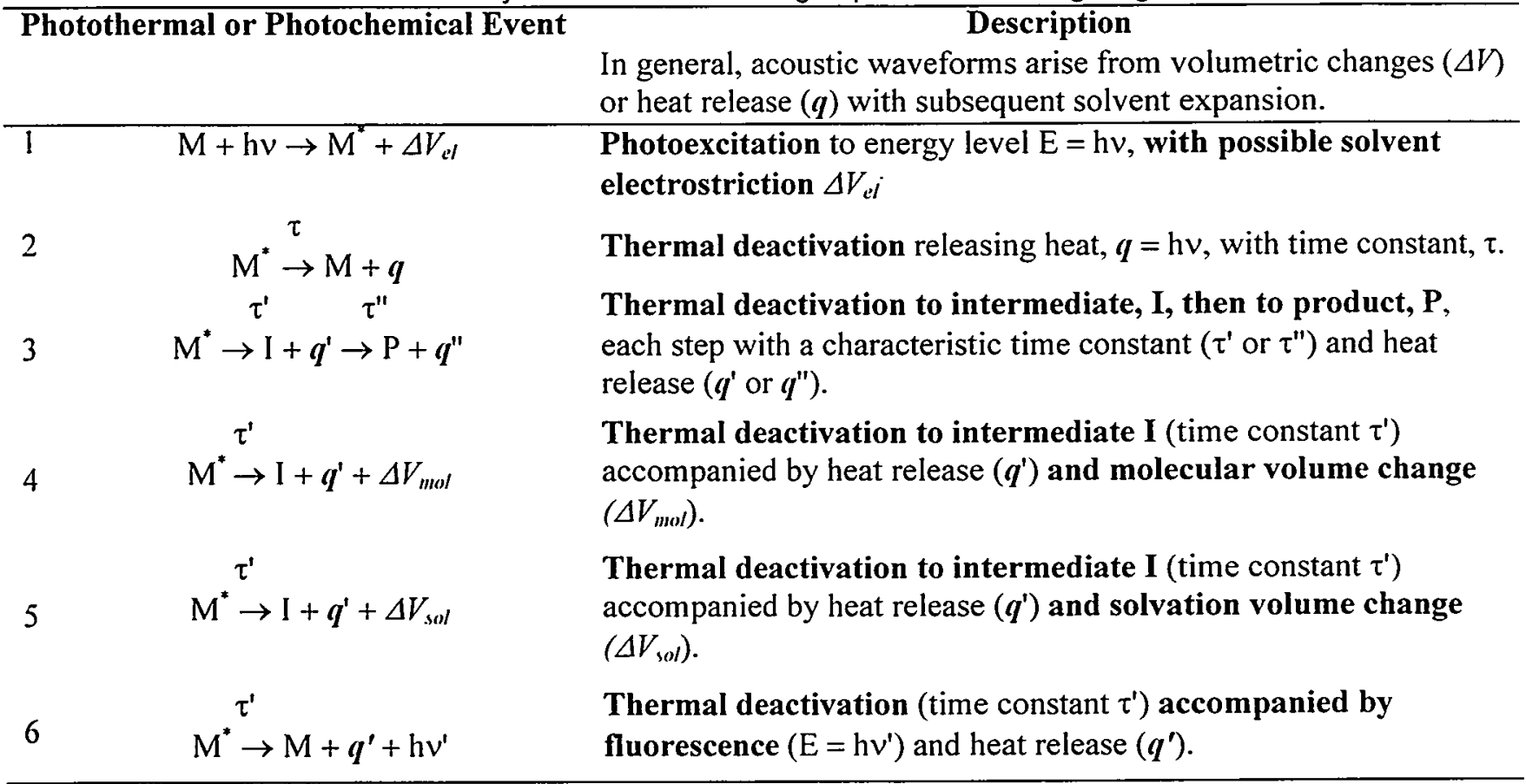


excited state $M^{*}$ (event 1 ). However, none of the subsequent events ( 2 through 6 ) requires photon absorption for photoacoustic detection, thus obviating the need for a chromophore in subsequent species. Instead, photoacoustic waveforms result from heat release (q, q', or q") and/or specific volumetric changes $\left(\zeta \mathrm{V}_{\mathrm{el}}, \zeta \mathrm{V}_{\text {mol }}\right.$, or $\left.\zeta \mathrm{V}_{\text {sol }}\right)$ occurring with associated time constants ( $\left.\hat{o}, \hat{o}^{\prime}, \hat{o}^{\prime \prime}\right)$. In fact, the heat release (q, $q^{\prime}$, or $\left.q^{\prime \prime}\right)$ is detected volumetrically, generally by solvent expansion in response to temperature increase.

Aqueous solutions offer a unique opportunity for studying the specific volumetric changes $\left(\zeta \mathrm{V}_{\text {mol }}\right.$ and $\zeta \mathrm{V}_{\text {sol }}$ ) in that a convenient temperature exists (around $4^{\circ} \mathrm{C}$ ) at which the thermal volumetric expansion coefficient for water is zero. At $\sim 4^{\circ} \mathrm{C}$ in aqueous solution, all heat-release processes ( $q, q^{\prime}$, or $\left.q^{\prime \prime}\right)$ become transparent, and molecular and/or solvation volumetric changes $\left(\zeta \mathrm{V}_{\text {mol }}\right.$ and $\left.\zeta \mathrm{V}_{\text {sol }}\right)$ can be studied in detail. The third specific volumetric change, solvent electrostriction $\left(\zeta \mathrm{V}_{\mathrm{el}}\right)$, is an artifact of the interaction of the laser light with solvent. occurring prominently with some photoacoustic cell geometries. Electrostriction is characterized by a unique waveform shape and is easily eliminated mathematically from subsequent data analysis.

The LPAS technique can be applied analytically to determine the concentration of an analyte in homogeneous or heterogeneous samples and/or changes in that concentration as a function of time, calorimetrically to measure such parameters as heats of formation of metastable intermediates and fluorescence quantum yields, kinetically to measure the rates of photo-induced reactions, and volumetrically to detect photon-induced expansions and contractions of light-absorbing molecules or ions and the solvent molecules that surround them.

\section{Nanoscale Quartz Capillary Photoacoustic Cell (Autrey et al. 1998a,b) \\ T. Autrey' and N. S. Foster-Mills}

A new photoacoustic cell was developed for use in on-line characterization situations where analysis of minute quantities of sample are desirable or necessary due to precious quantity, hazardous properties, or space constraints. This nano-scale time-resolved calorimetric experimental approach was developed using a photoacoustic cell made from narrow-bore flexible fused-silica capillary tubing and a layered prism cell (LPC). The fused silica capillary permits the transmission of an excitation source from the deep UV to the near infrared. The LPC is used to couple the excitation energy into the sample and to couple the acoustic signal to a piezoelectric detector.

Unlike conventional spectroscopic techniques, where the observed signal is proportional to the path length, the photoacoustic signal is proportional to the density of absorbed energy. The ability to measure a photoacoustic signal for minute sample volumes is due to the nature of the acoustic properties arising from the absorption of light and the detection of the transient pressure.

To demonstrate the unique capabilities of the fused silica capillary cell, the excited triplet state energy $\left(E_{1}\right)$ and lifetime $(\tau)$ of benzophenone in the presence and absence of a quencher was measured and results in agreement with literature values.

This nano-scale photoacoustic cell demonstrates the ability to obtain both kinetic and thermodynamic data with minute quantities of sample ( $100 \mathrm{~nL}$ volume). Not only does the narrow-bore flexible fused silica quartz capillary provide an experimental approach to investigate the kinetics and thermodynamics of reactive intermediates on a nano-scale, it may also provide the ability to perform high pressure photoacoustic experiments.

Potential applications include, for example, the health sciences for the characterization of specific constituents in blood (i.e., glucose, hemoglobin, or protein), industrial monitoring of lubricant breakdown or fuel oxidation, and detectors for capillary electrophoresis or supercritical fluid applications.

\section{Photoacoustic Evanescent-Wave Module \\ T. Autrey and N. S. Foster-Mills}

We have developed and characterized a novel total internal reflectance cell that relies on interactions between an evanescent light wave propagated at a solid surface and an absorbing analyte in solution or adsorbed to the surface to investigate dynamic properties at the solid/liquid interface (Figure 4.1). In conventional internal reflectance spectroscopy, attenuation of the incident light is measured after one 


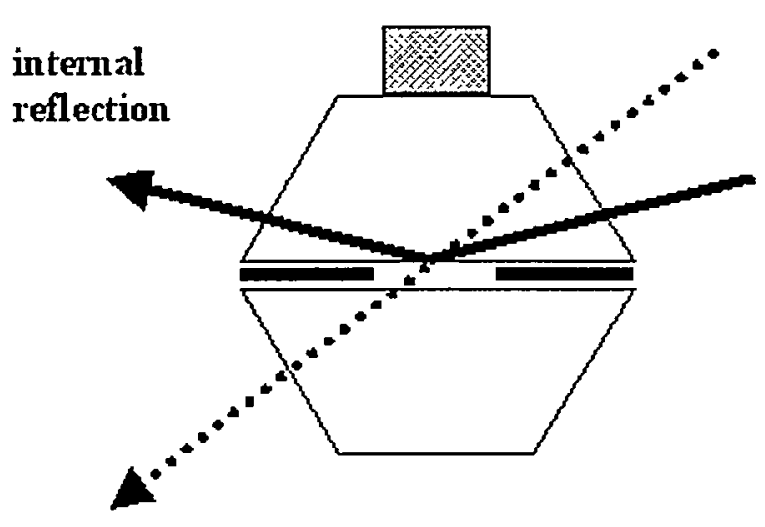

transmission

Figure 4.1. Illustration of TIR (interfacial properties) and transmission (bulk solvent properties) modes of the PEM.

or more internal reflections. In many instances a large number of reflections are required in order to detect the attenuation. That is, the conventional approach measures a small change in a large background signal. With our Photoacoustic Evanescent-Wave Module (PEM), a single reflection typically yields the experimental information. Single reflection data are possible because of the inherent sensitivity of the photoacoustic method that stems from the elimination of nearly all the background signal. Only those molecules that absorb the incident light yield a photoacoustic signal.

We have used the PEM to measure the kinetics, thermodynamics, and molecular volume conformational changes of meta-stable intermediates in aqueous media and organic solvents. For example, analysis of the absorption of an evanescent tail by benzophenone and a photoacoustic standard (OHB) in air saturated acetonitrile yields the energy of the meta-stable triplet excited state (lifetime ca. 160 nanoseconds, energy of the triplet $68+/-1 \mathrm{kcal} / \mathrm{mol}$ ).

These important results show that redox dynamics at an interface may be investigated with specially designed PEMs. The ability to measure thermochemical properties, rates of electron transfer processes, as well as solvation dynamics of the charge transfer complex will provide a powerful tool to investigate the fundamental properties of electron - transfer at a solid/liquid interface.

\section{Measurement of Absorbed, Scattered} and Emitted Light in Colloidal Silica Samples (Small et al. 1999)

J. R. Small, N. S. Foster-Mills, J. E. Amonette, and T. Autry

The absorption and scattering of light are the two principal components of the interaction of light with a variety of substances, from biological tissues, bacterial suspensions in fermenters and milk, to solgel materials, environmental water samples, and aerosols. In biomedical studies, quantitative measurement of light scattering and absorption will enhance our ability to image objects (such as tumors) in tissues. In the environmental arena, the same quantitative measurement of light scattering and absorption can be used to monitor the colloids, bacteria, algae, and other suspended particles in natural waters.

Ideally, a technique that is used to measure the interactions of light with turbid samples would have several desirable properties, including the complete separation of scattered light from absorbed light in the data presentation. Additionally, the technique would accurately measure true absorbance in the presence of scattering, and it would accurately measure kinetic phenomena (from ultrafast to very slow) using either the absorption or scattering data, or both. Finally, the technique would yield information about the scattering centers, for example, their concentration and size. While no technique yet fully accomplishes these ideals, we have explored the use of LPAS in fulfilling many of these properties.

Samples of Ludox ${ }^{\mathrm{TM}}$ colloidal silica, with and without added potassium chromate, were illuminated with pulses of 308 or $355-\mathrm{nm}$ light. The resulting oscilloscope tracing shows a pattern of signals originating from light scatter and light absorption that is consistent with experimental geometry and the speeds of light and sound (Figure 4.2), and linear with incident laser pulse energy. The absorbed light signals are independent of the distance of the laser beam from the transducer, while the scattered light signals are strongly distance-dependent. The absorbed light signals are more accurate in their determination of true sample absorbance than is a standard spectro photometer. Scattered light and fluorescent light behave very similarly in the LPAS technique. 


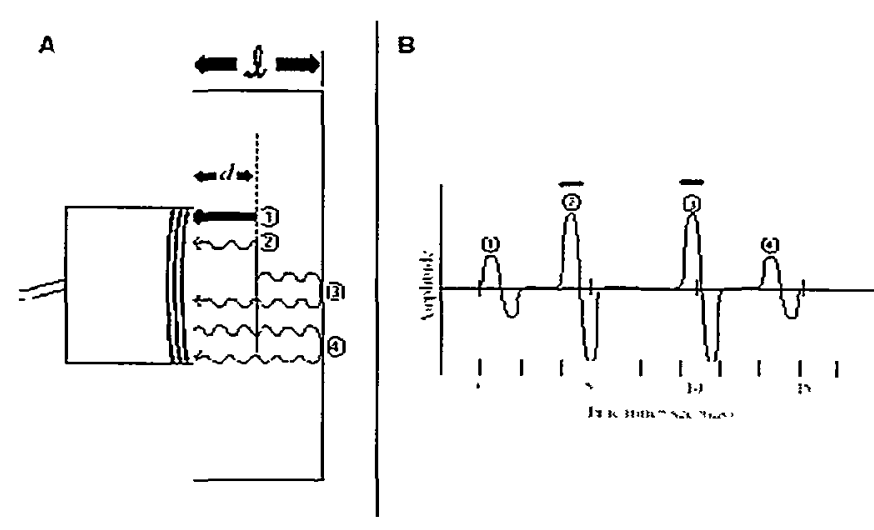

Figure 4.2. Origin and appearance of photoacoustic signals arising from the experimental geometry. In part $A, d$ is the distance of the laser beam from the cuvette wall and $f$ is the width of the cuvette. Processes (1)-(4) are (1) Scattered light (or emitted light) impinges on the transducer after traveling at the speed of light. Processes (2)-(4) involve waves traveling at the speed of sound. (2)-(3) Absorbed light energy is converted rapidly to heat, generating a solvent expansion and accompanying acoustic wave. In (2), the wave is directed toward the transducer; in (3), the wave is directed opposite to the transducer, and is reflected off the cuvette wall before traveling back toward the transducer. (4) The scattered (or emitted) light from (1) causes a pyroelectric effect in the transducer, generating an acoustic wave that travels across the cuvette, bounces off the side wall, and then travels back toward the cuvette. Processes (1)-(4) are summarized as responses to: (1) light; (2) heat \#1; (3) heat \#2; (4) light "echo." Part B shows the appearance of waveforms from processes (1)-(4) in a typical oscilloscope tracing of a photoacoustic experiment.

Our experiments were done with well-characterized colloidal silica samples, 7 to $22 \mathrm{~nm}$ in diameter, but the technique is readily extended to larger, more heterogeneous and photochemically complex biological and environmental samples.

\section{Competitive $\mathrm{Cr}(\mathrm{VI})$ Sorption on Hematite (Foster 1998) \\ J. E. Amonette and N. S. Foster-Mills}

We used LPAS to study the sorption of $\mathrm{Cr}(\mathrm{VI})$, a contaminant found in the groundwater at many $\mathrm{DOE}$ and industrial sites. on powdered hematite $\left(\alpha-\mathrm{Fe}_{2} \mathrm{O}_{3}\right)$, a common iron oxide mineral found in soils and sediments. when other competing oxyanions such as phosphate and sulfate were present. This work resulted in the development of a sorption model for phosphate and $\mathrm{Cr}(\mathrm{VI})$ competition based on the relative solution concentrations of the divalent anions and the acid dissociation constants of the monovalent anion species. The work is described in detail in a separate report in this volume.

\section{Protein Conformation Dynamics $Y$. Chen and E. Small}

How proteins fold into three-dimensional active structures is one of the fundamental questions of biology with important implications in a wide range of fields. For example, proteins are the final products of all DNA recombinant techniques. Often, these proteins cannot be made to be active, because we do not know enough about the natural processes that take a long string of amino acids and precisely fold it into the tertiary protein that has the desired activity. DNA recombinant techniques provide us with products ranging from pharmaceutical agents to industrial catalysts to proteins with activities useful for bioremediation useful for environmental cleanup. Understanding the processes of protein folding will be useful in all of these applications.

Currently, protein folding or unfolding is measured using stopped-flow technology, in which solutions of the protein are rapidly mixed with agents that affect protein conformation. However, stopped-flow methods have a "dead time" of a few milliseconds, before which no data may be obtained. During this dead time, about $50 \%$ of protein folding occurs for a typical protein. This $50 \%$ of the protein folding probably includes the most interesting events, because the fast events dictate the fidelity of the final product. Because of this deficiency in traditional methods, a few new techniques, including our approach, are under development to access these important fast events.

In our approach, we use a fast pulse of laser excitation to release chemically active groups and then monitor their binding to proteins and the subsequent conformational changes using acoustic detection of molecular volume changes. To date, we have used this method to monitor conformational changes induced by released protons and their binding to the polypeptides melittin, poly-L-lysine and poly-L-glutamate and to the protein pomyoglobin. In each case, we have been able to resolve kinetic events in the time range of 
$100 \mathrm{~ns}$ to 10 microseconds, some over 5 orders of magnitude faster than those observable with traditional approaches.

In experiments performed at EMSL, we used ultrafast, laser-induced $\mathrm{pH}$-jump experiments with timeresolved photoacoustic detection to investigate conformation transitions of the protein melittin. The $\mathrm{pH}$ jump was achieved by focusing the laser light on o-nitrobenzaldehyde in solution to release protons within the time-width of the laser pulse ( $<30 \mathrm{~ns}$ ). Protonation of the lysine moeities in melittin increases the repulsion between each unit of the protein and causes a change in the protein conformation (in this case, unfolding). Photoacoustic detection of the solution absorbance at $372 \mathrm{~nm}$ provided a means of monitoring the change in conformation. We observed a time constant of $200 \mathrm{~ns}$ with a negative volume change of $17 \mathrm{~mL} / \mathrm{mol}$ from photoacoustic measurements at different concentrations of melittin. The conformation transition was further confirmed in presence of salt where salt shifted the equilibrium transition at different $\mathrm{pHs}$. The negative volume change is consistent with the breaking of the hydrophobic core of melittin as it unfolds.

In addition, two new photoacoustic cells were designed, manufactured, and tested to facilitate the application of the technique in studying these biological processes. The new cells require much less solution than the normal cell but have better sensitivity.

\section{References}

Autrey, T., N. S. Foster, K. Klepzig, J. E. Amonette, and J. L. Daschbach, Rev. Sci. Instrum, 69, 2246-2258 (1998a).

Autrey, T., N. S. Foster, and K. Klepzig, J. Photochem Photobio. A, 125, 13-19 (1998b).

Foster, N. S., T. Autrey, J. E. Amonette, J. R. Small, and E. W. Small, American Laboratory, 31, 96S-108S (1998).

Small, J. R., N. S. Foster, J. E. Amonette, and S T. Autrey, App. Spect. 3(6), 735-740 (1999). 


\section{Mössbauer Spectroscopy}

\section{R. K. Kukkadapu and J. E. Amonette}

Mössbauer spectroscopy is a type of nuclear spectroscopy involving the resonant emission and absorption of $\gamma$-rays (i.e., the Mössbauer effect). This effect requires a "recoil-free" nuclear transition, i.e., a nuclear transition in which no net change in momentum is imparted to the nucleus. Secondly, the energy of the source photon must be exactly identical to the nuclear transition energy in the absorber. The probability for a recoil-free transition increases with the rigidity of the source and absorber (i.e., the sample being analyzed) and thus is highest for solids at low temperatures. In conventional instruments, the energy of the source photon is varied over a small range (tens of neV) using the Doppler effect. The source is repetitively accelerated through a range in velocities (from a few to hundreds of $\mathrm{mm} \mathrm{s}^{-1}$ ) to add or subtract energy to the photons being emitted. When a match in the energy of the source photon and the absorber transition energy is achieved, resonant absorption occurs. Because subsequent emission of the absorbed photon has no directional probability, in contrast to the source photon directed at the detector, a decrease in the intensity of the background signal is observed at the energies (velocities) where resonant absorption occurs, thus giving rise to a Mössbauer spectrum (Figure 4.3).

Although more than half the elements in the periodic table have isotopes exhibiting the Mössbauer effect, the ${ }^{57} \mathrm{Fe}$ isotope is the most favorable isotope for Mössbauer spectroscopy. This is because a) the recoil energy associated with absorption of the $\gamma$-ray of $14.41 \mathrm{keV}(\mathrm{I}=3 / 2$ to $\mathrm{I}=1 / 2$ transition $)$ is low, $b)$ the half-width of the resonant line is narrow $\left(3 \times 10^{-13}\right.$ times the energy of the $\gamma$-ray), and c) the natural abundance of ${ }^{57} \mathrm{Fe}$ is high $(2.14 \%)$. The main advantage of ${ }^{57} \mathrm{Fe}-\mathrm{Mössbauer}$ spectroscopy is that it is an Fe-specific technique with greater sensitivity than $x$-ray diffraction (XRD). For example, Fe oxidation states and local environments are identifiable for samples with Fe contents as low as $0.5 \mathrm{wt} \%$. The Mössbauer technique provides information on the valence state, coordination number, crystal field strengths [e.g.. low spin and high spin $\mathrm{Fe}(\mathrm{II})]$, and magnetic ordering temperatures. In contrast to XRD, amorphous materials). Common Fe-oxide phases it

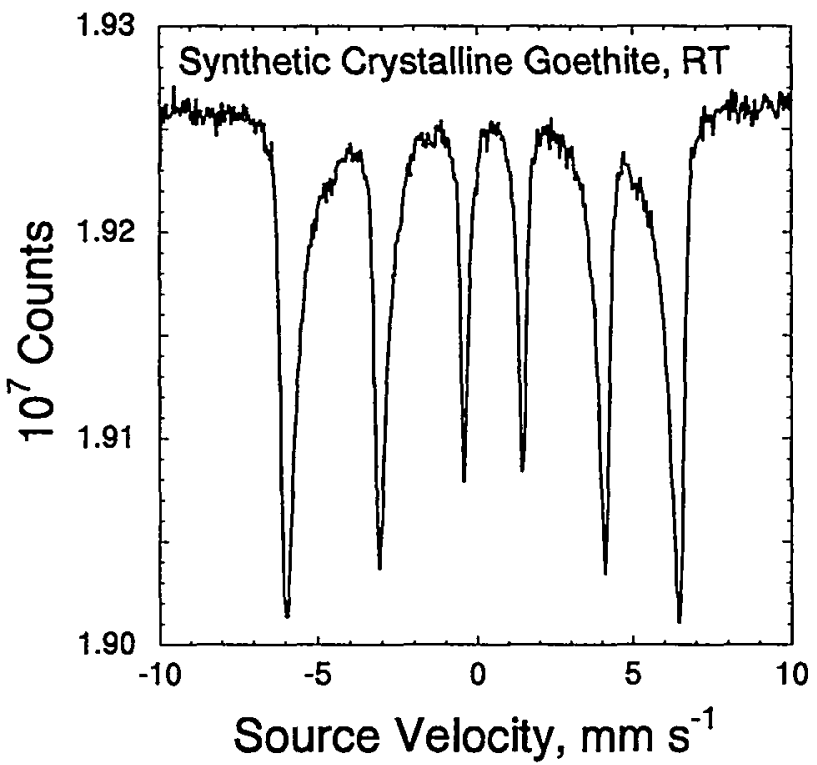

Figure 4.3. Conventional Mössbauer spectrum for a synthetic goethite ('-FeOOH).

also provides information on compounds that do not exhibit long-range order (poorly crystalline or such as magnetite and hematite, are readily distinguished from each other and from $\mathrm{Fe}$ in layer silicates and predominantly $\mathrm{Fe}$ (II) compounds. This versatile, highly sensitive, and nondestructive technique has a wide range of applications in various fields including geochemistry, soil science, and materials science.

The primary uses of ${ }^{57} \mathrm{Fe}-\mathrm{Mössbauer}$ spectroscopy at EMSL are to study mineralization associated with dissimilatory bacterial reduction of Fe(III)-oxides (Kukkadapu et al. 1999), to characterize natural and synthetic minerals, and to identify Fe-oxides in soils and sediments, catalysts, and Fe-doped glasses.

The Mössbauer spectroscopy laboratory at EMSL consists of two velocity transducers (a WissEL MVT-1000, and a Ranger Scientific MS-900A). The WissEL transducer is designed to allow simultaneous collection of data with two sources. Both room temperature and cryogenic temperature (ca. $2 \mathrm{~K}$ and above) measurements are carried out routinely. A Janis cryostat is employed for the low temperature measurements. The Ranger transducer is mostly used for room temperature measurements. The Wissell transducer can be configured to collect spectra for samples under an external magnetic field at field strengths $<12 \mathrm{~T}$ (Oxford Instruments SpectroMag 
$400010 / 12$ Tesla superconducting magnet). We are in the process of adding a third transducer for conversion-electron Mössbauer spectroscopy, which eliminates the high background of conventional transmission Mössbauer spectroscopy and offers high surface sensitivity. Although our focus is on ${ }^{57} \mathrm{Fe}$, a source is also available for ${ }^{151} \mathrm{Eu}$ Mössbauer spectroscopy.

In addition to the conventional Mössbauer capability here at EMSL, we also are experimenting with the synchrotron Mössbauer approach in collaboration with E. E. Alp at the Advanced Photon Source. This approach relies on pulsed monochromatic (bandwidth ca. $0.8 \mathrm{meV}$ ) $\mathrm{x}$-rays as an excitational source, monitors the intensity of the Mössbauer resonance in the time domain rather than in the energy domain, eliminates the high background associated with the conventional approach to maximize signal-to-noise, and thereby allows collection of complete Mössbauer spectra in periods of seconds or minutes rather than hours or days. Using ${ }^{57} \mathrm{Fe}$-enriched samples, we have demonstrated the potential of the technique for kinetic studies of $\mathrm{Fe}$ redox reactions in solids (Amonette 1998; Amonette et al. 1998).

\section{References}

Amonette, J. E., Labor. Dir. Res. Devel. Ann. Rpt., FY 1997, PNNL-1 1860/UC-400, 236 (1998).

Amonette, J. E., R. K. Kukkadapu, and E. E. Alp,

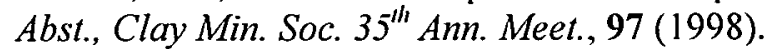

Kukkadapu, R. K., J. M. Zachara, and S. C. Smith, Abstr., Intern. Conf. Applic. Mössbauer Effect 99, T6/24 (1999). 
Commissioning and Initial Results from the PNC-CAT Insertion Device Beamline at the Advanced Photon Source

S. M. Heald, D. L. Brewe, ${ }^{(a)}$

J. O. Cross, ${ }^{(a)}$ E. D. Crozier, ${ }^{(b)}$

D. Jiang, ${ }^{(b)}$ and E. A. Stern ${ }^{(a)}$

Supported by DOE-BES. DOE-EM, NSF, and NSERC-Canada.

(a) University of Washington.

(b) Simon Fraser University.

The Pacific Northwest Consortium-Collaborative Access Team (PNC-CAT) is a consortium of Northwest institutions formed to construct and operate $x$-ray beamlines at the Advanced Photon Source. The lead institutions of the consortium are the University of Washington, Simon Fraser University in Canada, and PNNL. The PNC-CAT is constructing two beamlines at the Advanced Photon Source: one based on a high brilliance undulator-based insertion device source, and the other on a bending magnet source. The insertion device line is nearing completion and will be fully operational in early 2000 . Even in this commissioning stage, useful data can be obtained and a number of CAT members have used the line for initial experiments. The bending magnet line is under construction and will be fully operational in early 2001. Since the bending magnet source is of lower brilliance, the bending magnet line will service simpler "bulk" type samples with typical dimensions of $0.1-1 \mathrm{~mm}$, while the insertion device line can provide sub-micron capabilities. Otherwise the capabilities of the two beamlines will be similar. Both will eventually offer a full range of spectroscopic and diffraction based $x$-ray methods, and will have available a wide range of support equipment, including ultrahigh vacuum (UHV)/molecular-beam epitaxy (MBE) chambers, 4 and 8-circle diffractometers, a high power laser for time-resolved studies, fluorescence detectors, sample scanning stages, and low temperature capability. The rest of this report will describe the status and initial results for the insertion device line.

The insertion device line utilizes a liquid nitrogen cooled monochromator with rapidly exchangeable $\mathrm{Si}$ (111) and Si (311) monochromator crystals. This combination covers the energy range of $3-57 \mathrm{keV}$.
After some shakedown tests, it is now working well for the most demanding spectroscopy measurements. With a soon-to-be-installed focusing mirror, the full beam (approximately $10^{13}$ photons $/ \mathrm{sec}$ ) can be focused to less than $500 \mu \mathrm{m}$ at any position in two experimental enclosures. Additional focusing options are provided by Kirkpatrick-Baez (K-B) mirrors and tapered capillary concentrators. Two K-B mirror systems provide focusing to 1 and $3 \mu \mathrm{m}$ respectively, and flux densities better than $10^{11} \mathrm{ph} / \mathrm{sec} / \mu \mathrm{m}^{2}$. Submicron beams can be generated with the tapered capillaries. Currently 0.5 and $0.7 \mu \mathrm{m}$ capillaries are available, with smaller sizes possible in the future. While delivering smaller beams, the capillaries have two disadvantages: the sample must be within about $100 \mu \mathrm{m}$ of the capillary tip, and the energy dependence of their transmission generally precludes extended $x$-ray absorption fine structure (EXAFS) measurements (near edge measurements are still possible). Both the K-B mirrors and capillaries can be combined with fluorescence detectors for trace element imaging of elements with $Z>15$. The fluorescence detectors include high count-rate single and 13-element $\mathrm{Ge}$ detectors, and a high resolution Rowland circle spectrometer. Figure $4.4 \mathrm{a}$ shows an example of the type of elemental mapping that can be done using a $\mathrm{Ge}$ detector and the K-B mirror setup. After identifying interesting regions in the image, spectroscopic information can be obtained as also shown in Figure 4.4. Both sets of data were taken with a single detector. A recently commissioned 13-element detector will increase the data rate 13 times.

Common to both lines is the capability for micronscale tomography using the absorption or phase contrast signal. Labview-based acquisition and analysis software for the tomography is in final stages of development, and tomography will soon be available to CAT members. Figure 4.5 shows some examples of tomographic reconstructions using data from the insertion device line. These are 2-D slices from a full 3-D reconstruction.

A portable UHV/MBE system can be used for surface $x$-ray absorption fine structure (XAFS), reflectivity, and standing wave experiments on either beamline. It allows in situ sample preparation and characterization using standard surface science tools such a reflection high energy electron diffraction (RHEED) and 

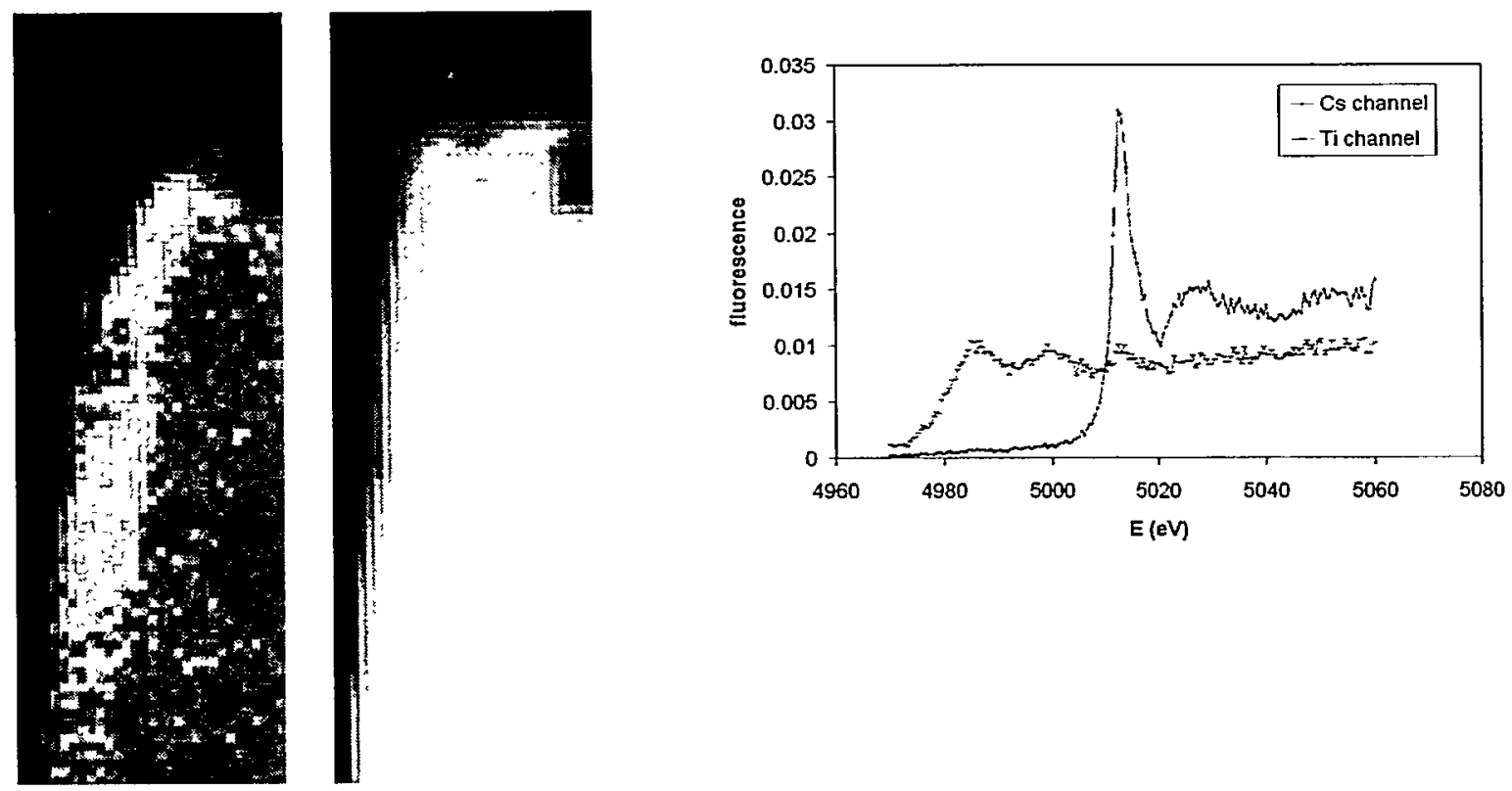

Figure 4.4. Images of the $\mathrm{Cs}$ (left) and $\mathrm{Fe}$ (center) content in a weathered biotite mica flake from the Hanford Site. The Fe gives the overall shape of the flake. The image size is $40 \times 180$ microns, with 1-micron pixels. The $\mathrm{Cs}$ is a result of a several month exposure to a dilute solution in the lab to determine the nature of Cs entrapment in natural Hanford minerals. Near edge spectroscopy from a similar sample in the region of the Ti Kand Cs $\mathrm{L}_{3}$ edge energies. These were recorded simultaneously using the resolving power of a Ge detector.
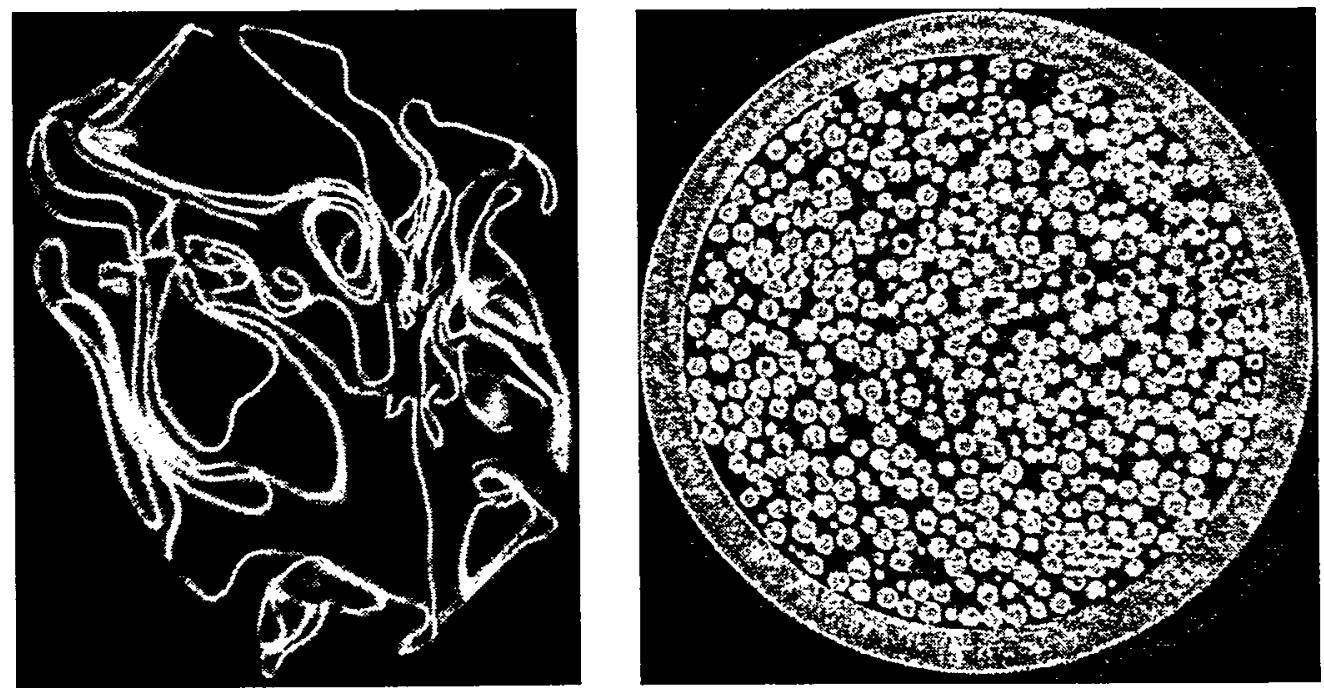

Figure 4.5. Two examples of slices from tomographic reconstructions. The left figure is for crumpled Al foil. Image size is $2.5-\mathrm{mm}$ square. On the right is a slice through a $1.5-\mathrm{mm}$ tube containing 60 -micron glass beads.

Auger spectroscopy. Initial experiments have concentrated on MBE grown Fe films on GaAs. Layer-by-layer single crystal growth has been demonstrated along with EXAFS and x-ray standing wave measurements. In the future such films will be studied with $\mathrm{x}$-ray magnetic circular dichroism (XMCD). A diamond wave plate has been commissioned that allows precise control of the polarization of the insertion device beam for polarization dependent studies and XMCD. 


\section{Appendix}




\section{Environmental Dynamics and Simulation Staff}

\section{Associate Director}

John M. Zachara

(509) 376-3254

john.zachara@pnl.gov

Ph.D. Washington State University 1986; Associ-

ate Director of the Environmental Dynamics and

Simulation Directorate. Research interests: geochemical behavior of metals, radionuclides complexed by organic ligands and on the influence of subsurface microbial processes on mineral surface chemistry and reactivity in groundwater.

\section{Staff}

James E. Amonette

(509) 376-5565

jim.amonette@pnl.gov

B.S. New Mexico State University 1979; M.S. Iowa State University 1983; Ph.D. Iowa State University 1988; joined PNNL as Senior Research Scientist in 1986. Research interests: influence of redox and structural properties of clay and oxide mineral surfaces on environmental chemistry associated with contaminant degradation/mobility and $C$ sequestration. Research techniques include laser photoacoustic, Mössbauer, infrared, and electron-paramagnetic resonance spectroscopy; synchrotron $\mathrm{x}$-ray and phase-contrast interferometric microscopy; quantitative wet-chemical analysis of Fe redox states.

Eric J. Bylaska

(509) 376-9114

eric.bylaska@pnl.gov

Ph.D. University of California San Diego 1998; joined PNNL as a Research Scientist in 1998. Projects include implementing a first principles molecular dynamics code into the NWChem program package, applying first principle to the degradation of volatile organic compounds in the subsurface, the study of aqueous ions, and the formation of polynuclear silica species in highbase solutions.
Andrew R. Felmy

(509) 376-4079

arfelmy@pnl.gov

B.S. Pennsylvania State University 1977; M.S.

University of Washington 1981; Ph.D. University

of California San Diego 1988. Research interests:

thermodynamics of aqueous electrolytes, development of geochemical models, and thermodynamics of surface, actinide chemistry, and complexation reactions.

Nancy S. Foster-Mills

(509) 376-1343

nancy.foster@pnl.gov

B.S. Purdue University 1989; Ph.D. University of Colorado 1994; Postdoctorate Research Associate, New Mexico State University 1994-1995;

Postdoctorate Research Fellow, PNNL, 1995-1998. Joined PNNL as a Research Scientist in 1998. Research interests: laser photoacoustic spectroscopy, environmental remediation technologies, semiconductor photocatalysis.

Paul L. Gasssman

(509) 376-7972

pl.gassman@pnl.gov

B.S. Geology Virginia Polytechnic Institute and S.U. 1983; M.S. Soil Mineralogy and Soil Chemistry Virginia Polytechnic Institute and S.U. 1990. Joined PNNL as a Senior Technical Specialist in 1990. Research interests: fluorescence spectroscopy of lanthanides, infrared spectroscopy of siderophores, mineral syntheses for biogeochemical studies, mineralogical characterization.

Steven M. Heald

(630) 252-9795

Steve.Heald@pnl.gov

B.S. Physics, University of Washington 1972;

Ph.D. Physics, University of Illinois 1976;

Research Associate, University of Washington, 1976-1979; Assistant Physicist, 1979-1981, Associate Physicist, 1981-1983, Physicist, 19831993, (received tenure 1993), Brookhaven National Laboratory; Senior Scientist, PNNL, 1993-present. Research interests: x-ray spectroscopy and imaging, $x$-ray studies of surfaces, synchrotron radiation instrumentation. 
Ravi Kukkadapu

(509) 376-3795

Ravi.Kukkadapu@pnl.gov

Ph.D. Indian Institute of Chemical Technology

1987; Robert R. Welch Foundation Postdoctorate

Fellow, University of Houston 1988-1991;

Research Associate, Michigan State University 1991-1995, Postdoctorate Research Fellow, PNNL, 1995-1998; joined PNNL in 1998 as a Research Scientist. Research interests: electron paramagnetic resonance, Mössbauer spectroscopy, iron oxides, environmental remediation.

Marvin Mason

(509) 376-5022

marvin.mason@pnl.gov

Kevin M. Rosso

(509) 376-7762

Kevin.Rosso@pnl.gov

B.S. Geological Sciences California State

Polytechnic University at Pomona 1992; M.S.

Geochemistry Virginia Polytechnic Institute and

State University 1996: Ph.D. Geochemistry

Virginia Polytechnic Institute and State University

1998. Joined PNNL in 1998 as a Research

Scientist. Research interests: elucidating the relationships between the atomic and electronic structure of earth materials with their reactivity and physical properties, particularly on surfaces, using various aspects of surface science, chemistry, solid state physics, mineralogy, and crystal chemistry; scanning tunneling microscopy and spectroscopy in UHV and ambient environments; the application of molecular modeling approaches to mineral surface chemistry.

Colleen K. Russell

(509) 376-8386

colleen.russell@pnl.gov

B.S. Reproductive Physiology Washington State

University Pullman 1978; B.S. Biology Eastern

Washington University Cheney 1986; B.A.

Secondary Education 4-12 Eastern Washington

University Cheney 1986. Staff member School of

Veterinary Medicine, Washington State

University. Micro-Pathology 1978-1983. Joined

PNNL 1987-1989, Field Biologist. Joined

Environmental Characterization and Risk

Assessment group 1989. Joined Environmental

Dynamics and Simulation group 1999.
James R. Rustad

(509) 376-3979

jim.rustad@.pnl.gov

Ph.D. University of Minnesota 1992. Research interests: theoretical interfacial and aqueous geochemistry.

Steven C. Smith

(509) 372-1226

steven.smith@.pnl.gov

B.S. Soils Washington State University 1979;

M.S. Soils Washington State University 1983;

Agricultural Research Technologist Washington

State University, 1982-1986; Senior Science and

Engineering Associate, PNNL, 1986-Present;

Adjunct Lecturer Washington State University,

1981-Present. Research interests: biogeochemistry of iron, physicochemical sorption mechanisms of chemical contaminants to geomaterials.

Zheming Wang

(509) 376-6119

zheming.wang@pnl.gov

B.S. Northwestern Normal University, China, 1982; Ph.D. Florida State University 1994; Postdoctoral Research Fellow, PNNL, 1995-1998; joined PNNL in 1998 as a Research Scientist. Research interests: technical development and application of laser fluorescence spectroscopy and scanning probe microscopy in contaminant transport, environmental remediation and nanoscience.

Tom W. Wietsma

(509) 376-6588

wietsma@.pnl.gov

B.S. Chemistry and Geology Calvin College 1992. Joined PNNL in 1993.

\section{Office Operations}

Kimberly Ballinger

Jamie Benward

Sonia Enloe

Linda Liikala

Joy Rosscup 


\section{Matrixed Staff}

Jim Fredrickson

Yuri Gorby

Ellyn Murphy

Steve Yabusaki

\section{Postdoctoral Fellows}

\section{Sreenivas Kota}

(509) 376-9326

Sreenivas.Kota@pnl.gov

B.E. Civil Engineering Osmania University India 1991; M.S. Civil Engineering University of

New Mexico 1993; Ph.D. Civil Engineering North

Carolina State University 1998; Postdoctoral

Research Fellow, PNNL, 1998-present. Research interests: biodegradation of hazardous contaminants, methods for evaluating in situ bioremediation, microbial ecology in contaminated subsurface environments, and innovative aquifer remediation technologies.

Chongxuan Liu

(509) 376-0129

Chongxuan.Liu@pnl.gov

B.S. Geology Zhejiang University P.R. China 1982; M.S.E. Hydrogeology in Hydro-

Geochemistry Zhejiang University P.R. China

1984; M.S. Geology in Aqueous Low-

Temperature Geochemistry University of
Alabama 1994; Ph.D. Environmental Engineering and Chemistry Johns Hopkins University 1998; Engineer at Zhejiang Hydropower Design Institute, China 1984-1988; Lecturer in Ningbo Oceanography Institute, China 1988-1992;

Postdoctorate Research Fellow at PNNL 1998present. Research interests: fate and transport of solutes and contaminants in subsurface environments, and biogeochemistry of metal reduction.

\section{Students}

Mike Beversluis

Mike Nicholas

AnnaJo Isbelle

Staci Hemmer

Brian William

Mark McKinely 


\section{Publications and Presentations 1999}

\section{Publications}

J. E. Amonette, F. A. Khan, H. Gan, J. W. Stucki, and A. D. Scott, "Comparison of Oxidimetric, Spectrophotometric, and Mössbauer-Spectroscopic Methods for Determination of Fe(II) in Nonrefractory Minerals," Proc. 1 th Int. Clay Conf., Ottawa, Canada, Can. J. Soil Sci. 277-286 (1999).

T. Autrey and N. S. Foster, "Nanojoules, Nanoliters, and Nanosecond Calorimetry; A Nanoscale Quartz Capillary Photoacoustic Cell for Time-Resolved Calorimetric Investigations," J. Photochem. Photobio. A Chem. 125, 13-19 (1999).

T. Autrey and N. Foster-Mills, "Experimental Approaches to Measure the Chemical and Physical Properties of Radical Intermediates; Time-Resolved Photoacoustic Calorimetry with the Layered Prism Cell," American Chemical Society, Division of Fuel Chemistry, Preprints of Symposia, 44(3), pp. 444-447, 218 th ACS National Meeting, New Orleans, Louisiana, August 22-26, 1999.

G. E. Brown, V. E. Henrich, W. H. Casey, D. L. Clark, C. Eggleston. A. R. Felmy, D. W. Goodman, M. Gratzel, G. Maciel, M. I. McCarthy. K. Nealson, D. A. Sverjensky. M. F. Toney, and J. M. Zachara, "Chemical Interactions at Metal Oxide-Aqueous Solution Interfaces," Chem. Rev. 99, 77-174 (1999).

E. J. Bylaska, J. H. Weare, and R. Kawai, "Development of Bond-Length Alternation in Very Large Carbon Rings: LDA Pseudopotential Results," Phys. Rev. B, Rapid Communications 58, R7488 (1998).

A. R. Felmy and D. Rai, "Application of Pitzer's Equations for Modeling the Aqueous Thermodynamics of Actinide Species: A Review," J. Soln. Chem. 28, 533-553 (1999).

N. S. Foster, J. E. Amonette, and S. T. Autrey, "In Situ Detection of Chromate Using Photoacoustic Spectroscopy," Applied Spectroscopy 53, 735-740 (1999).
N. S. Foster, T. Autrey, J. E. Amonette, J. R. Small, and E. W. Small, "Laser Photoacoustic Spectroscopy: A Versatile Absorption-Spectroscopic Technique," American Laboratory 31, 96S-108S (1999).

J. K. Fredrickson, D. W. Kennedy, S. C. Smith, C. C. Ainsworth, and J. M. Zachara, Microbial Reductive Dissolution and Solubilization of Geothite (FeOOH) with Co-Precipitated Cobalt or Sorbed Lead, PNNL-11827, Pacific Northwest National Laboratory, Richland, Washington (1998).

J. K. Fredrickson, J. M. Zachara, D. W. Kennedy, H. Dong, T. C. Onstott, N. W. Hinman, and S.-M. Li, "Biogenic Iron Mineralization Accompanying the Dissimilatory Reduction of Hydrous Ferric Oxide by a Groundwater Bacterium," Geochim. Cosmochim. Acta 62, 3239-3257 (1998).

D. M. Friedrich, Z. Wang, A. G. Joly, K. A. Peterson, and P. R. Callis, "The Ground State Proton-Transfer Tautomer of Salicylate Anion," J. Phys. Chem. A 103, 9644-9653 (1999).

G. V. Gibbs, K. M. Rosso, D. M. Teter, M. B. Boisen, and M. S. T. Bukowinski, "Model Structures and Properties of the Electron Density Distribution for Low Quartz at Pressure: A Study of the SiO Bond," J. Mol. Struct. 486, 13-25 (1999).

J. D. Istok, J. E. Amonette, C. R. Cole, J. S. Fruchter, M. D. Humphrey, J. E. Szecsody, S. S. Teel, V. R. Vermeul, M. D. Williams, and S. B. Yabusaki, "In Situ Redox Manipulation by Dithionite Injection: Intermediate-Scale Laboratory Experiments," Ground Water 37, 884-889 (1999).

J. T. Kloprogge, S. Komarneni, and J. E. Amonette, "Synthesis of Smectite Clay Minerals: A Critical Review," Clays Clay Miner 47, 529-554 (1999).

C. Liu and W. P. Ball, "Application of Inverse Methods to Contaminant Source Identification from Aquifer Diffusion Profiles at Dover AFB, Delaware," Water Resources Research 35, 1975-1985 (1999).

R. S. Maxwell, R. K. Kukkadapu, J. E. Amonette, and H. Cho, ${ }^{2} \mathrm{H}$ Solid-State NMR Investigation of Terephthalate Dynamics and Orientation in Mixedanion Hydrotalcite-like Compounds," J. Phys. Chem. 103, 5197-5203 (1999). 
M. McCarroll, A. G. Joly, Z. Wang, D. M. Friedrich, and V. Wandruszka, "Time-Resolved Fluorescence Anisotropies in Mixed Surfactant Solutions," J. Colloid \& Interface Sci. 218, 260-264 (1999).

N. T. Nelson, M. Oostrom, M. L. Brusseau, and T. W. Wietsma, "The Partitioning Tracer Method for In situ Measurement of DNAPL Saturation: Influence of Heterogeneity and Sampling Method," Environ. Sci. Tech. 33, 4046-4053 (1999).

N. T. Nelson, M. Oostrom, T. W. Wietsma, and M. L. Brusseau, "An Experimental Investigation of the Partitioning Tracer Method to Detect and Quantify Dense Nonaqueous Phase Liquids in a Heterogeneous System," Proceedings of the 19th American Geophysical Union Hydrology Days, H. J. Morel-Seytoux, ed., pp. 307-318, Hydrology Days Pub., Atherton, California (1999).

D. Rai, A. R. Felmy, N. J. Hess, D. A. Moore, and M. Yui, "A Thermodynamic Model for the Solubility of $\mathrm{UO}_{2}(\mathrm{am})$ in the Aqueous $\mathrm{K}-\mathrm{Na}-\mathrm{HCO}_{3}-\mathrm{CO}_{3}-\mathrm{OH}-$ $\mathrm{H}_{2} \mathrm{O}$ System," Radiochim. Acta 82, 17-25 (1998).

D. Rai, N. J. Hess, A. R. Felmy, D. A. Moore, and M. Yui, "A Thermodynamic Model for the Solubility of $\mathrm{NpO}_{2}(\mathrm{am})$ in the Aqueous $\mathrm{K}^{+}-\mathrm{HCO}_{3}-\mathrm{CO}_{3}{ }^{2}-\mathrm{OH}^{-}-$ $\mathrm{H}_{2} \mathrm{O}$ System," Radiochim. Acta 84, 159-169 (1999).

K. M. Rosso, U. Becker, and M. F. Hochella, Jr., -Atomically Resolved Electronic Structure of Pyrite [100] Surfaces: An Experimental and Theoretical Investigation with Implications for Reactivity," Amer. Mineralogist 84, 1535-1548, (1999).

K. M. Rosso, U. Becker, and M. F. Hochella, Jr., "The interaction of pyrite [100] surfaces with $\mathrm{O}_{2}$ and $\mathrm{H}_{2} \mathrm{O}$ : Fundamental Oxidation Mechanisms," Amer.

Mineralogist 84, 1549-1561 (1999).

K. M. Rosso and M. F. Hochella, Jr., "A UHV STM/STS and Ab Initio Investigation of Covellite (001) Surfaces," Surf. Sci. 423, 364-374 (1999).

K. M. Rosso, G. V. Gibbs, and M. B. Boisen, "SiO Bonded Interactions in Coesite: A Comparison of Crystalline, Molecular, and Experimental Electron Density Distributions," Phys. Chem. Min. 26, 264-272 (1999).
J. R. Rustad, D. A. Dixon, and A. R. Felmy, "Trivalent Ion Hydrolysis Reactions: A Linear Free Energy Relationship Based on Density Functional Electronic Structure Calculations," J. Am. Chem. Soc. 121, 3234 (1999).

J. R. Rustad, D. A. Dixon, K. M. Rosso, and A. R. Felmy, "Trivalent Ion Hydrolysis Reactions: A Linear Free-Energy Relationship Based on Density Functional Electronic Structure Calculations," J. Am. Chem. Soc. 121, 3234-3235 (1999).

J. R. Rustad, E. Wasserman, and A. R. Felmy, “A Molecular Dynamics Investigation of Surface Reconstruction on Magnetite (001)," Surface Science 432, L583 (1999).

J. R. Rustad, E. Wasserman, and A. R. Felmy, "Molecular Modeling of the Surface Charging of Hematite. II. Optimal Proton Distribution and Simulation of Surface Charge Versus pH Relationships," Surface Science 424, 28 (1999).

M. H. Schroth, M. Oostrom, T. W. Wietsma, and J. D. Istok, "In-situ Oxidation of Liquid Trichloroethylene by Permanganate Solutions: Preliminary Results of Iolumn Studies," Proceedings of the 19th American Geophysical Union Hydrology Days, H. J. MorelSeytoux, ed., pp. 411-420. Hydrology Days Pub., Atherton, California (1999).

E. C. Thornton and J. E. Amonette, "Hydrogen Sulfide Gas Treatment of Cr(VI)-Contaminated Sediment Samples from a Plating-Waste Disposal Site-Implications for In-Situ Remediation," Environ. Sci. Technol. 33, 4096-4101 (1999).

M. M. Urrutia, E. E. Roden, and J. M. Zachara, "Influence of Aqueous and Solid-Phase Fe(II) Complexants on Microbial Reduction of Crystalline Fe(III) Oxides," Environ. Sci. Tech. 33, 4022-4028 (1999).

Z. Wang, L. J. van de Burgt, and G. R. Choppin, "Spectroscopic Study of Lanthanide (III) Complexes with Carboxylic Acids," Inorg. Chim Acta 293, 167 177 (1999). 
E. Wasserman, J. R. Rustad, and A. R. Felmy, "Molecular Modeling of the Surface Charging of Hematite. I. The Calculation of Proton Affinities and Acidities on a Periodic Surface," Surface Science 424, 19-27 (1999).

J. M. Zachara, J. K. Fredrickson, S. Li, D. Kennedy, S. C. Smith, and P. L. Gassman, "Bacterial Reduction of Crystalline Fe(III) Oxides in Single Phase Suspensions and Subsurface Materials," Amer. Mineralogist 83, 1426-1443, (1998).

\section{In Press}

E. J. Bylaska, D. A. Dixon, and A. R. Felmy, "The Free Energies of Reactions of Chlorinated Methanes with Aqueous Monovalent Anions: Application of ab initio Electronic Structure Theory," J. Phys. Chem. A, in press.

H. Dong. J. Fredrickson, D. W. Kennedy, J. M. Zachara, R. K. Kukkadapu. and T. C. Onstott, "Mineral Transformations Associated with the Microbial Reduction of Magnetite," Chemical Geology, in press.

S. H. Elder, F. M. Cot, Y. Gao, S. M. Heald, Y. Su, A. C. Kolwaite, M. L. Balmer, M. K. Bowman, K. A. Magrini, and D. M. Blake, "Interfacially Driven Bandgap Energy Tuning in Nanocrystalline $\mathrm{TiO}_{2}-$ $\left(\mathrm{MoO}_{3}\right)$ Core-Shell Materials," J. Am. Chem. Soc., in press.

A. R. Felmy, D. A. Dixon, Z. Wang, A. G. Joly, J. R. Rustad, and M. J. Mason, "The Aqueous Complexation of Eu(III) with Organic Chelates at High Base Concentration: Molecular and Thermodynamic Modeling Results," ACS Symposium Series, in press.

J. K. Fredrickson. J. M. Zachara, D. W. Kennedy, M. C. Duff. Y. A. Gorby, S. W. Li, and K. M. Krupka, "Reduction of U(VI) in Goethite (a-FeOOH)

Suspensions by a Dissimilatory Metal-Reducing Bacterium." Geochim. Cosmochim. Acta, in press.

M. A. Hoffman, J. G. Darab, S. M. Heald, C. R. Yonker, and J. L. Fulton, "New Experimental Developments for In-situ XAFS Studies of Chemical Reactions under Hydrothermal Conditions," Chemical Geology, in press.
C. Liu, J. E. Szecsody, J. M. Zachara, and W. P. Ball, "Use of the Generalized Integral Transformation Method for Solving Equations of Solute Transport in Porous Media," Advances in Water Resources, in press.

M. I. Lubin, E. J. Bylaska, and J. H. Weare, "Ab Initio Molecular Dynamics Simulations of Aluminum Solvation," Chem. Phys. Lett., in press.

C. S. Oakes, A. R. Felmy, and S. M. Sterner, "Thermodynamic Properties of Aqueous Calcium Nitrate $\left[\mathrm{Ca}\left(\mathrm{NO}_{3}\right)_{2}\right]$ to the Temperature of $373 \mathrm{~K}$ Including New Enthalpy of Dilution Data," J. Chem. Thermodynamics, in press.

D. Rai, N. J. Hess, A. R. Felmy, D. A. Moore, and M. Yui, "A Thermodynamic Model for the Solubility of $\mathrm{PuO}_{2}(\mathrm{am})$ in the Aqueous $\mathrm{K}^{+}-\mathrm{HCO}_{3}{ }^{-}-\mathrm{CO}_{3}{ }^{2}-\mathrm{OH}^{-}-$ $\mathrm{H}_{2} \mathrm{O}$ System," Radiochim. Acta, in press.

J. R. Rustad and D. A. Dixon, "Computational studies of mineral-water interfaces," Molecular Modeling of Clay Minerals, Clay Mineral Society, Washington D.C., in press.

J. R. Rustad, D. A. Dixon, and A. R. Felmy, "Intrinsic Acidity of Aluminum, Chromium(III) and Iron(III) $\mu_{3}$ Hydroxo Functional Groups Via Density Functional Theory," Geochim. Cosmochim. Acta, in press.

J. R. Rustad and K. M. Rosso, "Equation of State of Diaspore (-AlOOH) Calculated from Planewave Pseudopotential Methods," Solid State Communications (submitted).

J. R. Rustad and K. M. Rosso, "The Structures and Energies of $\mathrm{AlOOH}$ and $\mathrm{FeOOH}$ Polymorphs from Planewave Pseudopotential Calculations," American Mineralogist (submitted).

J. R. Rustad, E. Wasserman, and A. R. Felmy, "Structure and Energetics of Two Vacuum and Hydroxylated Terminations of Magnetite (001) Via Molecular Dynamics Calculations," Proceedings of the United Engineering Foundation Alloy Conference, in press. 
Z. Wang, C. C. Ainsworth, D. M. Friedrich, P. L. Gassman, and A. G. Joly, "Kinetics and Mechanism of Surface Reaction of Salicylate on Alumina in Colloidal Aqueous Systems," Geochem. Cosmochem. Acta, in press.

E. Wasserman, A. R. Felmy, and A. Chilakapati, "Non-Equilibrium Thermodynamic Simulation of Metal Uptake in the Bacterial Electrical Double Layer," Colloids and Surfaces B: Biointerfaces, in press.

J. M. Zachara, S. C. Smith, and J. K. Fredrickson, "The Effect of Biogenic Fe(II) on the Stability and Sorption of Co(II)EDTA2- to Goethite and a Subsurface Sediment," Geochim. Cosmochim. Acta, in press.

\section{Patents}

T. Autrey, J. E. Amonette, N. S. Foster-Mills, and G. J. Posakony, "Multi-Band Transducer for Photoacoustic Detection," patent pending.

S. T. Autrey, J. L. Daschbach, J. E. Amonette, and N. S. Foster-Mills, "Photoacoustic Spectroscopy Sample Cells and Methods of Photoacoustic Spectroscopy," patent pending.

R. K. Kukkadapu and J. E. Amonette, "Highly Charged Hydrotalcite-like Compounds and Method of Making Same," patent pending.

\section{Presentations}

\section{Presenter underlined.}

J. E. Amonette, N. S. Foster, B. K. William, and A. E. Taylor, "Trace-level Chromate Sorption Dynamics at Hematite Surfaces: A Spectroscopic Approach," 217th ACS National Meeting, Anaheim, California, March 21-25, 1999.

J. E. Amonette, N. S. Foster, B. K. William, and A. E. Taylor, "Competitive Trace-Level Sorption of Chromate and Phosphate to Hematite Surfaces: A Spectroscopic Approach," 36th Annual Meeting of the Clay Minerals Society, Purdue University, West Lafayette, Indiana, June, 1999.
J. E. Amonette, "Iron Redox Chemistry of Clays and Oxides: Environmental Applications," Pre-meeting workshop on "Electrochemistry and Clays," 36th Annual Meeting of the Clay Minerals Society, Purdue University, West Lafayette, Indiana, June, 1999.

J. E. Amonette, G. R. Holdren, K. M. Krupka, C. W. Lindenmeier, and A. B. Amonette, "Assessing the Environmental Availability of Uranium in Soils and Sediments," 218th ACS National Meeting, New Orleans, Louisiana, August 22-26, 1999.

T. Autrey, N. Foster-Mills, K. Klepzig, J. Kempf, K. Notter, E. McMillan, J. Amonette, and J. Daschbach, "Torturing Molecules with Light. Just to Hear Them Scream?" Laser Optoacoustics and Photothermal Phenomena, La Jolla, California, February 22-26, 1999.

U. Becker and K. M. Rosso, "Surface Diffusion and Oxidation of Pyrite (100) Surfaces at the Molecular Scale as Investigated Using STM, STS, and Molecular Simulation Techniques," Meeting of the German Mineralogical Association, 1999.

U. Becker, K. M. Rosso, R. Weaver, and M. F. Hochella, Jr., "The Nature of the Bond Between a Metal ( $\mathrm{Ag}, \mathrm{Cu})$ Atom and a Semiconducting Mineral Surface," American Geophysical Union 1999 National Fall Meeting, San Francisco, California, December 13-16, 1999.

E. J. Bylaska, D. A. Dixon, and A. R. Felmy, "The Free Energies of Reactions of Chlorinated Methanes with Aqueous Monovalent Anions: Application of ab initio Electronic Structure Theory," Environmental Molecular Sciences Symposia and First Users ${ }^{*}$ Meeting, PNNL, Richland, Washington, July 21-24. 1999.

E. J. Bylaska, "NWChem's Implementation of CarParrinello, NWChem Tutorial," Environmental Molecular Sciences Symposia and First Users Meeting, Richland, Washington, July 21-24, 1999.

S. B. Clark, Z. Wang, and A. R. Felmy, "Surface Charge and Metal Adsorption: Modeling and Measurement with Ideal and Actual Surfaces,' Environmental Molecular Sciences Symposia and First Users' Meeting, PNNL, Richland, Washington, July 21-24, 1999. 
S. B. Clark, Z. Wang, and A. R. Felmy, "Determination of Surface Charge of Iron Oxides Using Atomic Force Microscopy," 54th American Chemical Society Northwest Regional Meeting, Portland, Oregon, June 20-23, 1999.

\section{A. R. Felmy, J. R. Rustad, and D. A. Dixon, "The} Surface Charging of $\mathrm{Fe}(\mathrm{II}) / \mathrm{Fe}$ (III) Oxyhydroxides in Aqueous Solutions: Use of Molecular Simulations to Assess Site Binding," 217th ACS National Meeting, Anaheim. California, March 21-25, 1999.

A. R. Felmy, D. A. Dixon, and M. J. Mason, "The Aqueous Complexation of Eu(III) with Organic Chelating Agents at High Base Concentration: Molecular and Thermodynamic Modeling Results," 217th ACS National Meeting, Anaheim, California, March 21-25, 1999.

A. R. Felmy, D. A. Dixon, M. J. Mason, and L. M. Onishi, "Displacement of $\mathrm{Sr}$ and Trivalent Actinides from Strong Organic Chelates in Tank Waste: Improved Thermodynamic ModeIs," 218th ACS National Meeting, New Orleans, Louisiana, August 22-26, 1999.

\section{A. R. Felmy, V. L. LeGore, and D. Rai, "Chemical} Characterization of Solubility and Leaching Controls on NRC Site Decommissioning Management Plan (SDMP) Wastes.” 218th ACS National Meeting, New Orleans, Louisiana, August 22-26, 1999.

N. Foster-Mills, T. Autrey, and J. Amonette, "LPAS Cell Designs and Applications," 1999 Gordon Research Conference on Photoacoustic and Photothermal Phenomena, Colby-Sawyer College, New London, New Hampshire, June 27-July 2, 1999.

D. M. Friedrich, Z. Wang, A. G. Joly, K. A. Peterson, and P. R. Callis, "The Ground State Proton-Transfer Tautomer of Salicylate Anion," 217th ACS National Meeting. Anaheim. California, March 21-25, 1999.

G. V. Gibbs. K. M. Rosso, D. M. Teter, M. B. Boisen, and M. S. T. Bukowinski, "Electron Density Distributions Calculated for Earth Materials," American Geophysical Union 1999 National Fall Meeting. San Francisco. California, December 13-16, 1999.
S. M. Heald, "Designing and Building Beamlines at a Third Generation Light Source," 2nd Annual Users Meeting for the Canadian Light Source, Saskatoon, Canada, November, 1999.

R. K. Kukkadapu, S. C. Smith, and J. M. Zachara, "Microbial Reduction of Subsurface Sediments Enriched with Goethite: Characterization of Feoxides and Sub-mineral Phases by Mössbauer Spectroscopy and X-ray Diffraction," International conference on Applications of Mössbauer Effect, Garmisch-Partenkirchen, Germany, August 29September 03, 1999.

L. Li, H. Li, D. M. Strachan, M. Qian, L. L. Davis, J. G. Darab, and Z. Wang, "Optical Spectroscopic Study of Neodymium in Sodium-AluminoBorosilicate Glasses," 218th ACS National Meeting, New Orleans, Louisiana, August 22-26, 1999.

R. C. Moore, Z. Wang, A. R. Felmy, M. J. Mason, R. K. Kukkadapu, D. Rai, and Y. Xia, "Reduction of Plutonium through Corrosion on Mild Steel in High Strength Brines," Environmental Molecular Sciences Symposia and First Users` Meeting, PNNL, Richland, Washington, July 21-24, 1999.

N. T. Nelson, M. L. Brusseau, M. Oostrom, and T. W. Wietsma, "Influence of Porous Media Heterogeneity and DNAPL Distribution on the Dissolution and Removal of Trichloroethylene," American Geophysical Union 1998 National Fall Meeting, San Francisco, California, December, 1998.

N. T. Nelson, M. Oostrom, T. W. Wietsma, and M. L. Brusseau, "An Experimental Investigation of the Partitioning Tracer Method to Detect and Quantify Dense Nonaqueous Phase Liquids in a Heterogeneous System," Geological Society of America Annual Meeting, Denver, Colorado, 1999.

M. Oostrom, T. W. Wietsma, N. T. Nelson, and M. L. Brusseau, "Partitioning Tracers for In Situ Detection and Quantification of Dense Nonaqueous Phase Liquids in Groundwater Systems," Workshop on Nonlinear Systems in the Subsurface. Delft Technical University, The Netherlands, 1998. 
D. Rai, N. J. Hess, A. R. Felmy, and D. A. Moore, "Identification and Modeling of Carbonato Complexes of Tetravalent Actinides," 217th American Chemical Society National Meeting, Anaheim, California, March 21-25, 1999.

D. Rai, L. Rao, A. R. Felmy, and N. J. Hess, "Measuring and Modeling the Solubility of $\mathrm{Cr}$ (III) Compounds in Concentrated $\mathrm{NaOH}$ and $\mathrm{NaOH} / \mathrm{NaNO} 3$ Solutions: Applications to Pretreatment of High Level Waste Sludges," 218th ACS National Meeting, New Orleans, Louisiana, August 22-26, 1999.

K. M. Rosso and M. F. Hochella, Jr., "The Atomic and Electronic Structure of Covellite (001) Surfaces: Insights from Tunneling Spectroscopy," 217 th American Chemical Society National Meeting, Anaheim, California, March 21-25, 1999.

K. M. Rosso, E. J. Bylaska, and J. R. Rustad, "The Energetics of Cation Exchange in Muscovite Mica," American Geophysical Union 1999 National Fall Meeting, San Francisco, California, December 13-16, 1999.

J. R. Rustad, D. A. Dixon, K. M. Rosso, and A. R. Felmy, "Trivalent ion Hydrolysis Reactions: A Linear Free-Energy Relationship Based on Density Functional Electronic Structure Calculations," National Meeting of the Clay Minerals Society, June 1999.

J. R. Rustad, "Hydrolysis of Trivalent Metal Ions," Clay Minerals Society, Purdue University, West Lafayette, Indiana, June 1999.

J. R. Rustad, "Structure and Reactivity of Iron Oxide Surfaces and Interfaces," 2nd International Alloy Conference, Davos, Switzerland, August 1999.

J. R. Rustad, "Surface Structure of Magnetite (001)," American Chemical Society, New Orleans, Louisiana, August, 1999.

J. Small, J. Amonette, N. Foster, and T. Autrey,

"Towards Direct Spectroscopic Analysis of Sediments: Laser Photoacoustic Studies with Colloidal Silica Samples," Environmental Molecular Sciences Symposia and First Users' Meeting, PNNL, Richland, Washington, July 21-24, 1999.
S. Abbruzzetti, C. Viappiani, Y. Chen, J. R. Small, L. J. Libertini, and E. W. Small, "Photoacoustic Detection of Protein unfolding on Microsecond and Submicro-second Time Scales," Environmental Molecular Sciences Symposia and First Users' Meeting, PNNL, Richland, Washington, July 21-24, 1999.

D. M. Teter, C. T. Prewitt, and K. M. Rosso, "Inverse Perovskites at High Pressure," American Geophysical Union 1999 National Fall Meeting, San Francisco, California, December 13-16, 1999.

Z. Wang, A. R. Felmy, and M. J. Mason, "A Study of Steel Surface Corrosion Film in Brine Using XPS, AFM and ICP-MS," presented at the 54th American Chemical Society Northwest Regional Meeting Portland, Oregon, June 20-23, 1999.

Z. Wang, R. C. Moore, A. R. Felmy, D. Rai, and M. J. Mason, "Reduction of Plutonium through Corrosion of Mild Steel in High Ionic Strength Brines," 7th International Conference on the Chemistry and Migration Behavior of Actinides and Fission Products in the Geosphere, Lake Tahoe, Nevada, September 26-October 1, 1999.

Z. Wang, D. M. Friedrich, M. R. Beversluis, A. G. Joly, R. G. Riley, M. H. Huesemann, B. M. Peyton, M. J. Truex, and C. J. Thompson, "Laser Fluorescence Characterization of Organic Contaminant Distribution and Transport in Porous Media," 217th ACS Annual meeting, Anaheim, California, March 23-28, 1999.

Z. Wang, L. Li, H. Li, A. G. Joly, D. M. Strachan, M. Qian, L. Davis, and J. G. Darab, "A Fluorescence Spectroscopic Study of Gadolinium in SodiumAlumino-Borosilicate Glass," 218th ACS National Meeting, New Orleans, Louisiana, August 22-26, 1999.

J. M. Zachara, J. K. Fredrickson, Y. A. Gorby, R. K. Kukkadapu, S. C. Smith, and H. Dong, "Mineralization Associated with the Dissimilatory Bacterial Reduction of Fe(III) Oxides," 36th Annual Meeting of the Clay Minerals Society, Purdue University, West Lafayette, Indiana, June 1999. 
J. M. Zachara, J. K. Fredrickson, Y. A. Gorby, R. K. Kukkadapu, S. C. Smith, and H. Dong, "Biomineralization Processes Associated with Iron Reducing Bacteria and Implications to Trace Metal Cycling," 1999 International Symposium on Subsurface Microbiology, Vail, Colorado, August 24, 1999.
J. M. Zachara, S. C. Smith, R. J. Serne, "Cs" Adsorption by Micaceous Soils Minerals and Their Control on High Level Wastes Migration," 1999 Soil Science Society of America Annual Meeting, Salt Lake City, Utah, November 1, 1999. 


\section{Honors and Recognition}

Jim Amonette was appointed as an associate editor of the journal, Clays and Clay Minerals.

Jim Amonette organized/chaired the Environmental Chemistry and Transport Symposium at the Environmental Molecular Sciences Symposia and First Users' Meeting, PNNL, Richland, Washington, July 21-24, 1999.

Andrew Felmy served as host for the BES Geosciences 6th Topical Research Symposium "Interfacial Processes in Geosciences," Richland, Washington, February 1-2, 1999.

Andrew Felmy served as Laboratory Sector Manager of the BES Geosciences program.

Andrew Felmy served as the EMSP Program session chair for the 218th ACS National Meeting,

New Orleans, Louisiana, August 22-26, 1999.

Andrew Felmy was promoted to level V scientist in 1999 with PNNL, Richland, Washington.

Andrew Felmy served as a peer reviewer for the BES Heavy Element and Separations Program.

Nancy Foster-Mills, Jim Amonette, and Tom Autrey were featured in an article entitled "Photoacoustic Sensor Does It Faster, Cheaper," in the June, 1999 edition of Inside R\&D Alert Magazine.
James Rustad was promoted to level IV scientist in 1998 with PNNL, Richland, Washington.

John Zachara was named lead scientist of the newly established Hanford Science and Technology Program within the Groundwater/Vadose Zone Integration Project, which involves multiple site contractors at Hanford and national laboratory scientists.

John Zachara coordinated and served as Chair of the EMSP Principal Investigator Orientation Meeting, at the William R. Wiley Environmental Molecular Sciences Laboratory, Richland, Washington, November 16-18, 1999.

John Zachara finished a two-year appointment to a NAS/NRC study panel on "Intrinsic Remediation of Groundwater."

John Zachara served as environmental science coordination on the Stanford Synchrotron Radiation Laboratory (SSRL) Peer Review Panel (PRP).

John Zachara provided an invited presentation at an OBER/NABIR Workshop on Bioremediation of Metals and radionuclides and served as a session discussion leader. 


\section{Collaborations}

\section{External Collaborations}

Jim Amonette

Heritage College (H. Divanfard)

Dehalogenation of Chlorinated Hydrocarbons/

Toppenish Basin Ground Water Pollution

Jim Amonette

Whitman College (J. C. Templeton)

Determination of Mossbauer Recoil-free-fractions of Octahedral Fe(II) and Fe(III) in Layer Silicates

Jim Amonette and Zheming Wang

University of Idaho (P. Griffiths and A. Bjerke)

Exploration of the SEIRA Effect on Platinum Thin Films

Jim Amonette

Washington State University (J. Harsh)

Noncrystalline Aluminosilicates in Highly Weathered Soils

Jim Amonette and Ravi Kukkadapu

University of Wisconsin (W. Bleam)

Two-Dimensional NOESY Studies of Metal-Binding

Sites in Humic Substances

Jim Amonette

University of Illinois (R. J. Kirkpatrick)

Infrared Spectroscopic Investigations of Mixed-Metal Layered Hydroxides

Jim Amonette

Oregon State University (J. Baham)

Biogeochemical Transformations of Fe and MnOxide Minerals in Seasonally Reduced Soils

Jim Amonette and Ravi Kukkadapu

Lewis and Clark College (B. A. Balko)

The Effect of the Chemical Identity of M(IV) Dopants on the Reduction of Oxygen at Hematite

Electrodes

Jim Amonette and Ravi Kukkadapu

University of Delaware (C. Matocha and D. Sparks)

Kinetics of Mn Oxide Dissolution Measured by EPR Spectroscopy
Jim Amonette and Zheming Wang

Washington State University (B. Peyton and

H. Petermann)

Infrared Spectroscopic Investigations of Mixed-Metal Layered Hydroxides Surface Characterization of Iron Bearing and Matrix Minerals

Jim Amonette and Ravi Kukkadapu

Stanford University (A. C. Matin)

Characterization of Chromate Reductase of

Pseudomonas Putida

Jim Amonette and Nancy Foster-Mills

Quantum NW, Spokane, Washington (E. Small and Y. Chen)

Use of Photolabile Caged Compounds and Acoustic

Detection as a Fast Alternative to Stopped Flow

Eric Bylaska

University of California (J. Weare)

Simulating Mineral Surfaces

Eric Bylaska

Washington State University (S. B. Clark)

Development of Algorithms and Computer Code for Modeling the Electric Double-Layer Force Between a Silica Sphere Attached to an AFM Tip and an Iron Oxide Surface

Andy Felmy, Zheming Wang, and Ravi Kukkadapu

Sandia National Laboratories (R. Moore)

Steel Corrosion and Actinide Reduction by Zero-

Valence Iron in Brines

Andy Felmy and Zheming Wang

Washington State University (S. B. Clark)

Determination of Surface Charge of Iron Oxides

Using Atomic Force Microscopy

Nancy Foster-Mills and Jim Amonette

Eastern Washington University (J. R. Small)

Photoacoustic Studies on Fluorescent and Scattering Samples

Jim Fredrickson and Ravi Kukkadapu

Princeton University (H. Dong)

Mineral Transformations Associated with the

Microbial Reduction of Magnetite 
Paul Gassman

Howard University (M. S. Diallo and J. H. Johnson, Jr.)

Molecular Modeling of Hydrophobic Organic Contaminants: Uptake and Sequestration by Soil Organic Matter

Ravi Kukkadapu

Australian Nuclear Science and Technology Organization (V. Luca)

${ }^{57}$ Fe Mössbauer Spectroscopic Study of Fe Redox Centers in Titanium Silicates

Kevin Rosso

Virginia Tech (G. V. Gibbs)

Molecular Modeling Investigations of the Relationship Between Electron Density Distributions and Structural Deformation of Minerals Under Pressure

Kevin Rosso

Universitat Muenster, Germany (U. Becker)

STM and Molecular Modeling Investigations of the

Electronic Structure and Reactivity of Oxide and Sulfide Surfaces

Kevin Rosso

Sandia National Laboratories (D. M. Teter)

Ab Initio Modeling of the Structural Stability and Phase Transitions of Inverse Perovskites

Kevin Rosso

Virginia Tech (J. D. Rimstidt)

Molecular Modeling Investigations of the Mechanisms of Dissolution of Silicate Minerals

Kevin Rosso

State University of New York, Buffalo (H. Lou)

CdTe Quantum Dots on GaAs (111)

Kevin Rosso

Sandia National Laboratories (R. Cygan)

Bond Critical Point Properties of the Electron Density

Calculations for Pyrophyllite and Kaolinite

Kevin Rosso

Virginia Tech (B. Bickmore)

Calculations on the Relaxed Structure of Various

Step-Edge Terminations of 2:1 Layers for

Dioctahedral Clays
Zheming Wang

Whitman College (F. Moore)

Long Wavelength Luminescence of $\mathrm{C} 60$ at High Pressures

Zheming Wang

University of Idaho (R. Wandruszka)

The Fluorescence Anisotropy of Probes in Clouding Detergent Systems

Thomas W. Wietsma

Environmental Sciences and Engineering Analysis

(M. Oostrom and M. D. White)

Cain University (M. L. Brusseau)

University of Arizona (R. B. Cain)

Partitioning Tracers for In Situ Detection and Quantification of Dense Nonaqueous Phase Liquids in Groundwater Systems

John Zachara, Yuri Gorby, and Ravi Kukkadapu Indiana University (F. Picarda)

Identification of Biogenic Fe(II) Oxides Resulting from Microbial Reduction

John Zachara

Savannah River Ecology Laboratory (P. Bertsch)

Mineral Surface Processes Responsible for the

Decreased Retardation of Enhanced Mobilization of ${ }^{137} \mathrm{Cs}$ from HLW Tank Discharge

John Zachara

California Institute of Technology (J. Hering)

Significance of Vadose Zone Processes

John Zachara

University of Massachusetts (D. Lovley)

Solubilization of Radionuclides and Metals by Iron

Reducing Bacteria

John Zachara

University of Guelph (T. Beveridge)

Solubilization of Radionuclides and Metals by Iron Reducing Bacteria

John Zachara

Argonne National Laboratory (K. Kemner)

Electron Transfer at the Fe(II) Oxide Microbe Interface 
John Zachara

Binghamton University (K. Salvage)

Solubilization of Radionuclides and Metals by Iron

Reducing Bacteria

John Zachara, Nancy Foster-Mills, and Paul Gassman DOE-RL (Jeff Day)

The Influence of Soil Characteristics and Molecular

Properties of Hydrophobic Contaminants on

Bioavailability in Aged Soils.

\section{Collaborations within PNNL}

Jim Amonette

Process Technology and EM Resources (M. Truex)

Use of Extremophiles for Bioprocessing

Jim Amonette

Environmental Sciences and Engineering Analysis

Research (J. Fruchter)

Reductive Decomposition of Explosive Compounds

Jim Amonette and R. Kukkadapu

Environmental Sciences and Engineering Analysis

Research (K. Cantrell)

Determination of Iron Speciation in H2S Treated

Sediment

Nancy Foster-Mills

Physical. Organic, and Laser Spectroscopy

(T. Autrey)

Time-Resolve Laser Photoacoustic Spectroscopy

Nancy Foster-Mills

Computing and Information Sciences (J. Price and

M. Ginovska)

Improved Photoacoustic Detection Technology

Ravi Kukkadapu

Process Technology and EM Resources (H. Li)

Mössbauer Spectroscopic Study of Iron Redox in

Silicate Glasses.

Ravi Kukkadapu

Materials Resources (P. Rieke)

Electron Paramagnetic Resonance of Lithium Polymer Battery Electrolyte

Ravi Kukkadapu

Materials Resources (J. Liu)

Mössbauer Studies of $\mathrm{Fe}$ ion Exchangers
Kevin Rosso

Interfacial and Processing Science (M. Henderson)

Interaction of $\mathrm{H} 2 \mathrm{~S}$ with Oxide Surfaces

Kevin Rosso

Interfacial and Processing Science (S. Chambers)

Scanning Tunneling Microscopy and Spectroscopy of Magnetite 001

Zheming Wang

Process Technology and EM Resources (H. Li)

Laser-Induced-Time-Resolved Fluorescence (LIF)

Zheming Wang

Process Technology and EM Resources (M. Murphy)

Measurement of Luminescence Decay Time

Zheming Wang

Materials Resources (P. Martin)

Characterization of Polymer Surface Topography by AFM

Zheming Wang

Environmental Sciences and Engineering Analysis Research/Biogeochemistry Resources (B. Fellows and C. Ainsworth)

Microbial Siderophore Role in Metal Uptake by Oats and Crested Wheat Grass

Zheming Wang

Biogeochemistry Resources (B. Wood)

Use of Atomic Force Microscopy for Measurement of the Interaction Force Between a Bacterium and a Mineral Surface

Zheming Wang

Materials Resources (M. Shi)

Polymer Thin Film Characterization Using AFM

Thomas Wietsma

Environmental Sciences and Engineering Analysis (M. Oostrom)

Characterization and Fate and Transport Analysis of Brooklawn DNAPL Source Oxidation of Trichloroethylene with Permanganate Solutions

John Zachara

Biogeochemistry Resource (H. Bolton)

Mineral Surface Processes Responsible for the Decreased Retardation or Enhanced Mobilization of ${ }^{137} \mathrm{Cs}$ from HLW Tank Discharge 
John Zachara

Biogeochemistry Resource (J. Fredrickson)

Solubilization of Radionuclides and Metals by Iron

Reducing Bacteria
John Zachara

Environmental Sciences and Engineering Analysis

(R. Serne)

Mineral Surface Processes Responsible for the

Decreased Retardation or Enhanced Mobilization

of ${ }^{137} \mathrm{Cs}$ from HLW Tank Discharge 


\section{Acronyms and Abbreviations}

\begin{tabular}{|c|c|}
\hline AFM & atomic-force microscopy \\
\hline AWU & Associated Western Universities \\
\hline BER & DOE Office of Biological and \\
\hline & Environmental Research \\
\hline CAT & catechol concentration \\
\hline DFT & density functional theory \\
\hline DIRB & dissimilatory iron reducing bacteria \\
\hline DOE & U.S. Department of Energy \\
\hline DOE-EM & $\begin{array}{l}\text { DOE Office of Environmental } \\
\text { Management }\end{array}$ \\
\hline ED\&S & $\begin{array}{l}\text { Environmental Dynamics and } \\
\text { Simulation }\end{array}$ \\
\hline EHSD & $\begin{array}{l}\text { Environmental and Health Sciences } \\
\text { Division }\end{array}$ \\
\hline EMSI & $\begin{array}{l}\text { Environmental Molecular Science } \\
\text { Institutes }\end{array}$ \\
\hline EMSL & $\begin{array}{l}\text { William R. Wiley Environmental } \\
\text { Molecular Sciences Laboratory }\end{array}$ \\
\hline EMSP & $\begin{array}{l}\text { Environmental Management Science } \\
\text { Program }\end{array}$ \\
\hline EPA & U.S. Environmental Protection Agency \\
\hline EPR & electron paramagnetic resonance \\
\hline EPR-SF & $\begin{array}{l}\text { electron paramagnetic resonance } \\
\text { stopped-flow }\end{array}$ \\
\hline EXAFS & extended $\mathrm{x}$-ray absorption fine structure \\
\hline GGA & generalized gradient \\
\hline $\mathrm{HF}$ & hyperfine field \\
\hline HFD & hyperfine field distributions \\
\hline $\mathrm{HFO}$ & hydrous ferric oxide \\
\hline HLW & high-level waste \\
\hline HREELS & $\begin{array}{l}\text { high-resolution electron energy loss } \\
\text { system }\end{array}$ \\
\hline $\mathrm{K}-\mathrm{B}$ & Kirkpatrick-Baez \\
\hline LDA & local-density \\
\hline
\end{tabular}

$\begin{array}{ll}\text { LPAS } & \text { laser photoacoustic spectroscopy } \\ \text { LPC } & \begin{array}{l}\text { layered prism cell } \\ \text { molecular-beam epitaxy }\end{array} \\ \text { MBE } & \text { National Institute of Health } \\ \text { NIH } & \begin{array}{l}\text { non-local density functional } \\ \text { calculations }\end{array} \\ \text { NLDFT } & \text { National Science Foundation } \\ \text { PAH } & \text { polycyclic aromatic hydrocarbons } \\ \text { PAW } & \text { projector-augmented wave } \\ \text { PEM } & \text { Photoacoustic Evanescent-Wave } \\ & \text { Module } \\ \text { PFO } & \text { pseudo-first-order } \\ \text { PNC-CAT } & \text { Pacific Northwest Consortium- } \\ & \text { Collaborative Access Team } \\ \text { PNNL } & \text { Pacific Northwest National Laboratory } \\ \text { QM/MM } & \text { quantum mechanical/molecular } \\ & \text { mechanical } \\ \text { QSD } & \text { quadrupole splitting distributions } \\ \text { RHEED } & \text { Reflection High Energy Electron } \\ & \text { Diffraction } \\ \text { RT } & \text { room temperature } \\ \text { SNL } & \text { Sandia National Laboratory } \\ \text { SRB } & \text { sulfate-reducing bacteria } \\ \text { TCE } & \text { trichloroethylene } \\ \text { TNT } & \text { trinitrotoluene } \\ \text { TPD } & \text { temperature programmed desorption } \\ \text { UHV } & \text { ultrahigh vacuum } \\ \text { UV } & \text { ultraviolet } \\ \text { WIPP } & \text { Waste Isolation Pilot Plant } \\ \text { XAFS } & \text { x-ray absorption fine structure } \\ \text { XANES } & \text { x-ray absorption near edge spectroscopy } \\ \text { XMCD } & \text { x-ray magnetic circular dichroism } \\ \text { XPD } & \text { x-ray photoelectron diffraction } \\ \text { XPS } & \text { x-ray photoelectron spectroscopy } \\ \text { XRD } & \text { x-ray diffraction } \\ \text { XRM } & \text { x-ray microscopy } \\ & \\ & \end{array}$




\section{Where ED\&S Fits in PNNL}

Pacific Northwest National Laboratory (A. Roberts, Director)

Energy Science and Technology (D. P. McConnell, Sr: Vice President, Battelle)

Environmental and Health Sciences (G. M. Stokes, Associate Laboratory Director)

Analytical Chemistry Resources (J. F. Wacker)

Atmospheric Sciences and Global Change Resources (W. T. Pennell)

Biogeochemistry Resources (H. Bolton, Jr.)

Materials Resources (M. R. Thompson)

Molecular Biosciences Resources (R. A. Walters)

Statistics Resources (B. A. Pulsipher)

W. R. Wiley Environmental Molecular Sciences Laboratory (EMSL) (J. H. Futrell, Director) Chemical Structure and Dynamics (CS\&D) (S. D. Colson)

Interfacial and Processing Sciences (IPS) (J. W. Rogers, Jr.)

Macromolecular Structure and Dynamics (MS\&D) (D. W. Koppenaal)

Theory, Modeling, and Simulation (TM\&S) (D. A. Dixon)

Environmental Dynamics and Simulation (ED\&S) (J. M. Zachara)

Computing and Information Sciences (C\&IS) (R. A. Bair)

Environmental Technology (W. J. Apley, Associate Laboratory Director)

National Security Division (M. Kluse, Associate Laboratory Director) 